\title{
Numerical analysis: a virtual dream or practical reality?
}

\author{
D. M. POTTS
}

\begin{abstract}
The development of numerical analysis and its application to geotechnical problems over the past 20 years have provided geotechnical engineers with an extremely powerful analysis tool. However, the use of such analysis is still not widespread, and when it is used there is all too often evidence of bad practice. Part of the reason for this is a lack of education and of guidance, especially from codes of practice, as to the appropriate use of such methods of analysis. Clearly, some form of initiative is required to promote good practice and allow the full potential of this analysis tool to be realised, both from a safety and an economy perspective. This lecture begins by reviewing the key advantages of numerical analysis over conventional analysis tools, and then debates whether or not it can replace the conventional analysis tools in the design process. Examples from engineering practice are used extensively to illustrate the arguments both for and against the use of numerical analysis.
\end{abstract}

KEYWORDS: Rankine Lecture
Le développement de l'analyse numérique et ses applications aux problèmes géotechniques au cours des 20 dernières années ont donné aux ingénieurs géotechniciens un outil d'analyse extrêmement puissant. Cependant, l'utilisation de cette analyse est encore restreinte et même lorsqu'elle est utilisée, elle est trop souvent mal pratiquée. La raison en est, en partie, le manque d'information et de formation, notamment dans les codes de pratique, sur le bon emploi de ces méthodes d'analyse. Clairement, une certaine forme d'initiative est nécessaire pour encourager une bonne pratique et permettre la réalisation de tout le potentiel de cet outil d'analyse, tant sur le plan de la sécurité que d'un point de vue économique. Cette conférence commence par passer en revue les principaux avantages de l'analyse numérique par rapport aux outils d'analyse classiques, puis on débat pour savoir si elle peut ou non remplacer ces outils classiques dans le processus de conception. On utilise de nombreux exemples tirés de la pratique afin d'illustrer des arguments pour et contre l'utilisation de l'analyse numérique.

\section{INTRODUCTION}

The title of this Rankine Lecture, 'Numerical analysis: a virtual dream or practical reality?', essentially poses the question: 'Is numerical analysis just an advanced toy for academics and the privileged few, or is it in a position to provide a genuine tool for routine geotechnical analysis?'

This is a pertinent question to ask at this time as new codes of practice, for example Eurocode 7, are not as prescriptive as the older codes and allow the designer to choose an appropriate method of analysis. Recent comparisons (Gaba et al., 2002; Ravaska, 2002) indicate that the use of numerical analysis, as opposed to conventional methods, can lead to more economical design, and consequently the use of this type of analysis is likely to increase in the future.

Although most geotechnical engineers have had contact with numerical analysis, this has often been at arm's length, and many do not fully appreciate the complexities and subtleties involved in its use. For such analysis to be used in a constructive manner, and to avoid future disasters, it is important that geotechnical engineers understand both the enormous potential of this type of analysis and its pitfalls.

This lecture begins by discussing the role of analysis in design. The various different methods of analysis that are currently available to geotechnical engineers are then categorised and compared. This leads the author to propose a motion for debate: 'Numerical methods of analysis have reached the stage where they are superior to conventional approaches and can replace them in the geotechnical design process.' Cases both for and against the motion are then presented, using a series of practical examples. The lecture concludes by presenting some views about the future.

Manuscript received 19 March 2003; revised manuscript accepted 25 March 2003

Discussion on this paper closes 1 February 2004, for further details see p. ii.

* Department of Civil and Environmental Engineering, Imperial College of Science, Technology and Medicine, London.

\section{THE ROLE OF ANALYSIS IN DESIGN}

The role of analysis in the design process becomes clear once the design objectives have been considered.

When designing any geotechnical structure, the engineer must ensure that it is stable. Stability takes several forms. First, the structure and support system must be stable as a whole. There must be no danger of rotational, vertical or translational failure (see Fig. 1). Second, overall stability must be established. For example, if a retaining structure supports sloping ground, the possibility of the construction promoting an overall slope failure should be investigated.

The loads on, and forces in, any structural members such as walls, slabs, props, anchors or membranes must be estimated under the most adverse conditions, so that they may be designed to carry them safely. For example, when designing an embedded retaining wall to support an excavation, it is necessary to estimate the bending moments and axial and shear forces in the wall elements and any props or anchors.

Movements must be estimated, both of the structure and of the ground. This is particularly important if there are adjacent buildings or sensitive services. For example, if an excavation is to be made in an urban area close to existing services and buildings (Fig. 2), one of the key design constraints is the effect that the excavation has on the

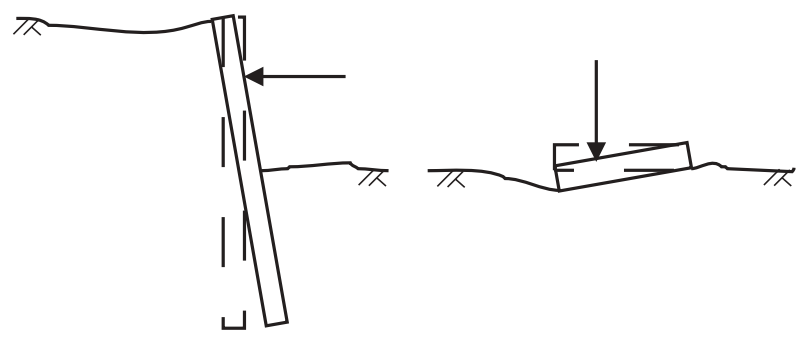

Fig. 1. Stability 


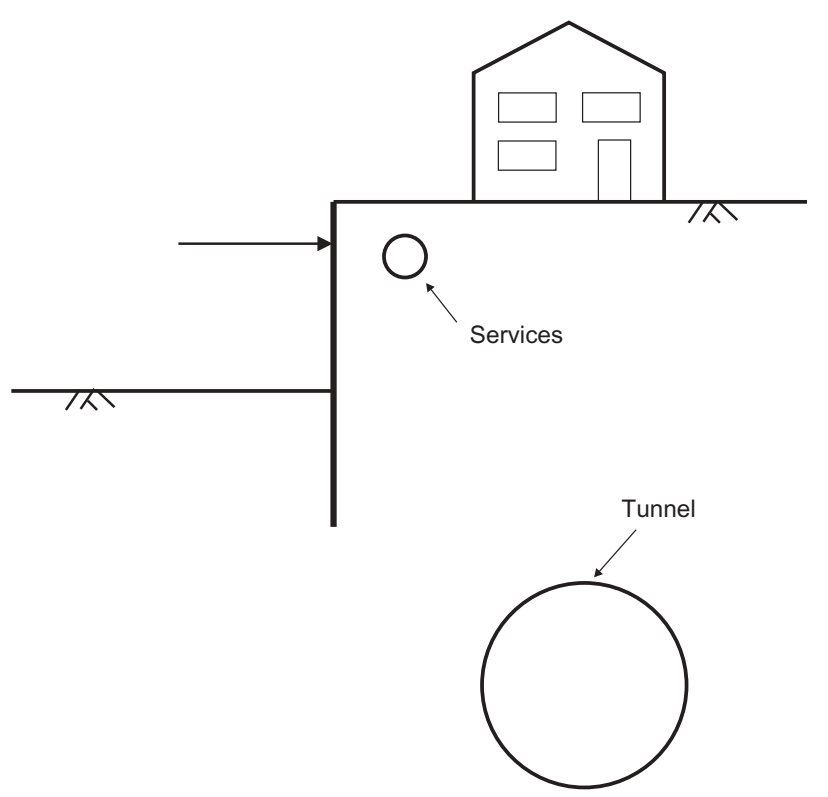

Fig. 2. Interaction of structures

adjacent structures and services. This could involve estimating both movements and induced structural forces.

To satisfy these design objectives, it is necessary for an engineer to perform calculations - for example by introducing a factor of safety into stability calculations, or by performing calculations to estimate movements and structural forces. Such calculations use mathematics and are based on analysis. A good analysis, which simulates real behaviour, allows the engineer to understand problems better. Analysis is not the only part of the design process, which involves many facets such as parameter identification and empiricism, but it plays an important role. The remainder of this lecture will concentrate on analysis.

\section{METHODS OF ANALYSIS \\ Introduction}

The objective here is to provide a framework in which to compare the different methods of analysis available to geotechnical engineers. This will enable the relative merits of numerical analysis, compared with conventional methods, to be established. However, before considering the different forms of analysis, it is instructive to briefly consider the theoretical requirements that must be satisfied. Essentially there are four of these.

Equilibrium. This can be divided into two parts: overall equilibrium and internal equilibrium. Overall equilibrium is associated with resolving forces and taking moments, whereas internal equilibrium is associated with establishing stress fields that satisfy the following well-known partial differential equations:

$$
\begin{aligned}
& \frac{\partial \sigma_{x}}{\partial x}+\frac{\partial \tau_{y x}}{\partial y}+\frac{\partial \tau_{z x}}{\partial z}+\gamma=0 \\
& \frac{\partial \tau_{x y}}{\partial x}+\frac{\partial \sigma_{y}}{\partial y}+\frac{\partial \tau_{z y}}{\partial z}=0 \\
& \frac{\partial \tau_{x z}}{\partial x}+\frac{\partial \tau_{y z}}{\partial y}+\frac{\partial \sigma_{z}}{\partial z}=0
\end{aligned}
$$

Note that the above equations are in terms of total stresses $\left(\sigma_{x}, \sigma_{y}, \sigma_{z}, \tau_{x y}, \tau_{x z}, \tau_{y z}\right)$ in accordance with a Cartesian coordinate system, and that self-weight $(\gamma)$ is assumed to act in the negative $x$ direction. Equilibrium is therefore concerned with forces and stresses.

Compatibility. Compatibility, on the other hand, is concerned with displacements and strains. It essentially requires that, if a body moves under loading, holes do not appear within it and overlapping of material does not occur. This is clearly a statement of common sense, but it must be remembered that within an analysis such restrictions must be formulated mathematically. In situations in which strains are small, this is achieved by imposing the condition that the variation of displacements throughout the body under consideration satisfies the following strain equations:

$$
\begin{aligned}
\varepsilon_{x} & =-\frac{\partial u}{\partial x} ; \varepsilon_{y}=-\frac{\partial v}{\partial y} ; \varepsilon_{z}=-\frac{\partial w}{\partial z} \\
\gamma_{x y} & =-\frac{\partial v}{\partial x}-\frac{\partial u}{\partial y} ; \gamma_{y z}=-\frac{\partial w}{\partial y}-\frac{\partial v}{\partial z} \\
\gamma_{x z} & =-\frac{\partial w}{\partial x}-\frac{\partial u}{\partial z}
\end{aligned}
$$

where $u, v$ and $w$ are the displacements in the $x, y$ and $z$ directions respectively. It can be shown mathematically that, for a compatible displacement field to exist, all the above components of strain and their derivatives must exist and be continuous to at least the second order.

Constitutive behaviour. This is a description of material behaviour. In simple terms it is the stress-strain behaviour of the soil. It usually takes the form of a relationship between stresses and strains, and therefore provides a link between equilibrium and compatibility. For calculation purposes the constitutive behaviour has to be expressed mathematically:

$$
\{\Delta \boldsymbol{\sigma}\}=[\boldsymbol{D}]\{\Delta \boldsymbol{\varepsilon}\}
$$

These equations can be expressed in terms of either total or effective stresses. However, if they are expressed in terms of effective stress, the behaviour of the pore fluid must be considered to enable total stresses to be derived, which can then be combined with the equilibrium equations. If the soil is linear-elastic, then accumulated stresses and strains can be related to each other via the elastic properties. However, because soil usually behaves in a non-linear manner, it is more realistic for the constitutive equations to relate increments of stress $(\Delta \sigma)$ and strain $(\Delta \varepsilon)$, as indicated in equation (3), and for the $[\boldsymbol{D}]$ matrix to depend on the current and past stress and strain history.

Boundary conditions. These are specific to the situation under consideration and define the nature of the boundary value problem to be investigated. For example, they could define a displacement constraint, a sequence of load application, excavation, construction, or a pore water pressure change.

The above discussion is clearly simplified. For example, if the flow of pore fluid is involved, then the continuity equation and boundary conditions involving prescribed flows or pore fluid pressures would also have to be accounted for. Likewise, if dynamic loading was involved, the equilibrium equations would have to be extended to account for inertia and damping effects.

Current methods of analysis can be conveniently grouped into the following categories: closed form, simple and numerical analysis. Each of these categories is now considered in turn. The ability of each method to satisfy the fundamental theoretical requirements and provide design information is summarised in Tables 1 and 2 respectively. 
Table 1. Basic solution requirements satisfied by various methods of analysis

\begin{tabular}{|c|c|c|c|c|c|c|}
\hline \multirow{3}{*}{\multicolumn{2}{|c|}{ Method of analysis }} & \multicolumn{5}{|c|}{ Solution requirements } \\
\hline & & \multirow[t]{2}{*}{ Equilibrium } & \multirow[t]{2}{*}{ Compatibility } & \multirow[t]{2}{*}{ Constitutive behaviour } & \multicolumn{2}{|c|}{ Boundary conditions } \\
\hline & & & & & Force & Displacement \\
\hline \multicolumn{2}{|c|}{$\begin{array}{l}\text { Closed form } \\
\text { Limit equilibrium } \\
\text { Stress field }\end{array}$} & $\begin{array}{l}\mathrm{S} \\
\mathrm{S} \\
\mathrm{S}\end{array}$ & $\begin{array}{c}\text { S } \\
\text { NS } \\
\text { NS }\end{array}$ & $\begin{array}{l}\text { Linear elastic } \\
\text { Rigid with failure criterion } \\
\text { Rigid with failure criterion }\end{array}$ & $\begin{array}{l}\mathrm{S} \\
\mathrm{S} \\
\mathrm{S}\end{array}$ & $\begin{array}{c}\mathrm{S} \\
\mathrm{NS} \\
\mathrm{NS}\end{array}$ \\
\hline Limit analysis & $\begin{array}{l}\text { Lower bound } \\
\text { Upper bound }\end{array}$ & $\begin{array}{c}\mathrm{S} \\
\mathrm{NS}\end{array}$ & $\begin{array}{l}\mathrm{NS} \\
\mathrm{S}\end{array}$ & Ideal plasticity with associated flow rule & $\begin{array}{c}\mathrm{S} \\
\mathrm{NS}\end{array}$ & $\begin{array}{c}\mathrm{NS} \\
\mathrm{S}\end{array}$ \\
\hline \multicolumn{2}{|c|}{ Full numerical analysis } & $\mathrm{S}$ & $\mathrm{S}$ & Any & $\mathrm{S}$ & $\mathrm{S}$ \\
\hline
\end{tabular}

S, satisfied; NS, not satisfied.

Table 2. Design requirements satisfied by the various methods of analysis

\begin{tabular}{|c|c|c|c|c|}
\hline \multirow{2}{*}{\multicolumn{2}{|c|}{ Method of analysis }} & \multicolumn{3}{|c|}{ Design requirements } \\
\hline & & Stability & Movements & Adjacent structures \\
\hline \multicolumn{2}{|c|}{$\begin{array}{l}\text { Closed form (linear-elastic) } \\
\text { Limit equilibrium } \\
\text { Stress field }\end{array}$} & $\begin{array}{l}\text { No } \\
\text { Yes } \\
\text { Yes }\end{array}$ & $\begin{array}{l}\text { Yes } \\
\text { No } \\
\text { No }\end{array}$ & $\begin{array}{l}\text { Yes } \\
\text { No } \\
\text { No }\end{array}$ \\
\hline Limit analysis & $\begin{array}{l}\text { Lower bound } \\
\text { Upper bound }\end{array}$ & $\begin{array}{l}\text { Yes } \\
\text { Yes }\end{array}$ & $\begin{array}{c}\text { No } \\
\text { Crude estimate }\end{array}$ & $\begin{array}{l}\text { No } \\
\text { No }\end{array}$ \\
\hline \multicolumn{2}{|c|}{ Full numerical analysis } & Yes & Yes & Yes \\
\hline
\end{tabular}

\section{Closed form solutions}

A closed form solution is the ultimate method of analysis. For a particular geotechnical structure, if it is possible to establish a realistic constitutive model for material behaviour, identify the boundary conditions, combine these with the equations of equilibrium and compatibility, and then perform the resulting integrations, an exact theoretical solution can be obtained. The solution is exact in a theoretical sense, but is still an approximation to the real problem, as assumptions about geometry, the applied boundary conditions and the constitutive behaviour have been made in idealising the real physical problem into an equivalent mathematical form. In principle, it is possible to derive a complete analytical solution for movements, forces, stresses and strains for every point within the problem domain, for all stages of the construction history. A single analysis will therefore provide information on both movements and stability.

However, as soil is a highly complex multi-phase material that behaves non-linearly when loaded, complete analytical solutions to realistic geotechnical problems are not usually possible. Solutions can be obtained only for two limited classes of problem.

First, there are solutions in which the soil is assumed to behave in an isotropic linear-elastic manner and the boundary conditions are simple. Although these can be useful for providing a first estimate of movements and structural forces, they are of little use for investigating stability. Comparison with observed behaviour indicates that such solutions are often inaccurate.

Second, there are some solutions for problems that contain sufficient geometric symmetries that the problem reduces to being essentially one-dimensional. Expansion of spherical and infinitely long cylindrical cavities in an infinite elastoplastic continuum are examples. Although they are useful, such solutions have restricted practical application.

\section{Simple methods}

Faced with the requirement for more appropriate analysis tools, the pioneers of geotechnical engineering made simplifications. These involved relaxing one or more of the solution requirements, usually the compatibility requirement. The resulting analysis methods can be broadly categorised as limit equilibrium, stress field and limit analysis methods (see Table 1).

Examples of limit equilibrium analysis are Coulomb's wedge analysis (Coulomb, 1776), the analysis performed by Caquot and Kerisel to derive the well-known active and passive earth pressure coefficients (Caquot \& Kerisel, 1948), and the methods of slices used in slope stability (Bromhead, 1992).

Rankine earth pressure coefficients (Rankine, 1857), the solutions of Sokolovskii $(1960,1965)$ and the bearing capacity coefficients are all examples of stress field solutions.

Limit analysis involves upper bound (that is, unsafe) and lower bound (that is, safe) solutions: see Chen (1975). The former neglects equilibrium and the latter compatibility. In principle, if upper bound and lower bound solutions can be found that furnish the same result, then this is the exact solution of the problem being analysed. However, there are few cases where this can be achieved, and even in these cases a very idealised constitutive model is employed.

It is important to note that all of these approaches essentially require an assumption as to the mechanism of failure. They are also restricted to assuming that the soil behaves either undrained or drained. In the former case a Tresca failure condition in terms of undrained strength, $s_{\mathrm{u}}$, is assumed. In the latter case a Mohr-Coulomb failure criterion in terms of cohesion, $c^{\prime}$, and angle of shearing resistance, $\phi^{\prime}$, is assumed.

In respect to satisfying the design requirements, these methods provide information on stability only. As they fail to satisfy all of the four theoretical requirements, they are 
only approximate solutions. For the remainder of this lecture, the closed form and simple methods of analysis will be referred to collectively as conventional methods.

\section{Numerical methods}

In this class of analysis all requirements of a theoretical solution are considered, but may only be satisfied in an approximate manner. These methods have been developed to a standard where they are useful to the design process only in the last $10-15$ years. They were therefore not available to the pioneers of geotechnical engineering.

Approaches based on finite difference and finite element methods are those most widely used. These methods essentially involve a computer simulation of the history of the boundary value problem from greenfield conditions, through construction and into the long term. A single analysis can provide information on all design requirements: see Table 2.

Their ability to accurately reflect field conditions essentially depends on the ability of the constitutive models to represent real soil behaviour and the ability of the geotechnical engineer to assign appropriate boundary conditions to the various stages of construction. Additional advantages over the conventional methods are that the effects of time on the development of pore water pressures can be simulated by including coupled consolidation/swelling, dynamic behaviour can be accounted for, and-perhaps most importantlyno postulated failure mechanism or mode of behaviour of the problem is required, as these are predicted by the analysis itself.

In many respects numerical methods are superior to conventional methods. However, they do contain approximations. The two main assumptions will now be discussed, using the finite element method as an example.

Discretisation approximation. When modelling a boundary value problem the geometry under investigation is represented by an assemblage of small regions, termed finite elements (see Fig. 3). These elements have nodes, defined on the element boundaries or within the element. To proceed with the method, a primary variable must be selected (such as displacement or stress), and rules as to how it should vary over a finite element must be established. This variation is expressed in terms of nodal values.

In geotechnical engineering it is usual to adopt displacement as the primary variable and assume that it varies in a polynomial manner over the element. For example, a 4noded plane-strain element assumes a linear variation, whereas an 8-noded element assumes a quadratic variation of displacements $u$ and $v$ : see Fig. 3. An analysis will therefore be accurate only if such an assumption accurately reflects the way the soil wants to deform in the boundary value problem being investigated. However, accuracy can be improved by using smaller elements and therefore more elements to represent a fixed volume of soil. This results in a trade-off between accuracy and calculation time. For further details see Potts \& Zdravkovic (1999).

Non-linear solution strategy. The basic theory behind numerical methods (that is, finite elements, finite differences and boundary elements) assumes that material behaviour is linear and that displacements are small. This in turn implies that material behaviour is essentially linear-elastic, with a constant stiffness and an infinite strength. Unfortunately, soil does not behave in this manner, and consequently, owing to material and/or geometric non-linearity, soil stiffness changes throughout an analysis. This is illustrated by the onedimensional load-displacement curve shown in Fig. 4.

A solution strategy is required that can account for this changing material behaviour. As a first approximation this change in stiffness may be accounted for by applying the loading in a series of increments (or steps). For each increment an appropriate stiffness is selected, and the incremental displacements, stresses and strains are calculated. As the load increments are of a finite size, this results in an

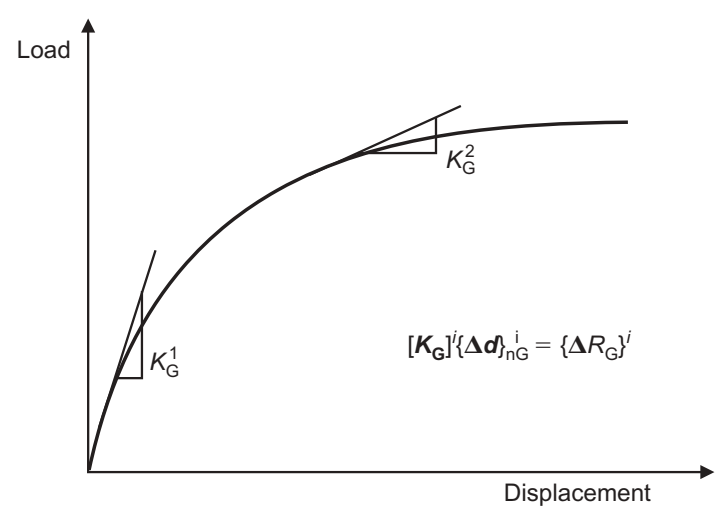

Fig. 4. Implications of non-linearity

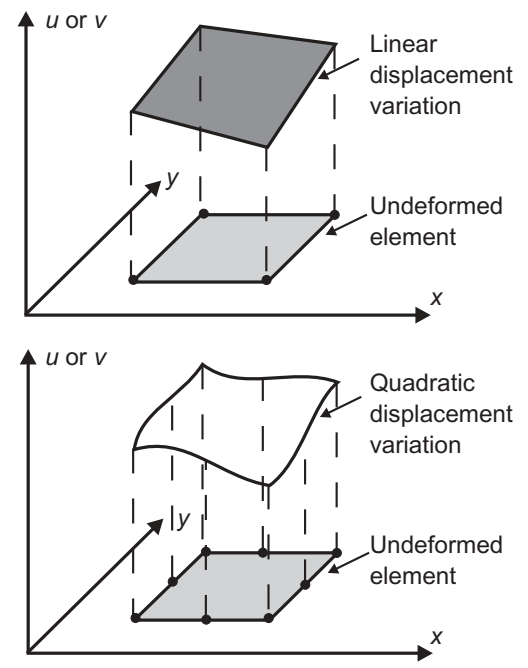

Fig. 3. Discretisation and displacement approximations 
approximation as the stiffness changes over the increments. Some of the more sophisticated software packages attempt to account for this, but there is no mathematically rigorous way of doing so: see Potts \& Zdravkovic (1999). Consequently, approximations, albeit of a much smaller value, still exist.

As the solution strategy is a key component of any nonlinear analysis, it can strongly influence the accuracy of the results and the computer resources required to obtain them. We shall return to this problem later in this lecture.

\section{THE MOTION}

Based on the above discussion, numerical analysis would appear to be able to do everything that the conventional methods can do, plus a lot more. This raises the question as to why we still use conventional methods. In the past there may have been some restrictions imposed by codes of practice, but this is not so with the newer codes (such as Eurocode 7).

To explore this question further the remainder of this lecture will be presented in a debate-style format. The motion to be considered is:

Numerical methods of analysis have reached the stage where they are superior to conventional approaches and can replace them in the geotechnical design process.

Note that the motion is not about whether or not numerical analysis should be used, but whether numerical analysis can replace conventional methods of analysis.

Cases for and against the motion will be presented. Each case will involve numerical examples: except where specifically stated, these have been performed using the Imperial College Finite Element Program (ICFEP) written by the author, with help from staff and research students at Imperial College.

\section{THE CASE FOR THE MOTION \\ Introduction}

The case for the motion is based on the premise that numerical analysis can:

(a) do everything conventional analysis can do

(b) accommodate realistic soil behaviour

(c) account for consolidation

(d) provide mechanisms of behaviour

(e) accommodate complex soil stratigraphy

( $f$ ) account for interaction between structures

$(g)$ accommodate three-dimensional geometries.

Each of these postulates will now be considered in turn, using examples from geotechnical practice.

\section{(a) Do everything conventional analysis can do}

To illustrate this postulate the behaviour of surface foundations will be considered. This is perhaps the simplest problem faced by geotechnical engineers. Ideally, for design, the complete load-displacement curve of the foundation is required: see Fig. 5. Conventional methods of analysis only provide estimates of the initial gradient of this curve (from closed form elastic solutions) and the ultimate load that can be supported by the soil (from one of the simple methods). For the purposes of this lecture, we shall concentrate on the prediction of ultimate load. Conventionally, this is usually expressed using the following well-known drained bearing capacity equation:

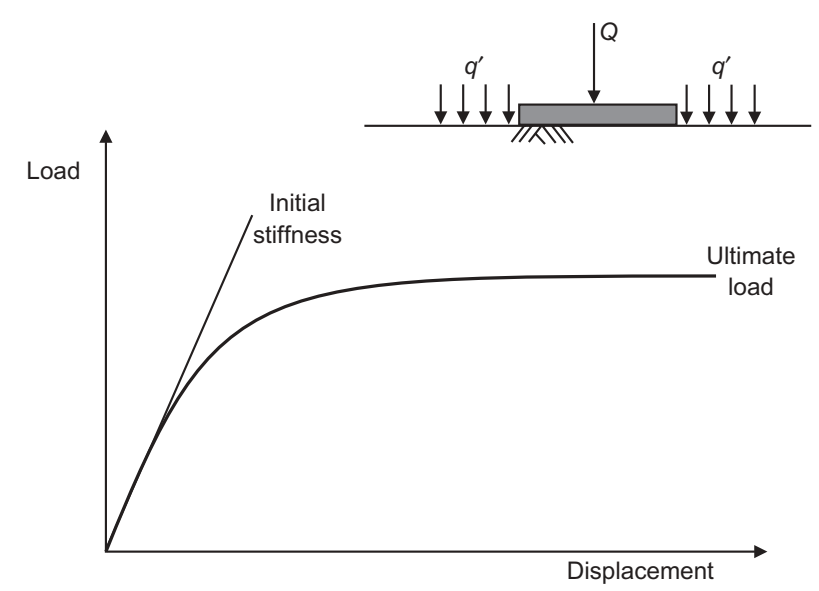

Fig. 5. Typical load-displacement curve for a footing

$$
\begin{aligned}
q_{\max }= & \frac{Q_{\max }}{A}=i_{c} d_{c} s_{c} N_{c}^{\text {strip }} c^{\prime}+i_{q} d_{q} s_{q} N_{q}^{\text {strip }} q^{\prime} \\
& +i_{\gamma} d_{\gamma} s_{\gamma} N_{\gamma}^{\text {strip }} B \gamma^{\prime}
\end{aligned}
$$

where $Q_{\max }$ is the maximum load that can be applied to the foundation; $A$ is the area of the foundation; $B$ is the half width of the foundation for a strip or rectangular footing, or the radius for a circular footing; $c^{\prime}$ is the drained cohesion of the soil; $q^{\prime}$ is the magnitude of any surcharge pressure existing on the ground surface adjacent to the footing (see insert in Fig. 5); $\gamma^{\prime}$ is the effective bulk unit weight of the soil; $N_{c}^{\text {strip }}, N_{q}^{\text {strip }}$ and $N_{\gamma}^{\text {strip }}$ are bearing capacity coefficients for a strip footing and are dependent on the angle of shearing resistance; $\phi^{\prime}, s_{c}, s_{q}$ and $s_{\gamma}$ are shape factors to account for the shape of the footing; $d_{c}, d_{q}$ and $d_{\gamma}$ are depth factors to account for the depth of the footing below ground surface level; and $i_{c}, i_{q}$ and $i_{\gamma}$ are inclination factors to account for the inclination of the load on the footing.

Several restrictions apply to this equation. First, it is limited to either fully saturated or dry soil; second, it is based on the Mohr-Coulomb failure criterion; and, third, it is not applicable to layered soils. It is also worth noting that not all the terms in the equation have a theoretical basis. In particular, the shape, depth and inclination factors are semiempirical.

There is no exact analytical expression for the coefficient $N_{\gamma}^{\text {strip }}$, and consequently there are many different expressions currently in use (Sieffert \& Bay-Gress, 2000). These are based on limit equilibrium, stress field or limit analysis calculations. The variation of $N_{\gamma}^{\text {strip }}$ with $\phi^{\prime}$ from some of the more popular expressions in current use is shown in Fig. 6. This figure indicates that, for example, for a soil with a $\phi^{\prime}=25^{\circ}$ the value of $N_{\gamma}^{\text {strip }}$ varies from 6.76 to $10 \cdot 89$ (that is, a difference of $61 \%$ ), depending on the solution adopted.

The coefficients $N_{c}^{\text {strip }}$ and $N_{q}^{\text {strip }}$ are theoretically exact for a strip footing (Prandtl, 1920), being based on a combination of stress and velocity field calculations. They are given by the following equations:

$$
\begin{aligned}
& N_{q}=\frac{1+\sin \phi^{\prime}}{1-\sin \phi^{\prime}} \mathrm{e}^{\pi \tan \phi^{\prime}} \\
& N_{c}=\left(N_{q}-1\right) \cot \phi^{\prime}
\end{aligned}
$$

Note, however, that these expressions are based on the assumption of (i) elasto-plastic soil behaviour with the Mohr-Coulomb failure criterion as a yield surface and (ii) associated plasticity. This latter assumption implies that the angle of dilation, $v$, which controls the plastic volume 


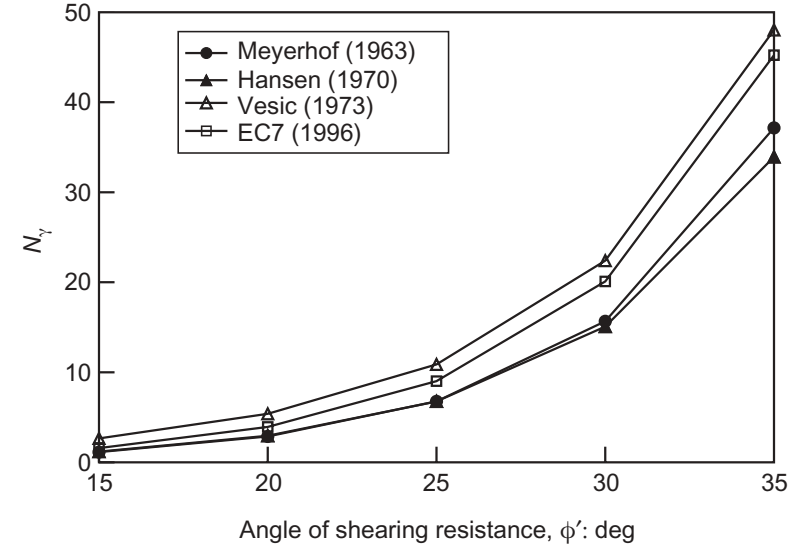

Fig. 6. Range of $N_{\gamma}$ values from different formulae

change, is equal to the angle of shearing resistance, $\phi^{\prime}$. Its effect on soil behaviour is best illustrated using a drained triaxial test on a Mohr-Coulomb soil as an example. In this respect Fig. 7 shows two predictions for an ideal (that is, no end effects) triaxial compression test, one based on $v=\phi^{\prime}$ and the other on $v=0^{\circ}$. All other properties are the same in both predictions. As can be seen from Fig. 7(a), the magnitude of the angle of dilation has no effect on the plot of deviatoric stress $\left(\sigma_{1}^{\prime}-\sigma_{3}^{\prime}\right)$ against axial strain $\left(\varepsilon_{\mathrm{a}}\right)$. However, the angle of dilation has a significant effect on the plot of volumetric strain $\left(\varepsilon_{\mathrm{vol}}\right)$ versus axial strain: see Fig. 7(b). In this figure both analyses initially predict identical elastic volumetric compression (that is, up to point A). After yielding occurs at point $A$ the plastic volumetric strain is controlled by the magnitude of $\nu$. For any value of $v$ other than zero, plastic dilation occurs indefinitely. Compared with real soil behaviour, both the magnitude of the dilation when $v=\phi^{\prime}$ and the indefinite increase in volume when $v>0^{\circ}$ are unrealistic. If $v=0^{\circ}$ no plastic volumetric strain occurs, and as there is no change in stress when yielding occurs, there is no further elastic volume strain either. Consequently, there is no further volumetric total strain predicted once yielding occurs: see Fig. 7(b). There are clearly severe limitations and shortcomings with the conventional bearing capacity equation.

Application of the finite element method to the problem of a rigid surface footing loaded centrally by a vertical load is now considered. The finite element mesh used for these analyses is shown in Fig. 8, and the soil is assumed to obey

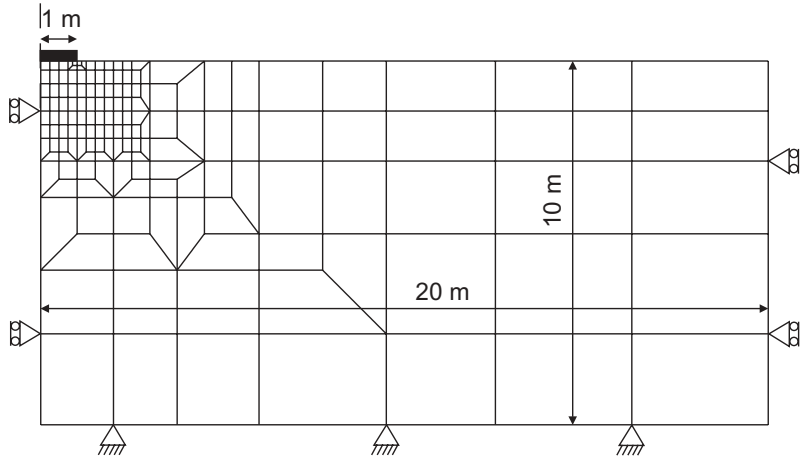

Fig. 8. Finite element mesh for surface footing problem

the Mohr-Coulomb model, having a Young's modulus, $E^{\prime}$, of $10 \mathrm{MN} / \mathrm{m}^{2}$, a Poisson's ratio, $\mu$, of $0 \cdot 3$, a cohesion, $c^{\prime}$, of 0.0 and an angle of shearing resistance, $\phi^{\prime}$, of $25^{\circ}$. To investigate the effect of the angle of dilation on bearing capacity, limiting values of $v=0^{\circ}$ and $v=\phi^{\prime}$ are used in the analysis. For this situation equation (4) reduces to

$$
q_{\max }=\frac{Q_{\max }}{A}=s_{q} N_{q}^{\text {strip }} q^{\prime}+s_{\gamma} N_{\gamma}^{\text {strip }} B \gamma^{\prime}
$$

Results from plane-strain analyses of both rough and smooth strip footings resting on a weightless $\left(\gamma^{\prime}=0\right)$ soil are presented in Fig. 9, in the form of normalised loaddisplacement curves. For this situation only the first term in equation (7) is non-zero, and $s_{q}=1$. The load has therefore been expressed in terms of the mobilised value of $N_{q}^{\text {mob }}=Q /\left(A q^{\prime}\right)$, where $Q$ is the load applied to the footing. Initially, before the footing is loaded in the numerical analysis, it is assumed to support a surcharge $q^{\prime}$ equal to that acting on the ground surface either side of the footing. Consequently, at the beginning of the analysis, before any displacement occurs, $N_{q}^{\mathrm{mob}}=1$ and it then increases as the footing displaces, until failure is reached when $N_{q}^{\text {mob }}=N_{q}$. The settlement of the footing, $\delta$ has been normalised by $B$, the half width of the strip footing.

Results from four analyses with a surcharge load $q^{\prime}=100 \mathrm{kPa}$ and one with $q^{\prime}=10 \mathrm{kPa}$ are presented in Fig. 9. For the analyses with $q^{\prime}=100 \mathrm{kPa}$, it can be seen that for both $v=0^{\circ}$ and $v=\phi^{\prime}$ the roughness of the footing has only a minor influence on both the load-displacement curve and the ultimate load (that is, the $N_{q}$ values for smooth and rough footings differ by less than $2 \%$ ). However, the value

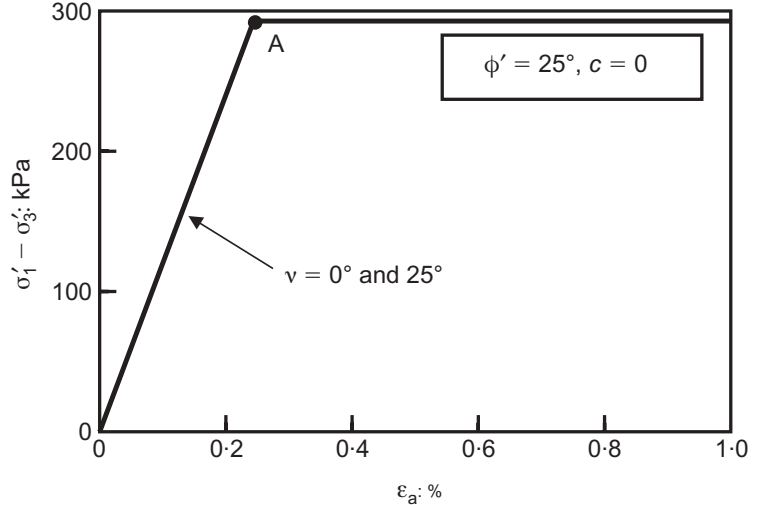

(a)

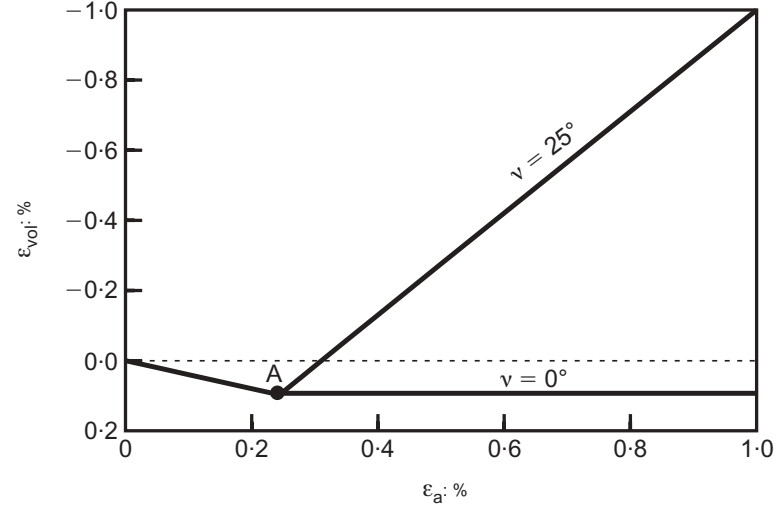

(b)

Fig. 7. Drained triaxial test with Mohr-Coulomb model (a) deviatoric stress against axial strain; (b) volumetric strain against axial strain 


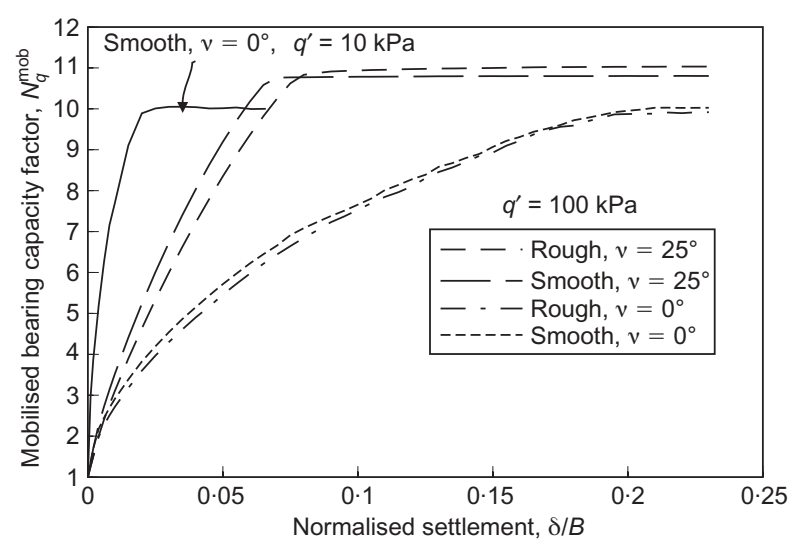

Fig. 9. Load-displacement curves for strip footings on weightless and cohesionless soil (effect of roughness, dilation and surcharge)

of the angle of dilation has a much greater effect. The load-displacement curves for the analyses with $v=0^{\circ}$ are much softer, and indicate an $N_{q}$ value some $7 \%$ lower than that for the analyses with $v=\phi^{\prime}$, which themselves give $N_{q}$ values within $2 \%$ of the theoretically exact value given by equation (5). In this respect note that the elastic properties are the same for all analyses, and that the differences in behaviour are due to the magnitude of $v$ alone.

The effect of the magnitude of the surcharge load, $q^{\prime}$, can be assessed by comparing, for example, the results from the analyses of a smooth footing with $v=0^{\circ}$ and with values of $q^{\prime}=10 \mathrm{kPa}$ and $q^{\prime}=100 \mathrm{kPa}$ respectively. Both analyses give similar values of $N_{q}$, but the load-displacement curve for the analysis with $q^{\prime}=10 \mathrm{kPa}$ is much stiffer than that for the analysis with $q^{\prime}=100 \mathrm{kPa}$.

The effect of footing shape was investigated by repeating the four analyses with $q=100 \mathrm{kPa}$ assuming axisymmetric conditions, which implies that the footing is circular in plan. The results are presented in Fig. 10. These results indicate that, in contrast to the results for the strip footing, the footing roughness does affect the ultimate load, there being a $22 \%$ difference in the $N_{q}$ value predicted for the smooth and rough footings with $v=\phi^{\prime}$. In addition, and again in contrast to the strip footing, the analyses indicate that the angle of dilation has only a small effect on the ultimate footing load. However, the magnitude of the angle of dilation does affect the load-displacement curves, the effect

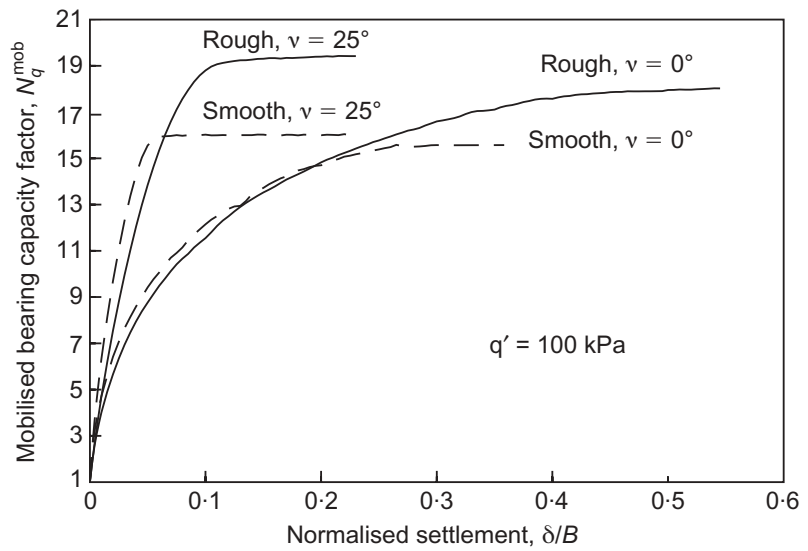

Fig. 10. Load-displacement curves for a circular footing on weightless and cohesionless soil (effect of roughness and dilation) being similar to that observed for the strip footing. Comparison of the results given in Figs 9 and 10 indicate that the shape factor, $s_{q}$, is approximately $1 \cdot 6$. Design codes recommend shape factors $1.2<s_{q}<1.5$ (Sieffert \& Bay-Gress, 2000), and consequently the finite element results predict a value slightly higher than that used in current practice.

Further analyses were then performed with a surcharge $q^{\prime}=0$, but with a soil with weight $\gamma^{\prime}=18 \mathrm{kN} / \mathrm{m}^{3}$. For this situation only the second term in equation (7) is non-zero, and for a strip footing $s_{\gamma}=1$. As before, the footing load has been expressed in terms of the mobilised value of $N_{\gamma}^{\mathrm{mob}}=Q /\left(A B \gamma^{\prime}\right)$, which at the beginning of an analysis is equal to zero and then increases to a maximum value of $N_{\gamma}^{\text {mob }}=N_{\gamma}$ at failure.

The results for the strip footing are presented in Fig. 11. In contrast to the $N_{q}$ analysis (see Fig. 9), the $N_{\gamma}$ value is dependent on footing roughness, but is less sensitive to the magnitude of the angle of dilation. In addition, the magnitude of the angle of dilation does not have a significant effect on the shape of the load-displacement curve. The results for the circular footing are presented in Fig. 12 and indicate similar trends to those of the strip footing, although the magnitudes of $N_{\gamma}$ are different.

The predicted $N_{\gamma}$ values are summarised in Table 3, where it can be seen that the values for rough footings are approximately twice those for smooth footings. Values of the shape factor $s_{\gamma}$ range from 0.87 to 0.98 and are therefore higher than typical values of $0.6<s_{\gamma}<0.9$ recommended in design codes (Sieffert \& Bay-Gress, 2000). Also shown in

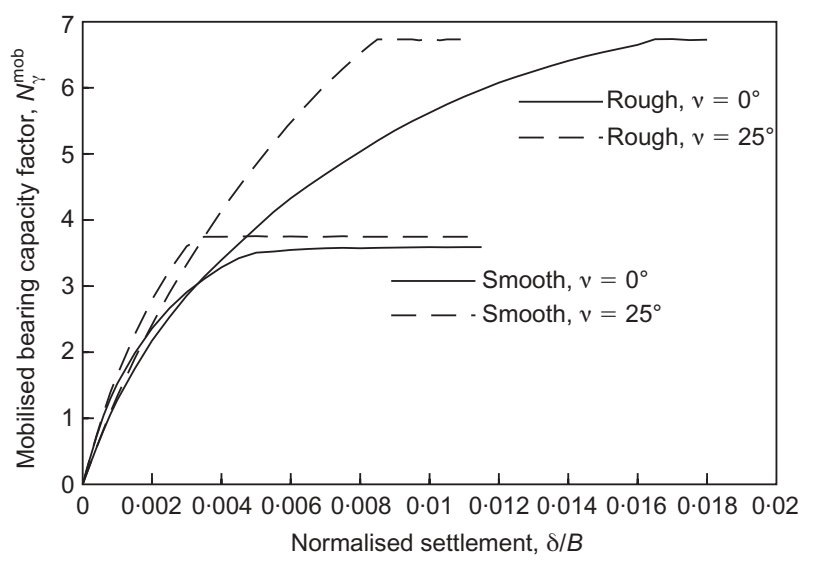

Fig. 11. Load-displacement curves for a strip footing on a cohesionless soil (effect of roughness and dilation)

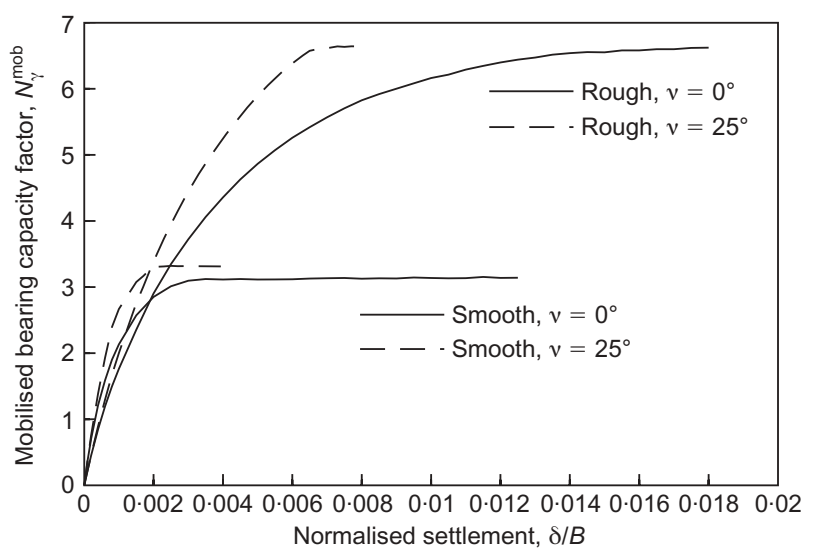

Fig. 12. Load-displacement curves for a circular footing on a cohesionless soil (effect of roughness and dilation) 
Table 3. Bearing capacity factor $N_{\gamma}$

\begin{tabular}{l|c|c|c}
\hline Footing & \multicolumn{2}{|c|}{$\begin{array}{c}\text { Finite element } \\
\text { analysis }\end{array}$} & \multirow{2}{*}{ Shape factors } \\
\cline { 2 - 3 } & Strip & Circle & \\
\hline Smooth, $v=0^{\circ}$ & 3.59 & $3 \cdot 14$ & 0.87 \\
Smooth, $v=25^{\circ}$ & $3 \cdot 74$ & $3 \cdot 31$ & 0.88 \\
Rough, $v=0^{\circ}$ & $6 \cdot 74$ & $6 \cdot 62$ & 0.98 \\
Rough, $v=25^{\circ}$ & $6 \cdot 72$ & $6 \cdot 64$ & 0.98 \\
Hansen, (1970)\& & $6 \cdot 76$ & & \\
Meyerhof, (1963) & $10 \cdot 87$ & & \\
Vesic, (1973) & $9 \cdot 01$ & & \\
Eurocode 7 & & \\
\hline
\end{tabular}

Table 3 are $N_{\gamma}^{\text {strip }}$ values from four widely used expressions. It can be seen that the finite element results are in good agreement with the $N_{\gamma}^{\text {strip }}$ values given by Hansen (1970) and Meyerhof (1963), which have been widely used in design codes in the past. However, it is interesting to note that the $N_{\gamma}^{\text {strip }}$ value given by Eurocode 7 is considerably higher, and therefore less conservative, than the finite element results.

Before leaving this drained bearing capacity problem it is of interest to examine the predicted failure mechanisms. These are shown in Fig. 13 for both the $N_{q}$ and $N_{\gamma}$ cases for the smooth strip footing with $v=\phi^{\prime}$. The arrows shown in this figure represent the vectors of incremental displacement for the last increment of each analysis when a limit load had been reached. The length of the arrows and their orientation represent the magnitude and direction of the movement respectively. To identify the failure mechanism it is not the absolute magnitudes of the movements, but their relative magnitudes, that are important.

As both the plots shown in Fig. 13 are drawn to the same geometric scale, it is clear that the $N_{q}$ failure mechanism is much deeper and wider than the $N_{\gamma}$ mechanism. This difference in the size and extent of the failure mechanisms has important implications for the situation when both $q^{\prime} \neq 0$ and $\gamma^{\prime} \neq 0$. It also has implications for the conventional bearing capacity equation, equation (4), which assumes superposition of the $N_{c}, N_{q}$ and $N_{\gamma}$ terms that have been determined independently from analyses with $q^{\prime}=\gamma^{\prime}=0, c^{\prime}=\gamma^{\prime}=0$ and $c^{\prime}=q^{\prime}=0$ respectively.

The superposition assumption has been examined in greater detail by performing an analysis of a rough strip footing on a soil with weight and with surcharge loading. Values of $c^{\prime}=0, \quad v=\phi^{\prime}=25^{\circ}, \quad q^{\prime}=10 \mathrm{kPa}, \quad \gamma^{\prime}=18 \mathrm{kN} / \mathrm{m}^{3} \quad$ and
$B=1 \mathrm{~m}$ were assumed. The analysis predicted an ultimate footing load $Q_{\max }=556 \mathrm{kN} / \mathrm{m}$. From the analyses discussed above, which considered the $N_{q}$ and $N_{\gamma}$ cases separately, values of $N_{q}=11.03$ and $N_{\gamma}=6.72$ were obtained. Substituting these values into equation (7) gives an ultimate load $Q_{\max }=463 \mathrm{kN} / \mathrm{m}$. Comparison of these two estimates of $Q_{\max }$ indicates that the superposition assumption used in the conventional bearing capacity equation results in an estimate of $Q_{\max }$ that is conservative by $17 \%$.

The results presented above clearly show that numerical analysis can do all that conventional methods can do for the surface footing problem. It can also do more: for example, it can provide the complete load-displacement curve, can account for different values of the angle of dilation, can predict failure mechanisms, and do all this in a matter of minutes with modern computer hardware and software.

\section{(b) Accommodate realistic soil behaviour and (c) account for consolidation}

In the foregoing discussion we have seen that numerical analysis can deal with non-associated plasticity and enable solutions in which $v \neq \phi^{\prime}$ can be obtained. Although such solutions are an improvement on conventional analysis, the Mohr-Coulomb model is restricted in its ability to simulate real soil behaviour. This is clearly evident from Fig. 7, which shows the behaviour of a drained triaxial test on a Mohr-Coulomb material. Although the deviator stress-strain curve represents a passable representation of soil behaviour, the unlimited dilation indicated in the volumetric-axial strain curve is unrealistic.

The Mohr-Coulomb model is adopted by most conventional methods of analyses because of its relative simplicity, but it is possible to accommodate more realistic constitutive models in numerical analysis. In fact, the only way that the more complex constitutive models that have been developed over recent years can be used to analyse real geotechnical problems is by incorporating them into a numerical analysis. Even the relatively simple critical-state-type models, such as Cam clay (Roscoe \& Schofield, 1963) and modified Cam clay (Roscoe \& Burland, 1968), must be incorporated into a numerical analysis if they are to be of use in geotechnical practice. Such models are an improvement over the MohrCoulomb model because they link compression and shear behaviour in a realistic manner. This can be seen in Fig. 14, which shows the results of ideal drained triaxial tests on both normally and overconsolidated modified Cam clay. For the normally consolidated sample volumetric compression is

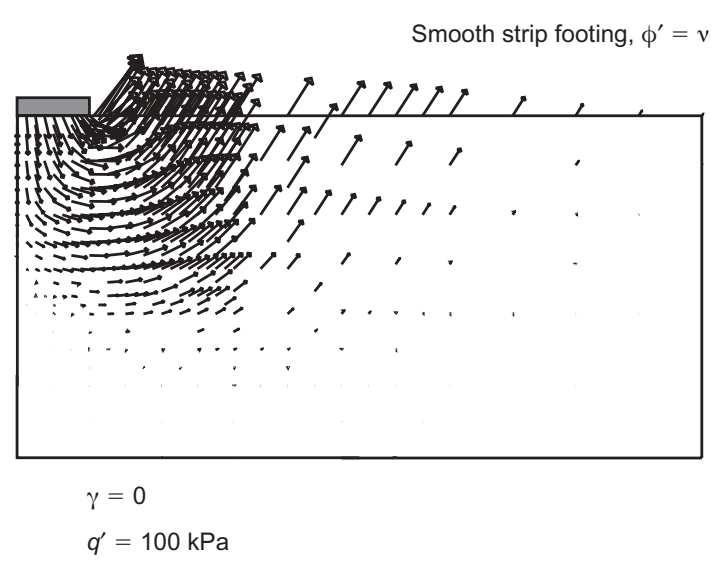

(a)

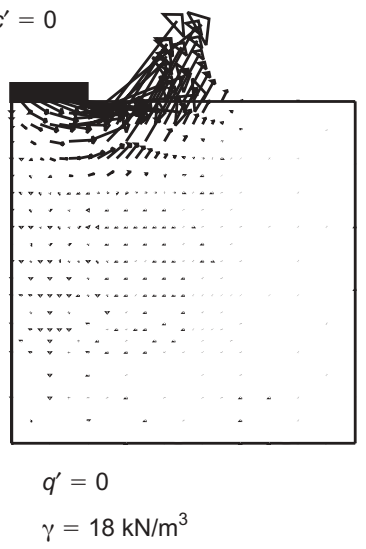

(b)

Fig. 13. Comparison of failure mechanisms: (a) $N_{q}$ failure mechanism; (b) $N_{\gamma}$ failure mechanism 

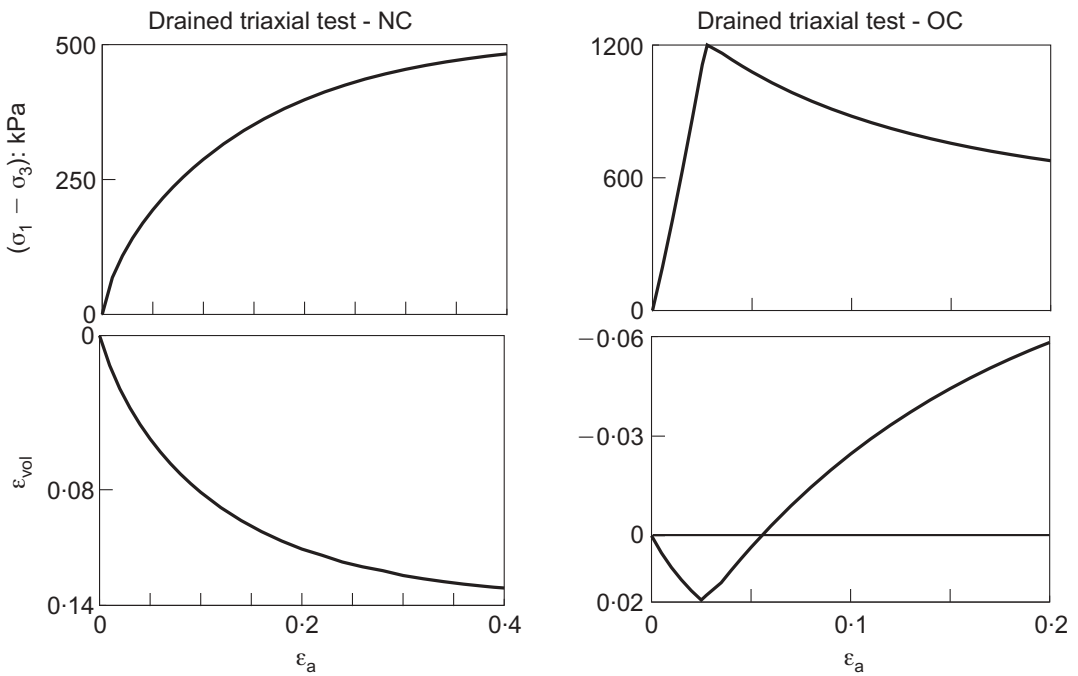

Fig. 14. Drained triaxial compression tests with modified Cam clay

predicted, whereas for the overconsolidated clay sample initial compression followed by dilation is predicted. The rate of volumetric compression (normally consolidated sample) and dilation (overconsolidated sample) reduces as the axial strain increases, and eventually, when the critical state is reached, the change in volume becomes zero. The stressstrain curve for the overconsolidated sample also indicates strain-softening behaviour. Although such behaviour is a more realistic representation of real soil behaviour, and a vast improvement on the Mohr-Coulomb model, it is still approximate. For example, for the overconsolidated sample the linear stress-strain curve pre-peak and the sudden change in gradient of the stress-strain curve at peak strength are only a crude approximation of real soil behaviour. To overcome the shortcomings of the simple critical-state models many complex constitutive models have been developed: see Potts \& Zdravkovic (1999).

As an example of the use of an advanced constitutive model, the problem of a rigid strip footing resting on the surface of a typical soft clay will be considered. The footing is $2 \mathrm{~m}$ wide and the clay stratum is normally consolidated below a depth of $2 \mathrm{~m}$, with a stronger crust at the surface. The initial profile of undrained strength with depth is shown in Fig. 15.
At the design stage the following information is required:

(i) the initial short-term bearing capacity

(ii) the settlements, both initially (that is, short term) and in the long term, of the footing when loaded with a load factor of $2 \cdot 5$

(iii) the undrained bearing capacity of the footing in the long term after all excess pore water pressures due to the initial loading have dissipated. This is relevant if additional load is to be added in the future, or if the footing is to be reused. This is particularly relevant in the current climate of sustainable development.

A variant of the modified Cam clay model was used to represent the clay layer, and the model parameters and initial stress conditions were based on a site investigation from a site in Grimsby (Mair et al., 1992). The soil properties were: $\phi^{\prime}=32^{\circ} ; \gamma_{\text {sat }}=17 \mathrm{kN} / \mathrm{m}^{3}$; slope of the virgin consolidation line, $\lambda=0 \cdot 22$; slope of the swelling lines, $\kappa=0 \cdot 02$; specific volume at a mean effective stress of $1 \mathrm{kPa}$ on the virgin consolidation line, $v_{1}=3 \cdot 0$; elastic shear modulus, $G=$ $1700 \mathrm{kPa}$; and permeability, $k=5 \times 10^{-10} \mathrm{~m} / \mathrm{s}$. The initial undrained strength $\left(s_{\mathrm{u}}\right)$, overconsolidation ratio (OCR) and coefficient of earth pressures at rest $\left(K_{0}\right)$ profiles are given in Fig. 15. As the information required for the design
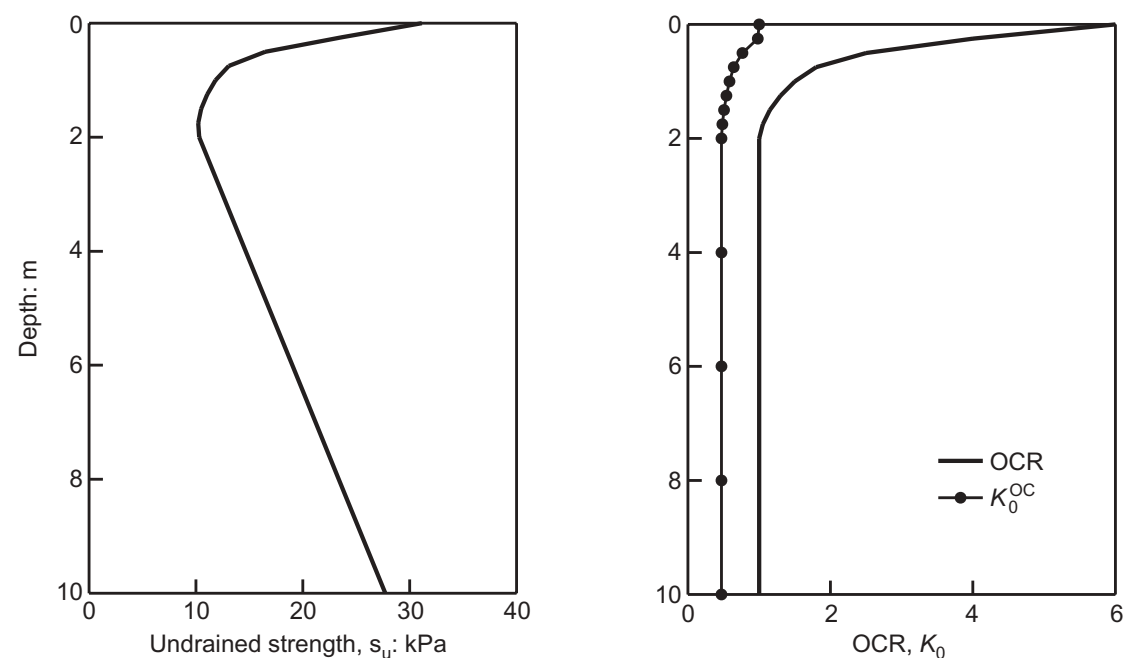

Fig. 15. Undrained strength, OCR, and $K_{0}$ profiles for soft clay 
involved both short-term and long-term predictions, a coupled finite element analysis was undertaken linking the mechanical and pore fluid flow behaviour. For further information see Potts \& Zdravkovic (2001).

The results of the analyses are shown in Fig. 16. Initially, an analysis was performed in which the footing was loaded rapidly until failure occurred. This enabled the short-term bearing capacity to be obtained (point A in Fig. 16). A second analysis was then undertaken in which the footing was loaded until $40 \%$ of the initial undrained bearing capacity was mobilised (that is, a load factor of $2 \cdot 5$ : $\mathrm{O}$ to B in Fig. 16). This stage of the analysis was again performed in a short time period to maintain undrained conditions. From the results of this analysis it was possible to obtain an estimate of the short-term footing settlement.

The load on the footing was then maintained constant (B to $\mathrm{C}$ in Fig. 16) and a series of time steps were applied until all excess pore water pressures, arising from the initial rapid loading, dissipated (that is, long-term consolidation was simulated). During this stage of the analysis the footing settled (distance BC in Fig. 16).

In the third stage of this analysis further load was rapidly applied to the footing to estimate the increase in bearing capacity as a result of the pre-loading and consolidation (point D in Fig. 16). The analysis indicates that the bearing capacity has increased by $11 \%$ (that is, the difference between footing loads at points A and D).

This example demonstrates the ability of numerical analysis to account for complex constitutive models and coupled behaviour. It has also indicated that the numerical analysis can furnish estimates to important design questions.

It is interesting to consider how the design requirements could have been satisfied using conventional analysis. In this respect it is noted that some approximation to the initial undrained strength profile would have to be made to estimate the initial short-term bearing capacity, as conventional methods cannot deal with the complex distribution of strength shown in Fig. 15. It would also be possible to estimate settlements, but with difficulty. However, it would not be possible to estimate the long-term undrained bearing capacity, as it is not possible to estimate the long-term distribution of undrained shear strength with conventional methods.

(d) Provide mechanisms of behaviour and (e) accommodate complex soil stratigraphy

To illustrate the ability of numerical analysis to predict mechanisms of behaviour and account for complex soil stratigraphy, the stabilisation of the Pisa Tower will be

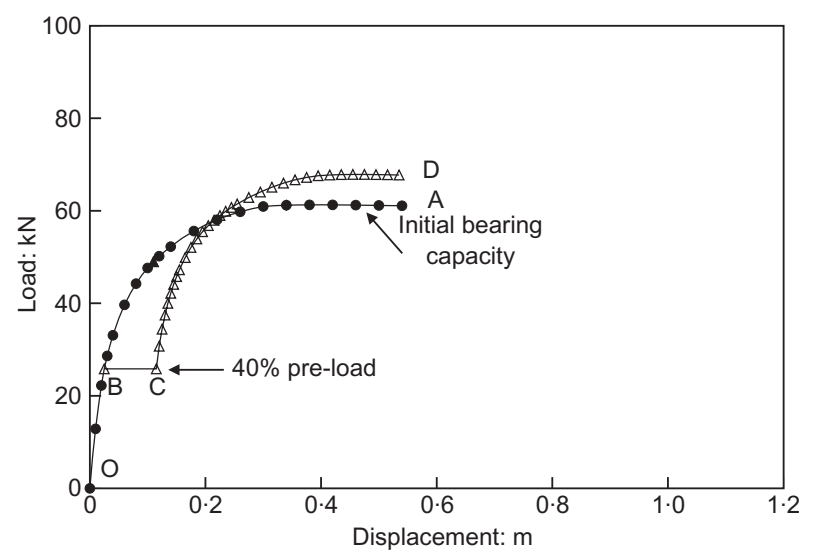

Fig. 16. Load-displacement curve for pre-loading on soft clay considered. This has been probably the most challenging foundation problem of modern times.

The impetus to the activities undertaken to stabilise the Tower, over the past 10 years, was the collapse, without warning, of the nearby civic tower of Pavia in 1989, which killed four people. The Italian government appointed a commission to advise on the stability of the Pisa Tower and to develop and implement measures for stabilising it. One of the early decisions of the Commission was to develop a numerical model of the Tower and the underlying ground that could be used to assess the effectiveness of various possible remedial measures. Professor John Burland (a member of the Commission) and the author were asked to undertake this task.

Figure 17 shows a picture of the Tower and a crosssection through it. It is essentially a hollow cylinder $60 \mathrm{~m}$ high and the foundations are $19.6 \mathrm{~m}$ in diameter. The mass of the Tower is $14500 \mathrm{t}$, and in 1990 the foundations were inclined due south at $5.5^{\circ}$ to the horizontal.

The Tower is a campanile for the cathedral, construction of which began on 9 August 1173. By 1178 construction had progressed to about one quarter of the way up the fourth storey, when work stopped. The reason for the stoppage is not known, but had it continued much further the foundations would have experienced an undrained bearing capacity failure. The work recommenced in 1272 , after a pause of nearly 100 years, by which time the strength of the ground had increased owing to consolidation under the weight of the Tower. By 1278 construction had reached the seventh cornice, when work again stopped owing to military action. Once again there can be no doubt that, had work continued, the Tower would have fallen over. In 1360 work on the bell chamber commenced, and it was completed in about 1370 , nearly 200 years after commencement of the work. In 1838 a walkway was excavated around the foundations. This is known as the catino, and its purpose was to expose the column plinths and foundation steps for all to see, as was originally intended.

Figure 18 shows the ground profile underlying the Tower. It consists of three distinct horizons, the properties of which are described in AGI (1991) and Potts \& Burland (2000). Horizon A is about $10 \mathrm{~m}$ thick and consists primarily of estuarine deposits laid down under tidal conditions. As a consequence, the soil types consist of rather variable sandy and clayey silts. At the bottom of horizon $\mathrm{A}$ is a $2 \mathrm{~m}$ thick medium dense fine sand layer (the upper sand). Based on sample descriptions and piezocone tests, the material to the south of the Tower appears to be more silty and clayey than to the north, and the sand layer is locally thinner.

Horizon B consists of marine clay, which extends to a depth of about $40 \mathrm{~m}$. It is subdivided into four distinct layers. The upper layer is a soft sensitive clay known as the Pancone. It is underlain by a layer of stiffer clay (the intermediate clay), which in turn overlies a sand layer (the intermediate sand). The bottom of horizon B is a normally consolidated clay known as the lower clay. Horizon B is laterally very uniform in the vicinity of the Tower.

Horizon $\mathrm{C}$ is a dense sand that extends to a considerable depth (the lower sand). The water table in horizon $\mathrm{A}$ is between $1 \mathrm{~m}$ and $2 \mathrm{~m}$ below ground surface. The many borings beneath and around the Tower show that the surface of the Pancone clay is dished beneath the Tower, from which it can be deduced that the average settlement, at this level, is approximately $3 \mathrm{~m}$.

Before remedial measures could be designed, it was important to identify the cause of the inclination of the Tower. As a first step it was necessary to establish the history of inclination. This was accomplished by a fine piece of detective work by Professor John Burland. Based on the 

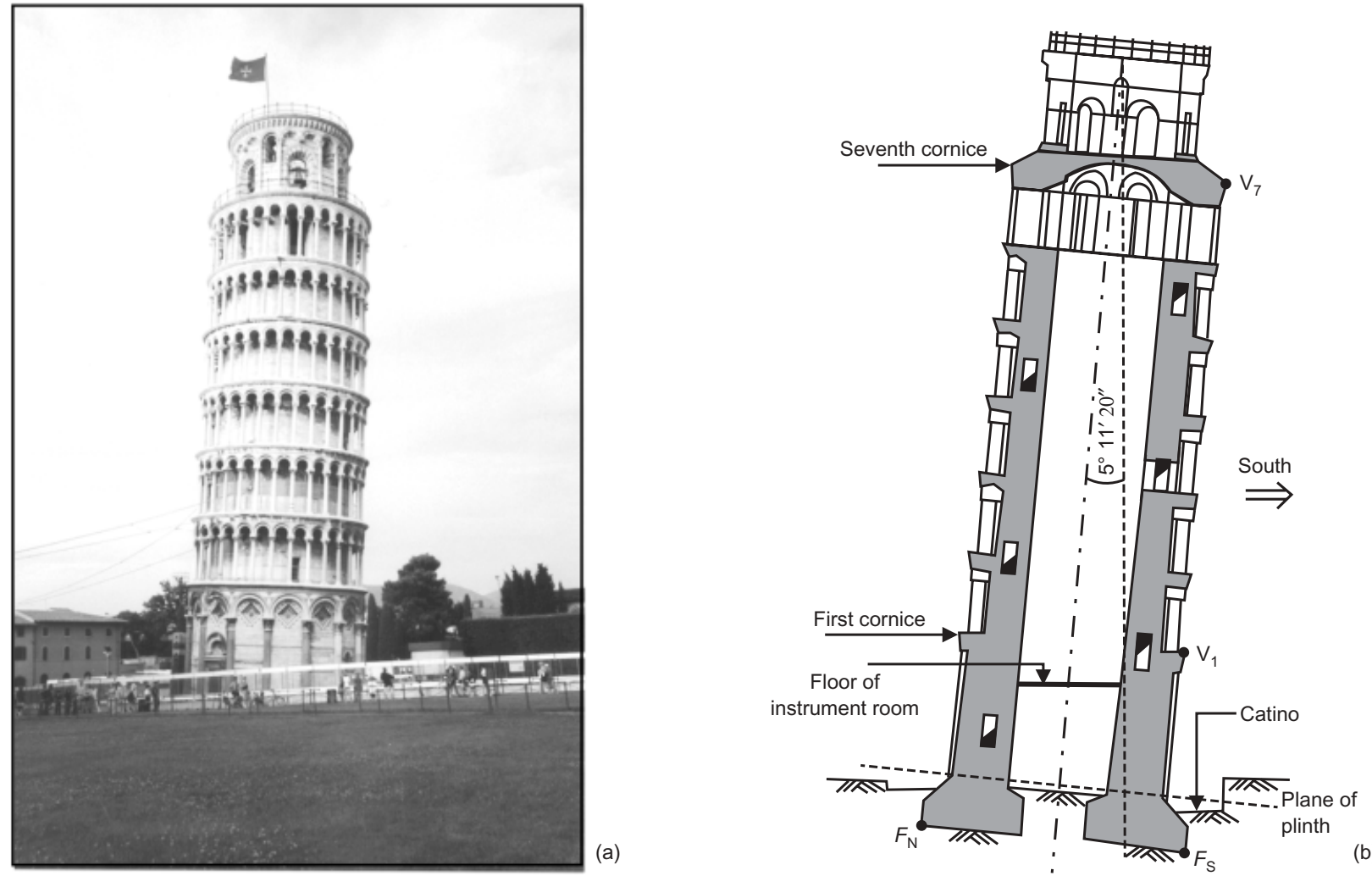

Fig. 17. (a) Pisa Tower; (b) schematic cross-section through the Tower

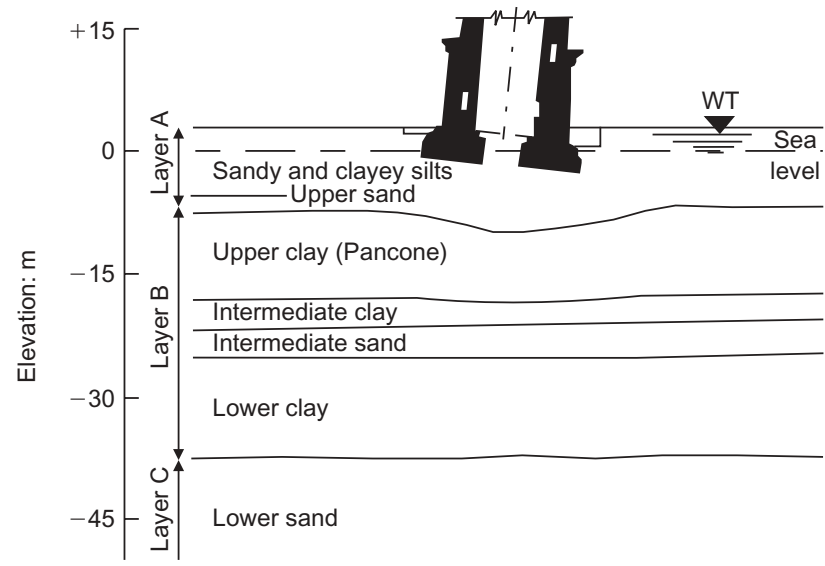

Fig. 18. Soil profile beneath Pisa Tower

measured thickness of each masonry layer and a hypothesis on the manner in which the masons corrected for the progressive lean of the Tower, Burland deduced the history of inclination of the foundations of the Tower shown in Fig. 19 (Burland \& Potts, 1994). In this figure the weight of the Tower is plotted against the deduced inclination of its foundation.

During the first phase of construction to the fourth storey (1173 to 1178) the Tower inclined slightly to the north. This northward inclination increased slightly during the rest period of nearly 100 years. When construction recommenced in 1272, the Tower began to move towards the south and accelerated shortly before construction reached the seventh cornice in 1278 . The movement continued during the following 90 years. After the completion of the bell chamber in 1370 the inclination of the Tower increased significantly, as

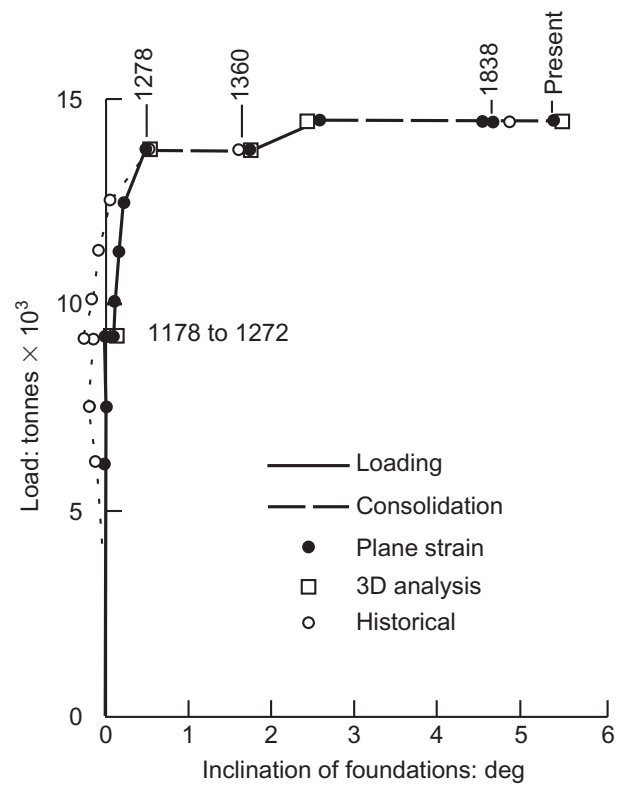

Fig. 19. Historical inclination of Pisa Tower

it did when the excavation for the catino was undertaken in 1834.

The nature of the movements shown in Fig. 19, and more recent measurements of the ongoing movements, are not consistent with a bearing capacity type failure discussed previously for the surface footing problem (Potts \& Burland, 2000). It is therefore of interest to consider the possible mechanisms associated with the stability of the foundations of tall towers.

There are two possible mechanisms that could account for failure of such a tower: (i) bearing capacity failure due to 
insufficient soil strength, and (ii) leaning instability due to insufficient soil stiffness. Bearing capacity failure is the more common type of foundation instability and the one covered in most textbooks and codes of practice. It is usually investigated using the formulae given in equation (4). Leaning instability is not so common and is only relevant to tall structures. It occurs at a critical inclination when the overturning moment generated by a small increase in inclination is equal to, or greater than, the resisting moment provided by the foundations and generated by the same small rotation. In all but very simple cases, it is difficult, probably impossible, to analyse without using numerical analysis.

These two alternative failure mechanisms are best demonstrated by a simple example. Fig. 20 shows a simple tower resting on a uniform deposit of undrained clay. The dimensions of the tower are similar to those of the Pisa Tower. To trigger a rotational failure some initial defect (imperfection) must be present. In this example the tower was given an initial tilt of $0.5^{\circ}$ (that is, the initial geometry of the tower had a tilt). The self-weight of the tower was then increased gradually in a plane-strain, large displacement finite element analysis, until failure occurred.

The clay was modelled as a linear-elastic Tresca material. Three analyses were performed, each with a different value of shear stiffness, $G$, of the soil. All other parameters were the same. In particular, the undrained strength, $s_{\mathrm{u}}$, was $80 \mathrm{kPa}$ in all analyses. Therefore, according to conventional methods, the bearing capacity of the tower was the same in all three analyses. Consequently, if instability was governed by bearing capacity failure, all three analyses should fail at the same weight of the tower. However, as can be seen from Fig. 21, this was not the case. This figure shows the increase in rotation of the tower, above the initial $0.5^{\circ}$ imperfection, plotted against the weight of the tower, for analyses with $G / s_{\mathrm{u}}$ values of 10,100 and 1000 . Real soils are likely to have properties that are between the two extreme values. The results show that failure occurs very abruptly, with little warning, and that the weight of the tower at failure is dependent on the shear stiffness of the soil. The weight at

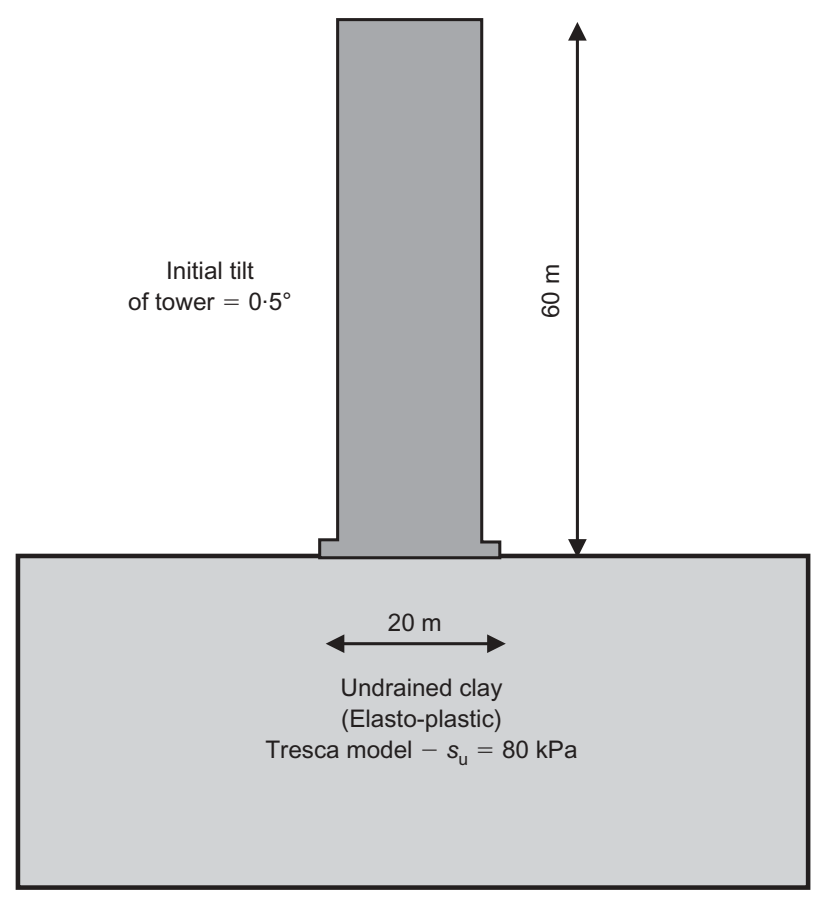

Fig. 20. Geometry for investigation of leaning instability of a tower

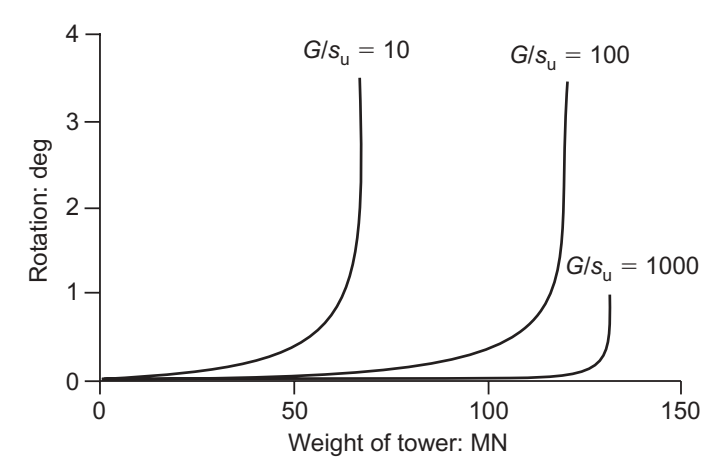

Fig. 21. Tower rotation with increase in weight

failure for the analysis with the softer soil, $G / s_{\mathrm{u}}=10$, is about half of that for the analysis with the stiffest soil, $G / s_{\mathrm{u}}=1000$.

It is of interest to examine the analyses with the two extreme values of $G / s_{\mathrm{u}}$ in more detail. In particular it is instructive to consider what is happening in the soil at failure. Fig. 22 shows vectors of incremental displacement for the soft soil $\left(G / s_{\mathrm{u}}=10\right)$ from the last increment of the analysis. They show that movements are located in a zone below the foundation, and indicate a rotational type of failure. At first sight this looks like a plastic-type collapse mechanism. However, examination of the zone in which the soil has gone plastic (also shown in Fig. 22) indicates that it is very small and not consistent with a plastic failure mechanism. Consequently, this figure indicates a mechanism of failure consistent with a leaning instability.

Considering the results from the analysis performed with the stiffer soil $\left(G / s_{\mathrm{u}}=1000\right)$, vectors of incremental displacement just before collapse are shown in Fig. 23. The mechanism of failure indicated by these vectors is very different from the one shown in Fig. 22 for the softer soil. Instead of the soil rotating as a block with the foundation, the vectors indicate a more traditional bearing capacity type mechanism, with the soil being pushed outwards on both sides. The plastic zone, also indicated in Fig. 23, is very large, and therefore the results clearly indicate a plastic bearing capacity type mechanism of failure. The mechanism is not symmetrical because the tower is leaning to one side.

In view of the temporary stabilisation scheme, which involved adding lead weights to the north side of the Pisa Tower and which will be discussed in more detail subsequently, it is of interest to examine the response of the

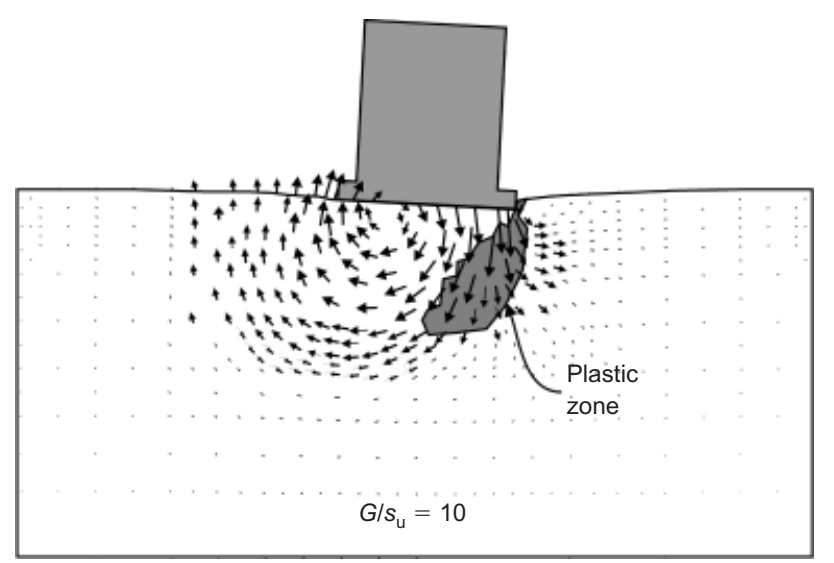

Fig. 22. Vectors of incremental displacements and plastic zone at failure (low soil stiffness) 


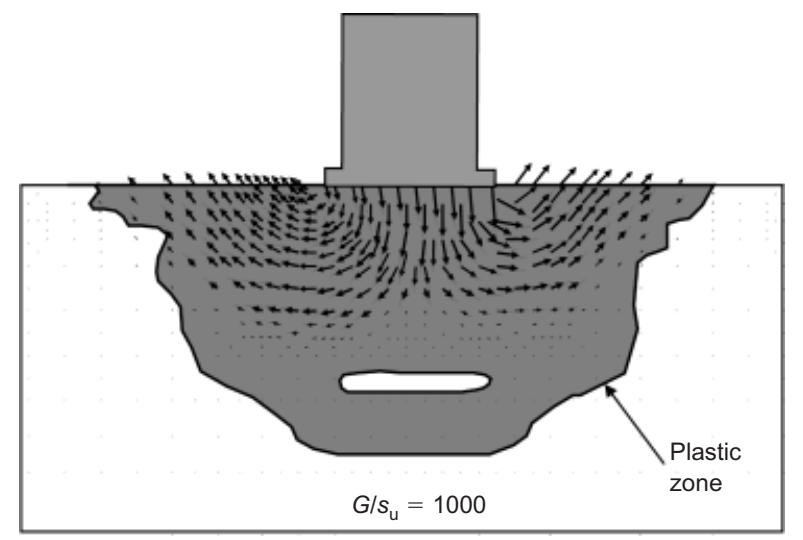

Fig. 23. Vectors of incremental displacements and plastic zone at failure (high soil stiffness)

simple tower in the above example if, at the point of collapse, weight is added to the higher side of the foundation. The effect of a $1.5 \mathrm{MN} / \mathrm{m}$ load is shown in Figs 24 and 25 for the soft $\left(G / s_{\mathrm{u}}=10\right)$ and stiff $\left(G / s_{\mathrm{u}}=1000\right)$ soils respectively. Again, vectors of incremental displacement are shown. These indicate the nature of the movements due to this additional load.

It is noted that for the soft soil (Fig. 23) the sense of movement is reversed: the tower rotates back and collapse is arrested. So if the tower is undergoing leaning instability,

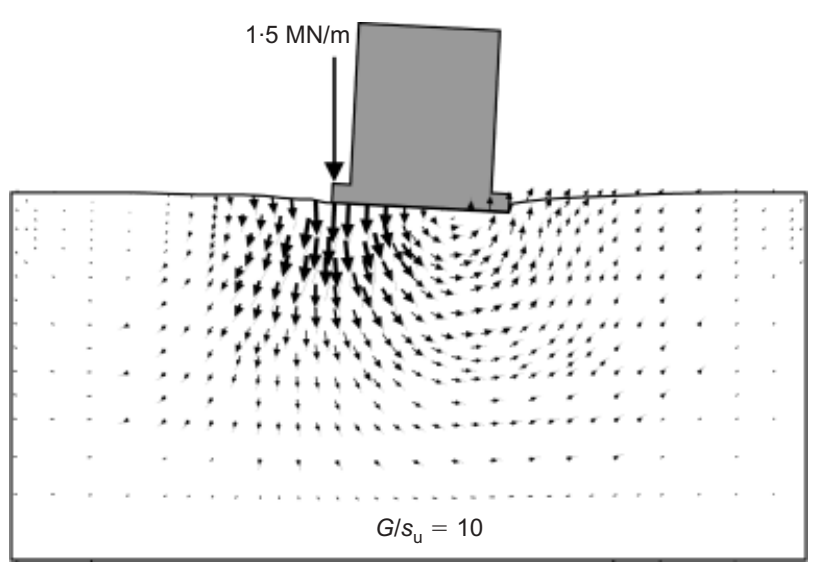

Fig. 24. Effect of north weighting (low soil stiffness)

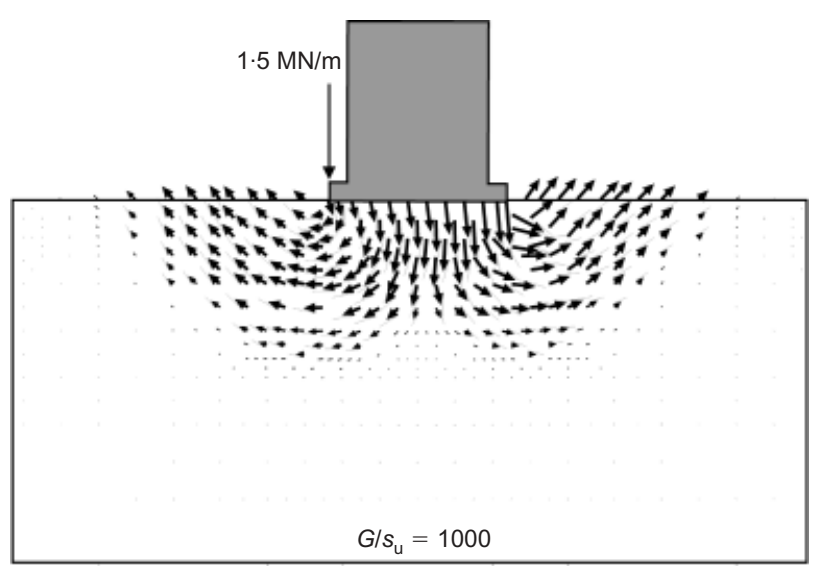

Fig. 25. Effect of north weighting (high soil stiffness) adding weight to reduce the overturning moment stabilises the tower. In contrast, for the stiffer soil (Fig. 24), the tower continues to increase its inclination when the load is applied. In fact, it was not possible to obtain a converged solution when the weight was added. The addition of the load initiates collapse, even though the load acts to reduce the overturning moment. This is, of course, consistent with conventional bearing capacity theory.

As well as demonstrating the difference between the two types of instability and the ability of numerical analysis to predict which is likely to occur, these analyses also indicate that a counterweight-type scheme will be beneficial to the Pisa Tower only if it is suffering a predominantly leaning instability. To complicate matters further, real soils are likely to have stiffness values between the two extremes considered above, and therefore both mechanisms of behaviour are likely to be active to some degree.

Returning to the Pisa Tower, before stabilisation schemes could be developed it was necessary to establish which mechanism was dominant. To achieve this, numerical analysis to simulate the past history of the Tower was undertaken. Comparison of the results from such an analysis with the observed behaviour given in Fig. 19 also allowed the computer model to be validated.

It must be emphasised that a prime objective of the analysis was to develop an understanding of the mechanisms controlling the behaviour of the Tower. It was felt that, until these had been clarified, it would be unhelpful to attempt highly sophisticated and time-consuming three-dimensional analyses. It should also be remembered that the initial analyses were performed in 1990, when computing resources were much more restricted than they are now. Accordingly, a plane-strain approach was used initially, recognising that the interpretation of the results would require some care. From 1994 three-dimensional analyses were carried out using the Fourier series aided finite element method (Potts \& Zdravkovic, 1999). Both small and large displacement analyses were performed, and all analyses involved coupled consolidation. It is important to note that, in all analyses, the overturning moment arising from the lean of the Tower was self-generated in the analysis; it was not imposed as an external boundary condition. As the results of the plane-strain and three-dimensional analyses were similar, they will simply be identified as 'predictions' in the figures that follow. For further details the reader is referred to Potts \& Burland (2000).

The soil stratigraphy shown in Fig. 18 was modelled as 13 different soil types. A simple Mohr-Coulomb model was used to represent the sand layers, whereas a form of the modified Cam clay model was used to represent the clay layers. The soil properties were obtained from laboratory tests, and are described in detail by Potts \& Burland (2000). A detail of the plane-strain finite element mesh close to the Tower foundation is shown in Fig. 26 (note that the complete mesh extended $100 \mathrm{~m}$ either side of the axis of the Tower and down to the top of horizon C). The properties of layer A1 varied from north to south, becoming more compressible and less permeable. This is believed to have provided the defect or trigger that initialised the tilting of the Tower.

The results of the analysis simulating the history of the Tower from 1173 to 1990 are shown in Figs 19 and 27. In this latter figure rotation and settlement of the foundation are plotted against time. Also shown in Fig. 27 are key tilt observations taken from Fig. 19. The agreement between the predictions and observations is quite remarkable. The results shown were based on initial estimates of soil parameters and geometric idealisations.

At the end of the analysis (which corresponds to the 


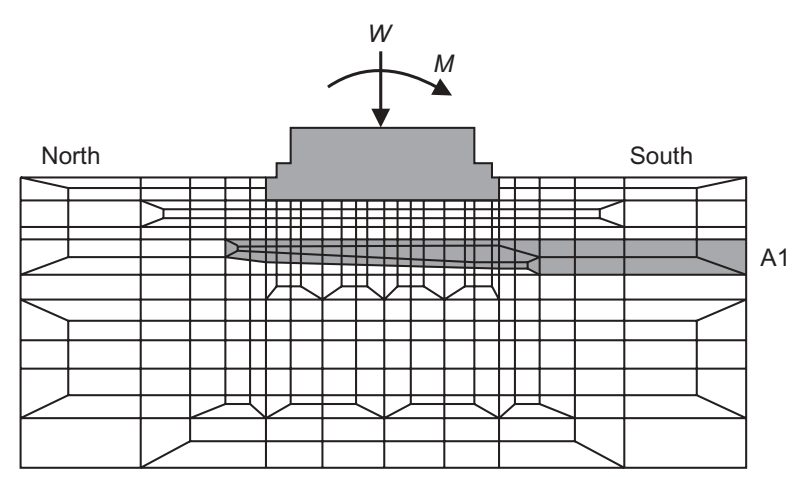

Fig. 26. Detail of finite element mesh close to Tower foundation

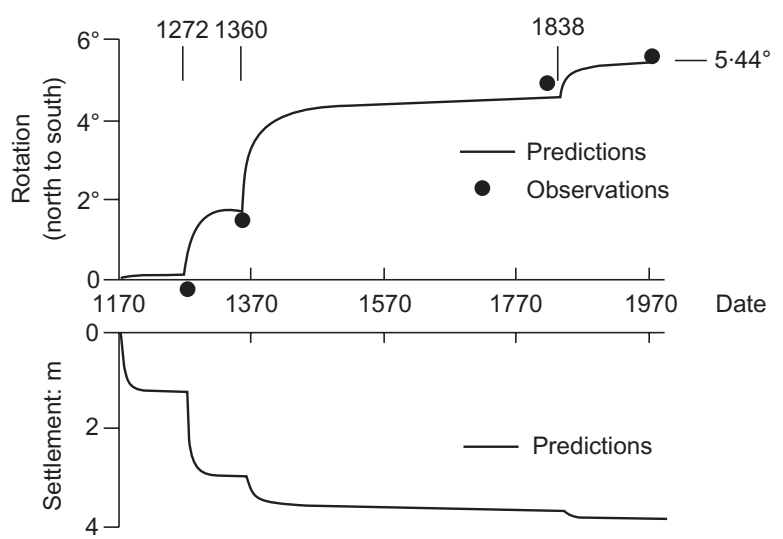

Fig. 27. Rotation and settlement of Tower with time

conditions in year 1990), the Tower was only just stable, and any small perturbation would cause collapse. To identify the dominant mechanism of instability it is instructive to examine the zones of soil in which its strength is fully mobilised. These are shown in Fig. 28. There are no zones of contained failure within the Pancone clay, but there are extensive zones within horizon A. The lowest zones are in the upper sand layer and result from the lateral extension of this layer. There is a zone beneath and outside the southern edge of the foundation, and a smaller zone underneath the northern side. It is evident from this figure that the impending instability of the Tower foundations is not due to the onset of a bearing capacity failure, but can be attributed to the

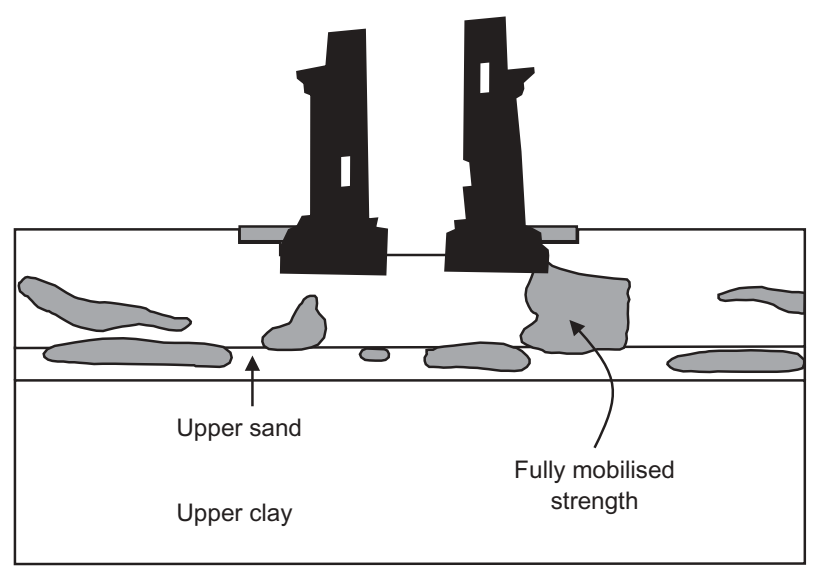

Fig. 28. Zones of fully mobilised strength: Pisa Tower, 1990 high compressibility of the Pancone clay, which results in leaning instability.

Having established the likely mechanism controlling the behaviour of the Tower, and having validated the numerical analysis, the analysis was then extended to investigate various stabilisation schemes. Fully aware that the selection, design and implementation of permanent stabilisation measures would take time, the Commission took an early resolution to implement short-term temporary and fully reversible measures to increase slightly the stability of the foundation. This would then provide time to develop a permanent solution.

In developing both the short- and long-term stabilisation methods the numerical analysis proved invaluable. To illustrate this the temporary counterweight scheme, which was actually adopted, will be considered. The scheme consisted of constructing a temporary prestressed concrete ring beam around the base of the Tower and loading it with lead weights: see Fig. 29.

Clearly, such a solution would not have been considered if it had not been recognised that leaning instability, rather than bearing capacity failure, was controlling the behaviour of the Tower. Before implementing such a solution it was essential that a detailed analysis should be carried out. The purpose of such an analysis was twofold: first, to ensure that the proposal was safe and did not lead to any undesirable effects; and, second, to provide a class A prediction that could be used to assess the observed response of the Tower as the load was being applied.

The numerical analysis performed to simulate the history of the Tower was used as the starting point to investigate the

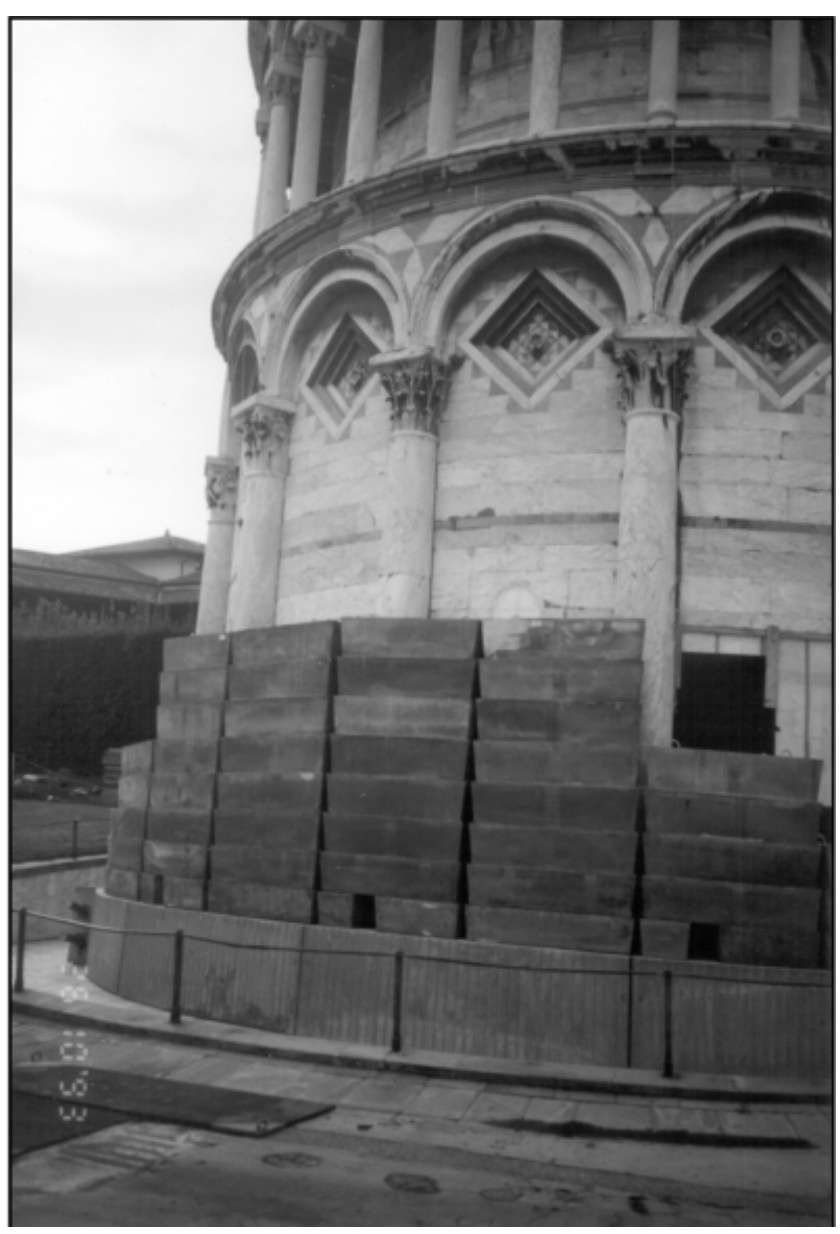

Fig. 29. Lead weights on the north side of the Tower 
counterweight scheme. Fig. 30 shows the predicted response of the Tower due to the application of a counterweight to the foundation masonry at eccentricities of $6.4 \mathrm{~m}, 7.8 \mathrm{~m}$ and $9.4 \mathrm{~m}$ to the north. The results show that as long as the load is less than $1200 \mathrm{t}$ the weighting has the desired effect of rotating the Tower to the north, with only small settlements. In this load range the behaviour is not sensitive to the eccentricity. In the event, practical considerations required the eccentricity to be $6.4 \mathrm{~m}$, and it was decided that a load of $690 \mathrm{t}$ would be applied. For this situation the numerical analysis predicted a rotation of the Tower of 27.5 arc seconds towards the north and a settlement of $2.4 \mathrm{~mm}$.

A comparison of the predictions with the observations that were made during application of the lead weights is shown in Fig. 31. Note that in this figure the load does not include the weight of the concrete ring beam. As can be seen, the predicted settlements agree very well with those observed, whereas the predicted rotations are $80 \%$ of those observed.
The accuracy of the predictions is perhaps surprising as the rotations are two to three orders of magnitude smaller than the accumulated ones arising from the history of the Tower and used to validate the numerical model.

The measured data were then used to further refine the computer model (that is, a class C prediction; Lambe, 1973). To obtain an excellent match with the observed data it was necessary only to make a reduction to the shear stiffness of the upper soil layers in horizon $\mathrm{A}$, which was done within the scatter of experimental data. The results are shown in Fig. 32, where the load now includes the weight of the concrete ring beam.

The refined model was then used to analyse the permanent stabilisation schemes and, in particular, the soil extraction scheme actually used. For further information the reader is referred to Potts \& Burland (2000).

The Pisa Tower example clearly shows that numerical analysis can deal with complex soil stratigraphy and, perhaps

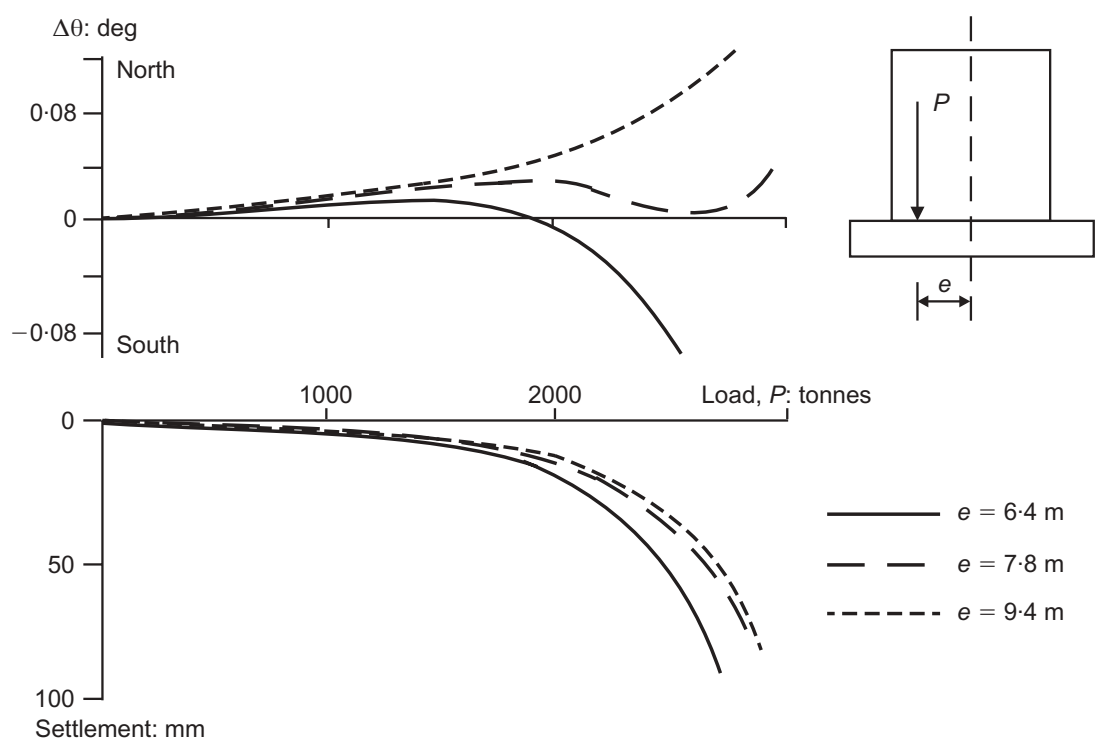

Fig. 30. Predicted response of the Tower due to north weighting

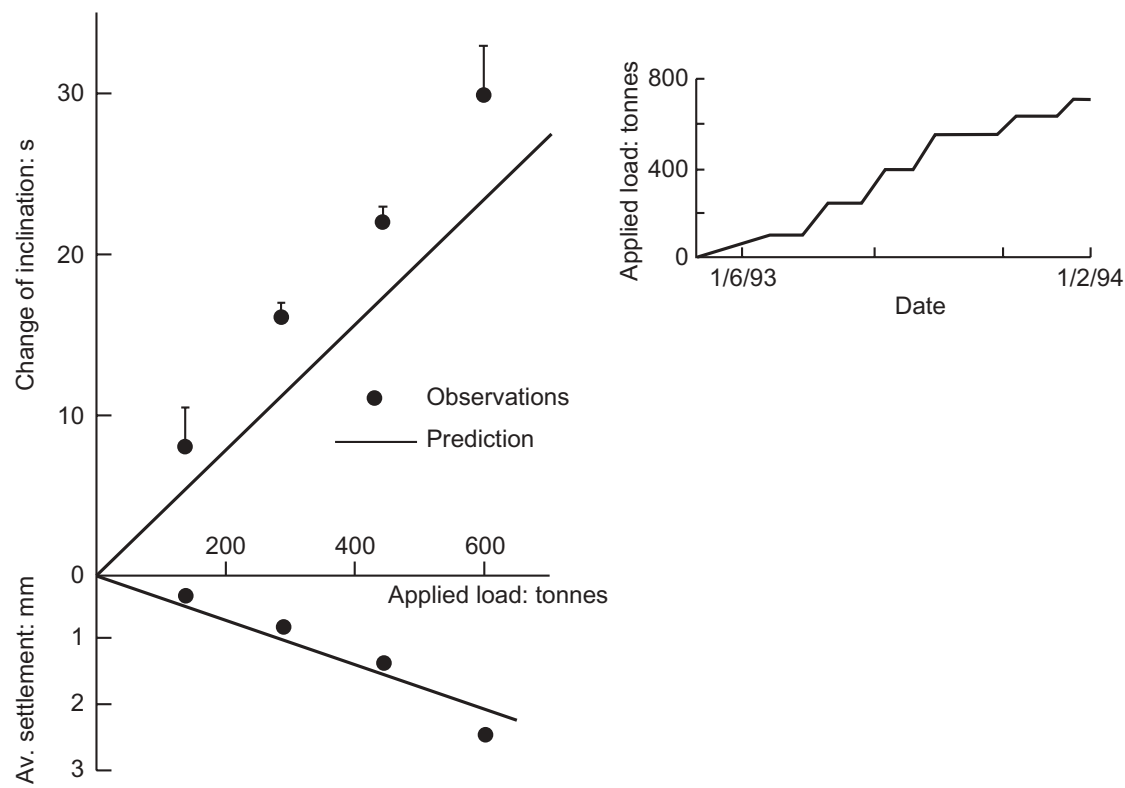

Fig. 31. Predicted and observed response due to application of counterweight (class A prediction) 


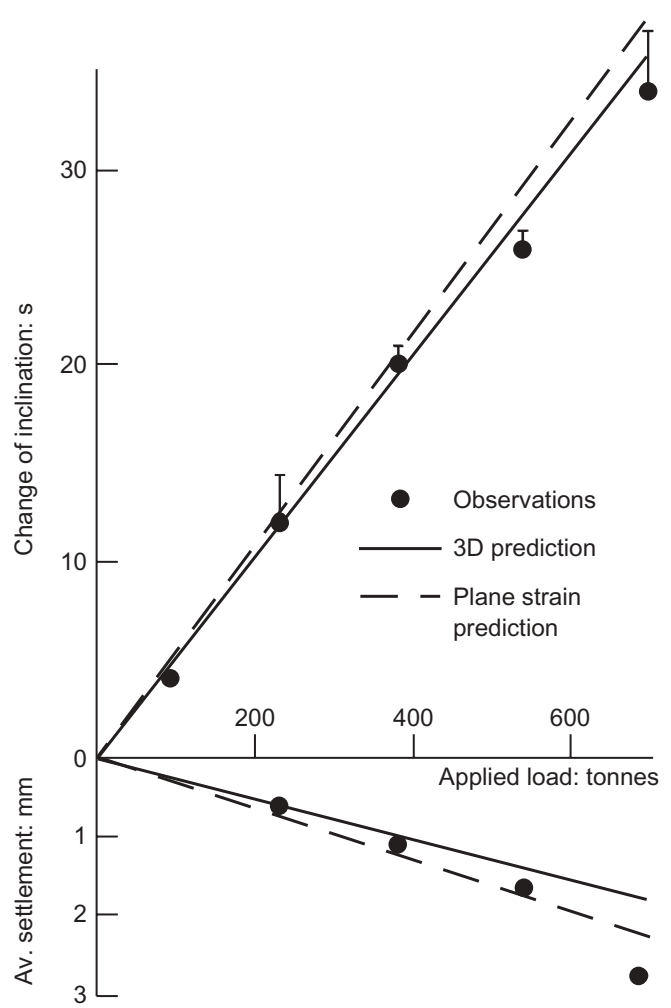

Fig. 32. Predicted and observed response due to application of counterweight (class $\mathrm{C}$ prediction)

more importantly, can predict the correct mechanism of instability. In the author's opinion it is the ability to predict mechanisms of behaviour that sets numerical analysis in a league of its own. The fact that the analysis also gave quantitatively correct predictions is of course also impressive and extremely useful. At this point it is worth asking the question: 'How else could the Pisa Tower have been modelled?'

\section{(f) Account for interaction between structures}

As noted earlier in this lecture, one of the design objectives is to estimate the effect that construction may have on adjacent structures and services. This is difficult, often impossible, to achieve using conventional methods of analysis. However, it is relatively easy to accommodate both adjacent structures and services in a numerical analysis. To illustrate this point the recent deep excavation performed at Westminster for the new underground station will be used as an example.

The original Westminster station served the District and Circle underground lines. However, construction of the Jubilee line extension required that the station be expanded, which in turn involved a deep excavation some $75 \mathrm{~m}$ by $28 \mathrm{~m}$ in plan and $37 \mathrm{~m}$ deep - one of the deepest in London. Above the station a new building, Portcullis House, was to be constructed. An aerial photo of the site is shown in Fig. 33. The Big Ben clock tower and the Houses of Parliament can be seen on the right of the picture, with the River Thames behind and Bridge Street to the left. The excavation site is clearly visible to the left of Bridge Street. The District and Circle underground lines run approximately parallel to the River Thames on the river side of the excavation, and the tunnels for the Jubilee line extension run below Bridge Street. Clearly, there are many important buildings and services adjacent to the excavation that are likely to be

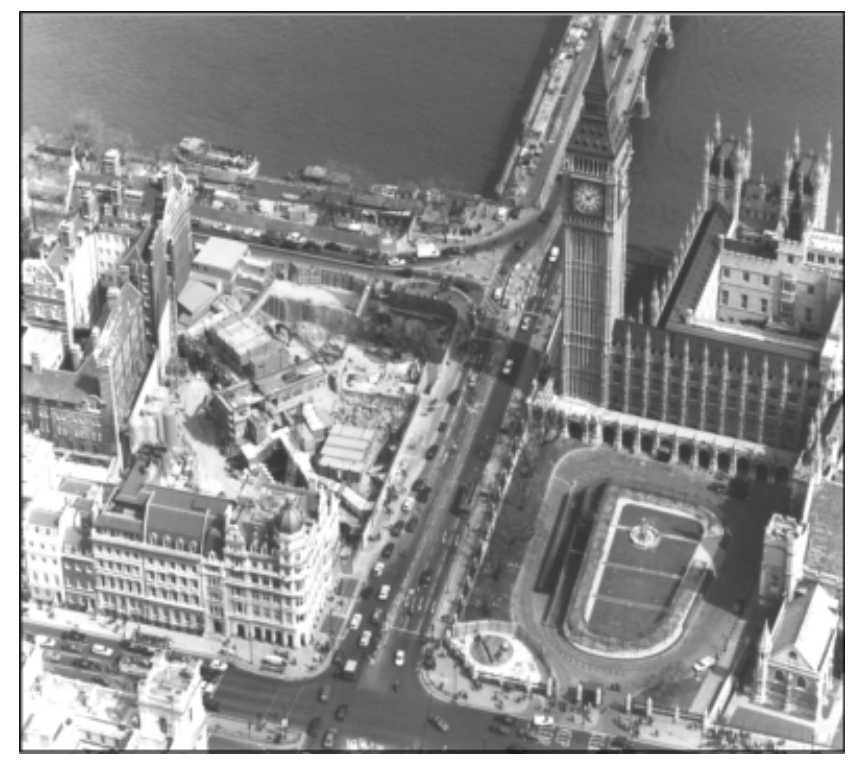

Fig. 33. Jubilee line extension site at Westminster

affected by its construction. In particular there was concern about the potential movement of the Big Ben clock tower. To complicate matters, construction of both the deep excavation and the tunnels for the Jubilee line extension were to take place simultaneously.

A cross-section through the excavation, approximately parallel to the River Thames, is shown in Fig. 34, and it can be seen that the tunnels for the Jubilee line extension are very close to the excavation. The sequence of construction was as follows: the westbound (WB) running tunnel, the diaphragm wall for the excavation, the eastbound (EB) running tunnel, enlargement of the WB running tunnel to form the WB station tunnel, excavation to a level of $83.6 \mathrm{~m}$, enlargement of the EB running tunnel to form the EB station tunnel, and finally full excavation to a level of $69 \cdot 5 \mathrm{~m}$.

A considerable number of numerical analyses were performed during the design process, most of which were plane-strain finite element analyses, as at the time computer resources were not available to perform three-dimensional analyses. An important aspect of these analyses was that they incorporated constitutive models for the soils that simulated their small-strain behaviour. This was essential if realistic predictions of movements of adjacent structures were to be accurately predicted. These analyses indicated:

(i) A bottom prop was required to support the walls of the station box before any excavation took place. Without this prop movements adjacent to the excavation were predicted to be too large and detrimental. In the event these props were constructed by digging shafts and then horizontal adits, which were filled with reinforced concrete.

(ii) Even with the provision of the bottom props, the movements of the Big Ben clock tower were likely to be too large. This resulted in the provision of compensation grouting facilities, which in the event were used on several occasions during the construction period to correct for movements of the clock tower foundations.

(iii) Possible movements and structural forces in the walls and props of the excavation, in the Jubilee line tunnel linings and other adjacent structures.

As an example of some of the predictions that were made, Fig. 35 shows a comparison between predicted and observed 


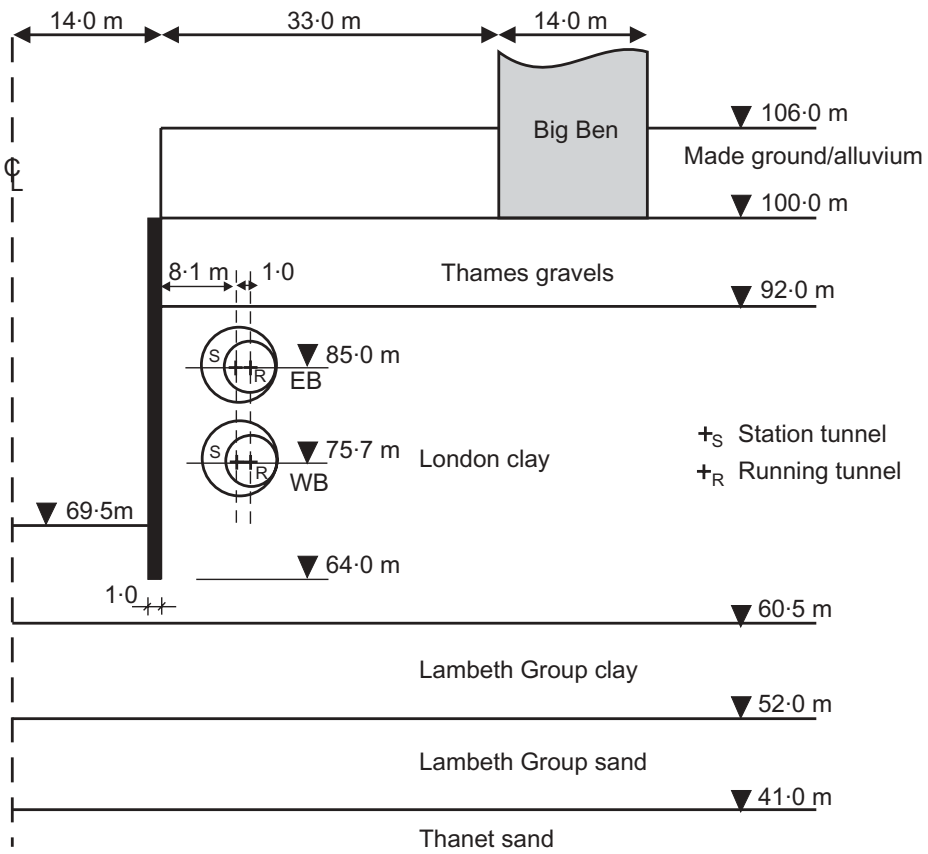

Fig. 34. Cross-section through excavation at Westminster

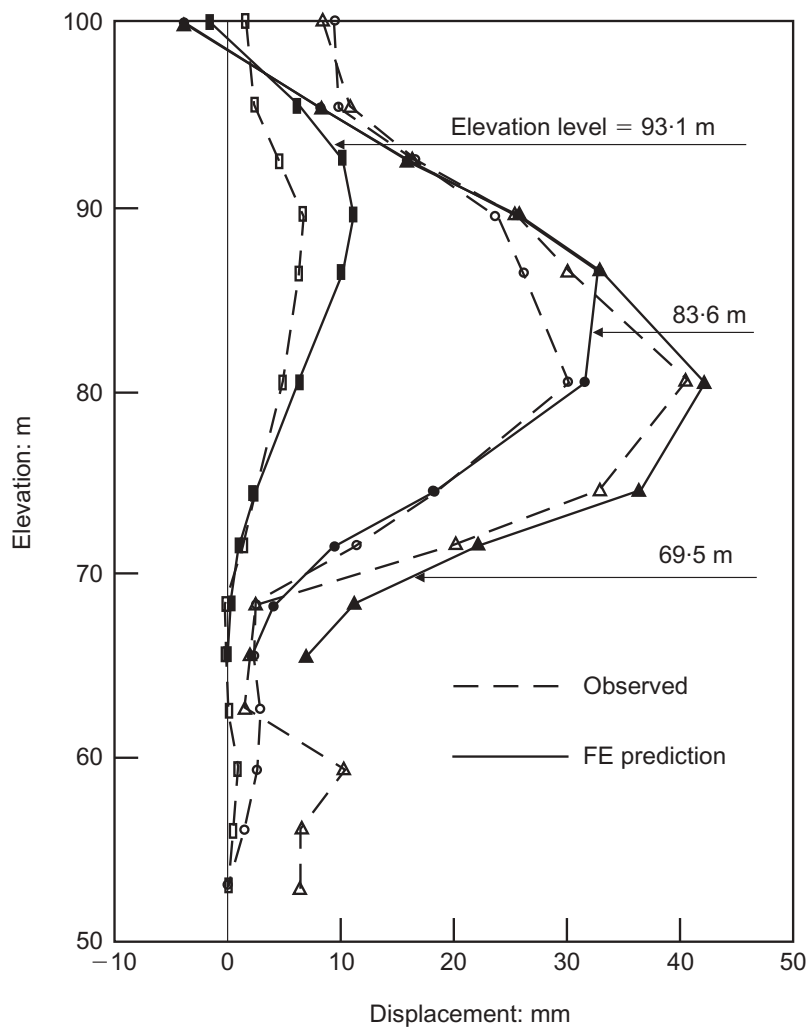

Fig. 35. Comparison of measured and predicted displacements of Westminster station wall

lateral movements of the wall of the excavation shown in the cross-section in Fig. 34. Results are given for three excavation depths. Note that the predictions were made before construction, and therefore they are class A predictions in Lambe (1973) terminology. For further details of the constitutive models and material parameters the reader is referred to Higgins et al. (1996).
Inspection of Fig. 35 indicates that there is good agreement between the predictions and observations, with the predictions being slightly larger than the observations. This is probably due to the fact that the analysis assumed planestrain conditions, whereas in reality the problem is more three-dimensional. This will be discussed further in the next section.

Clearly, it would have been extremely difficult, if not impossible, to have modelled this construction with conventional methods of analysis.

(g) Accommodate three-dimensional geometries

In most conventional analyses it is common to assume one- or two-dimensional geometries. This often involves assuming plane-strain or axisymmetric conditions. Until very recently this was also true for numerical analysis, if realistic constitutive models were to be included. However, in many real situations such assumptions are questionable. Over the last four years developments in computer hardware have enabled limited three-dimensional analyses to be performed, and with further hardware developments such analyses are likely to become more widespread in the future.

To illustrate the use of three-dimensional finite element analysis, another deep excavation problem will be considered. This is associated with the Crossrail underground scheme. Although this scheme is still in the planning stages, the route of the proposed tunnels between Paddington and Liverpool Street is fixed. At one location on this route it is the intention to construct an excavation $35 \mathrm{~m}$ by $35 \mathrm{~m}$ in plan and $40 \mathrm{~m}$ deep. Its purpose is to act as a launching chamber for tunnel-boring machines and then subsequently to form part of a station complex. Clearly, the excavation will affect adjacent structures and services, and analysis will be required to quantify these effects.

At present, the Moor House site, which is directly adjacent to the proposed Crossrail excavation (see Fig. 36), is under redevelopment, and as part of the design process the effect of the excavation on the foundations must be assessed. Current practice would be to perform two-dimensional plane-strain and/or axisymmetric numerical analysis to 


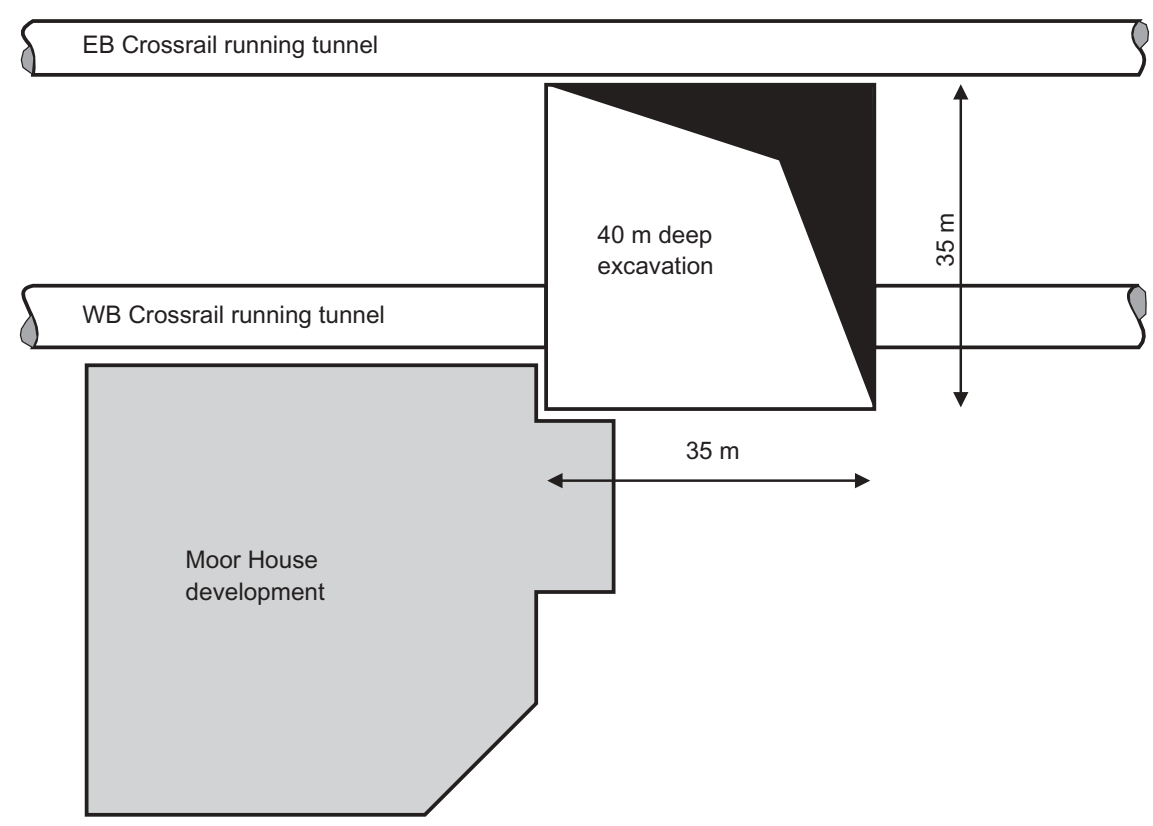

Fig. 36. Proposed Crossrail excavation near the Moor House development

predict ground movements and then use these movements to assess the effect on adjacent structures. Clearly, engineering judgement is involved in this process.

The finite element mesh shown in Fig. 37, consisting of 800 eight-noded quadrilateral elements, has been used to perform such analyses. The concrete wall is assumed to be $1.2 \mathrm{~m}$ thick and have a total depth of $46.7 \mathrm{~m}(6 \mathrm{~m}$ below the bottom of the final excavation level). It is propped at seven levels. A realistic excavation procedure, in which excavation is performed to a depth below the intended prop position before the prop is inserted and the process repeated, was assumed. The soil layers were modelled with a constitutive model that accounts for small-strain stiffness changes. Excavation was performed relatively quickly so

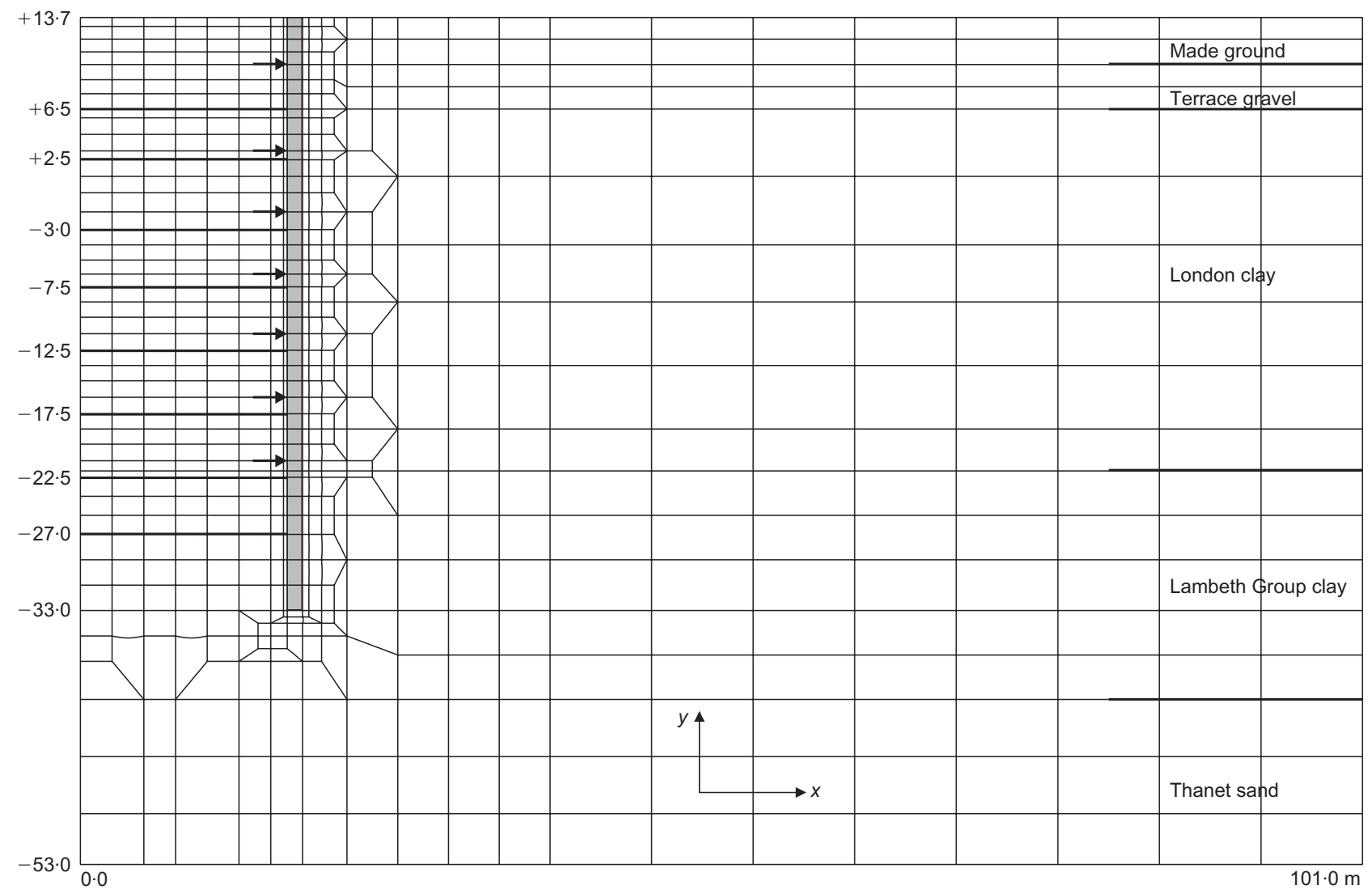

Fig. 37. Finite element mesh used in plane-strain and axisymmetric analyses 
that there was no time for excess pore water dissipation in the clay soils.

Results from a plane-strain analysis and two axisymmetric analyses are presented in Fig. 38 in the form of profiles of lateral wall deflection and surface settlement of the retained ground. In one of the axisymmetric analyses (labelled 'stiff out of plane' in Fig. 38) isotropic properties were assumed for the wall, which implies the same stiffness in the circumferential and vertical directions. This analysis predicts very little wall movement and surface settlement, and is therefore unrealistic. This is not surprising, as it is difficult to construct a wall that has substantial circumferential stiffness. The second axisymmetric analysis (labelled 'soft out of plane' in Fig. 38) assumes anisotropic wall properties with a low stiffness (Young's modulus) in the circumferential direction. This analysis gives larger and more realistic movements. Of course, the out of plane stiffness of the wall does not affect the results of a plane-strain analysis and, as can be seen from Fig. 38, such an analysis produces larger wall movements and surface settlements than the 'soft out of plane' axisymmetric analysis. This is particularly true for the settlements of the retained ground, where the magnitude of movements from the plane-strain analysis are more than double those of the axisymmetric analysis.

Design engineers would have to use engineering judgement as to which of the two predictions, plane strain or axisymmetric ('soft out of plane'), is appropriate to their design. In this respect they might use the plane-strain results as being appropriate to the mid side of the excavation, and the axisymmetric results for the corner. Some sort of interpolation would then be required for wall positions in between.

This problem can be resolved by performing a threedimensional analysis. The finite element mesh used for such an analysis is shown in Fig. 39. It is similar to the two- dimensional mesh in the vertical plane (Fig. 37), and consists of 4500 20-noded hexahedral elements. Because of the eightfold symmetry of the excavation, only one eighth of the problem has been modelled in the analysis.

The same constitutive models for the soils and structural members and the same construction procedure as adopted in the two-dimensional analysis presented above were used. However, three-dimensional analysis presents additional complications. For example, the modelling of the wall requires particular attention. Fig. 40 shows plan views of typical diaphragm and contiguous pile walls. The diaphragm wall has been assumed to consist of a series of reinforced concrete panels separated by unreinforced joints. Ideally, the individual structural forms (panels or piles) and the joints between them should be modelled in any analysis. However, this leads to an excessive number of elements and complications, especially with modelling the joints. Consequently, it is common practice to use either solid or shell elements to model the wall, even though these are continuous in the horizontal direction. Care must therefore be exercised when choosing appropriate wall properties. If isotropic properties are used, as is usual for plane-strain analysis, then the walls will have the same axial and bending stiffness in both the vertical and horizontal directions. This is clearly unrealistic for the same reasons discussed above for the axisymmetric analysis.

A typical diaphragm wall will have a very low bending stiffness in the horizontal direction, but a finite horizontal axial stiffness, albeit considerably smaller than the vertical axial stiffness. It is not possible to model such behaviour with solid elements, and consequently shell elements must be used, as the bending and axial stiffness can be independently varied in such elements. Note that, at present, most commercial software packages do not have such facilities.

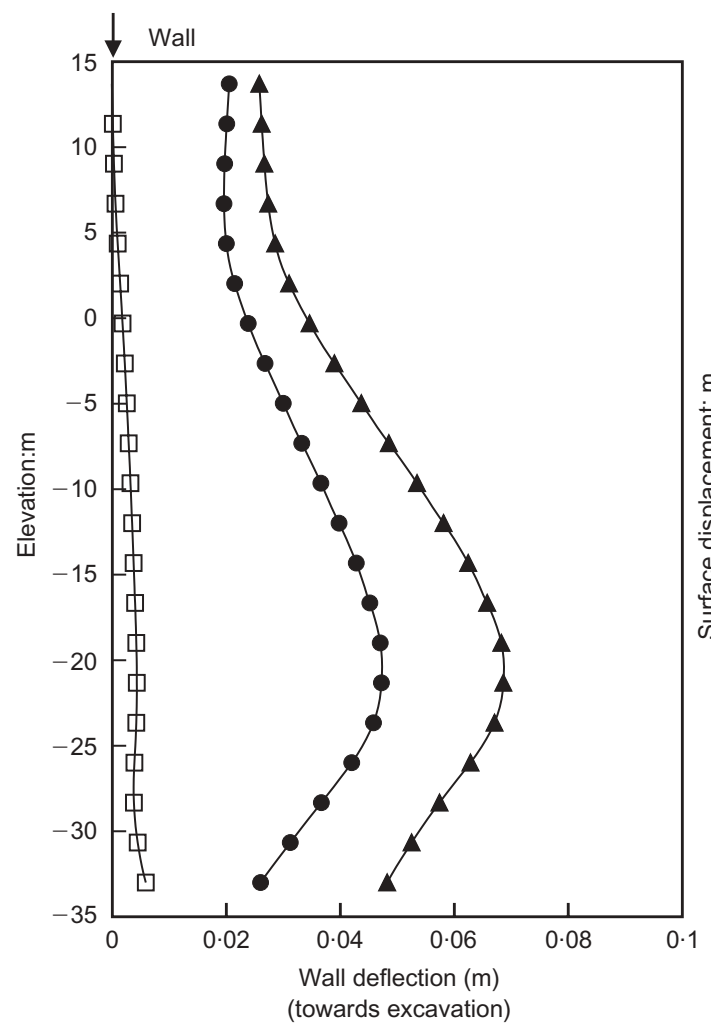

(a)

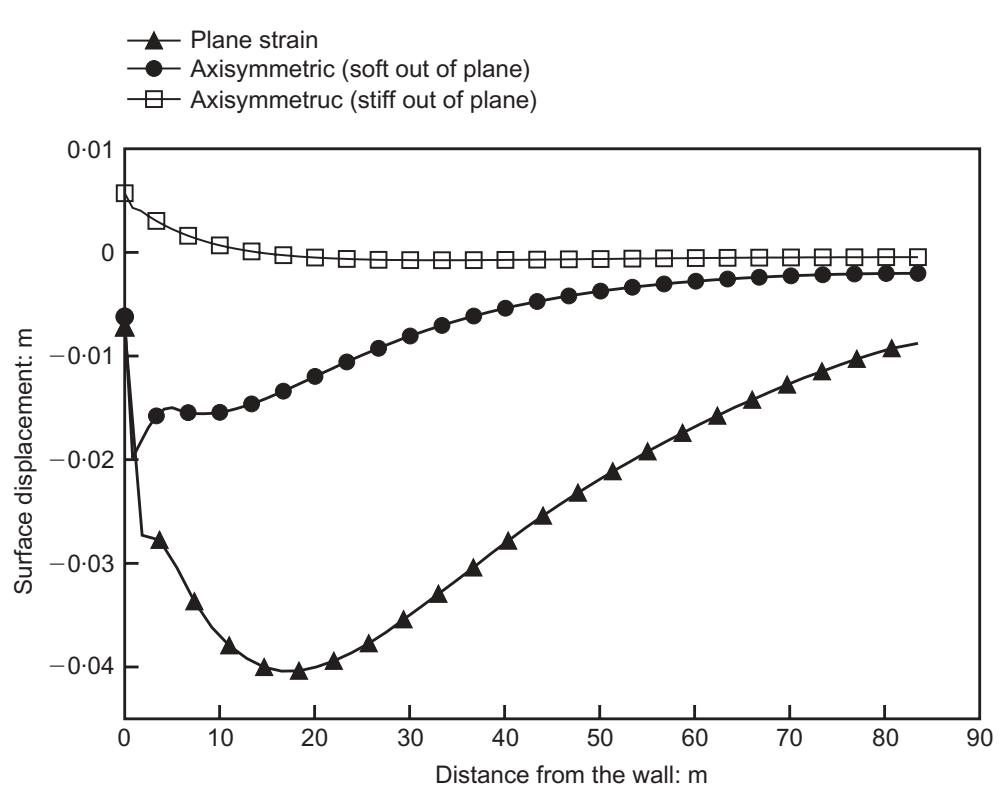

(b)

Fig. 38. Comparison of results for different geometries: (a) wall deflection; (b) surface displacements of retained ground 


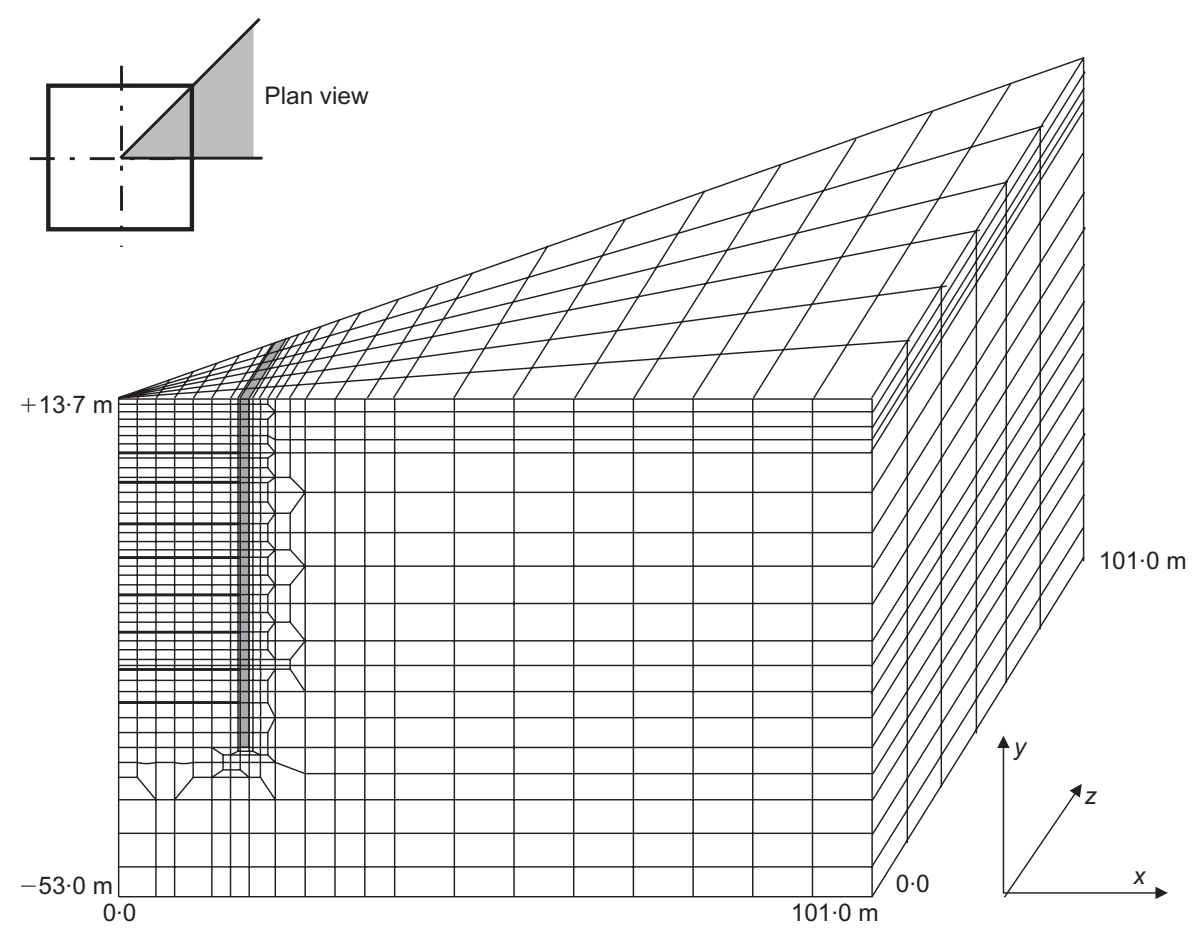

Fig. 39. Finite element mesh used in 3D analysis
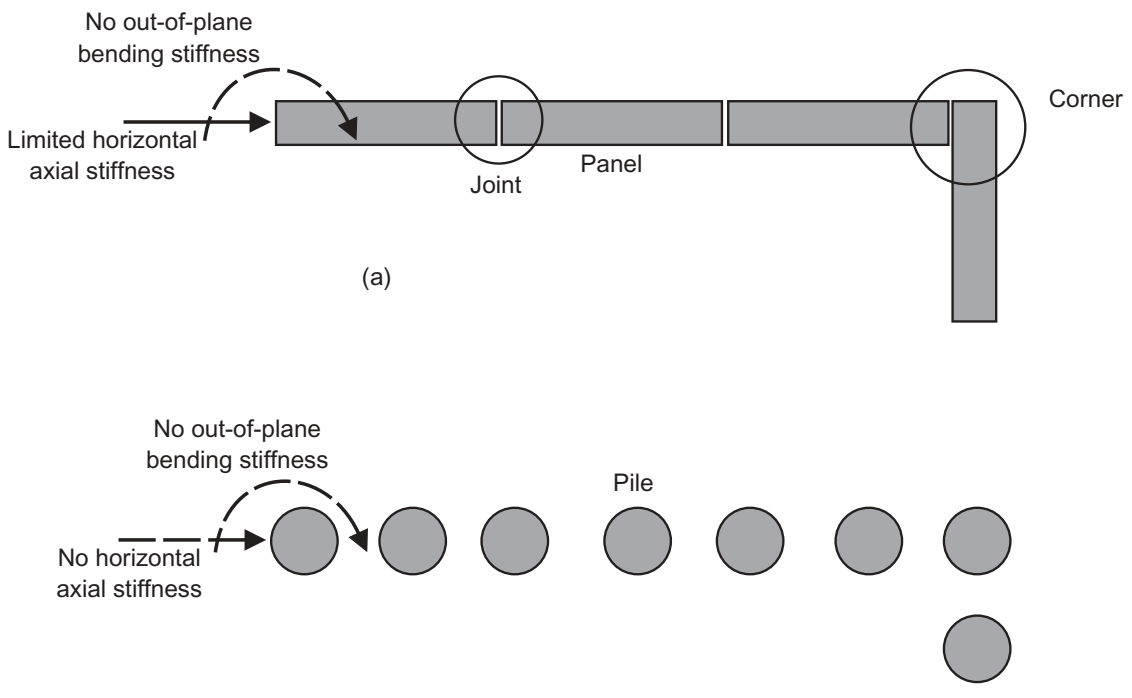

(b)

Fig. 40. 3D modelling of different wall types: (a) diaphragm wall; (b) contiguous pile wall

As both the horizontal bending and axial stiffness are very small for a contiguous pile wall, it can be modelled with either solid or shell elements, combined with an anisotropic elastic constitutive model giving a low Young's modulus in the horizontal direction.

Two three-dimensional analyses, one for a diaphragm wall where the horizontal axial stiffness is one fifth of the vertical stiffness and one for a contiguous pile wall, were performed. The diaphragm wall was represented using shell elements, whereas the contiguous pile wall was modelled using solid elements. Results showing the profiles of lateral wall movement and settlement of the retained ground surface at mid excavation and in the corner of the excavation are presented in Figs 41 and 42. Also shown in these figures for comparison are results from plane-strain and axisymmetric ("soft out of plane') analyses.

Considering Fig. 41, it is evident that at mid excavation both three-dimensional analyses give similar predictions. The lateral wall movements and surface settlements are between those predicted from the plane-strain and axisymmetric analyses, with the wall movements being nearer to those predicted by the plane-strain analysis, whereas the surface settlement trough is nearer to the axisymmetric results. The plane-strain analysis therefore overpredicts wall 


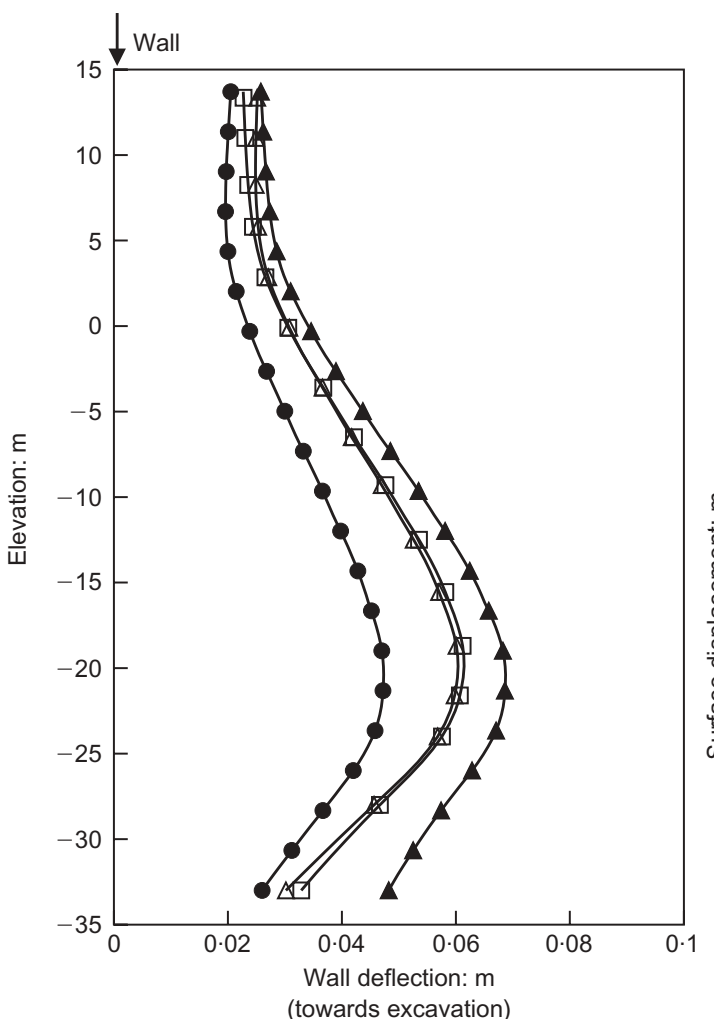

(a)

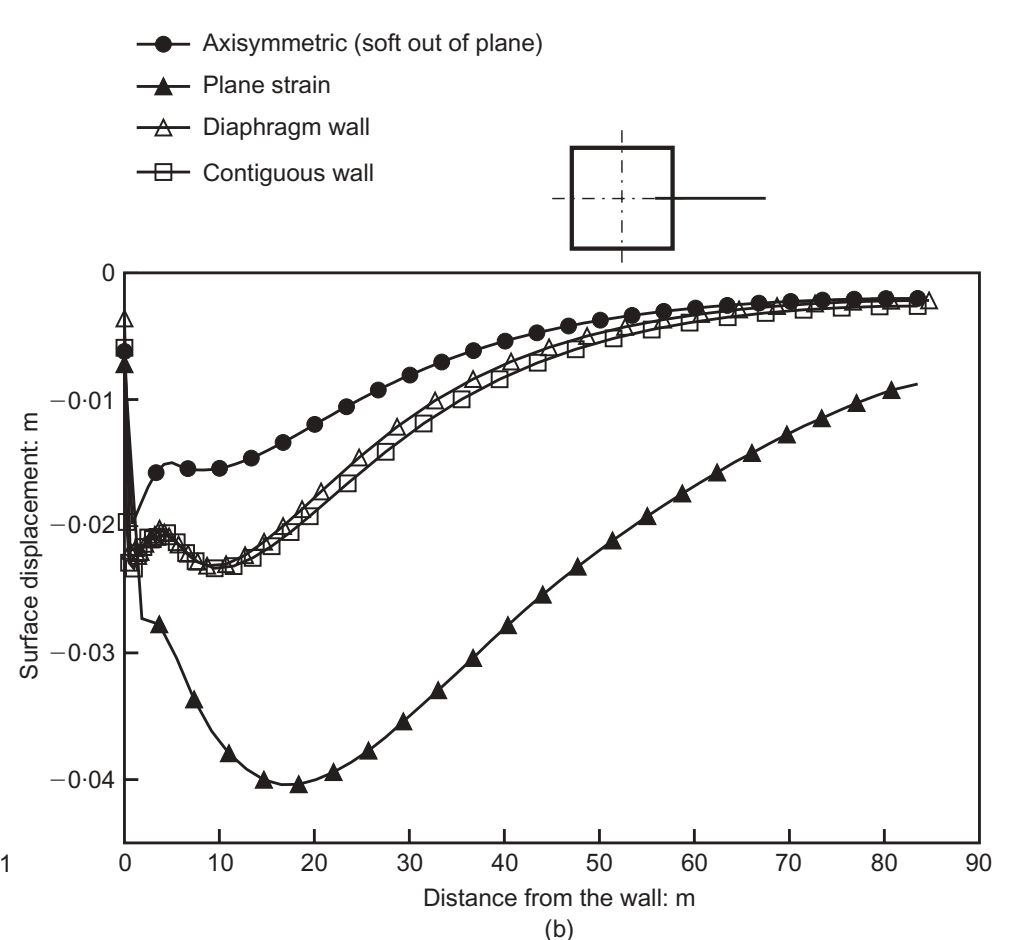

(b)

Fig. 41. Comparison of results from different geometries in the centre of the excavation: (a) wall deflections; (b) surface displacements of retained ground

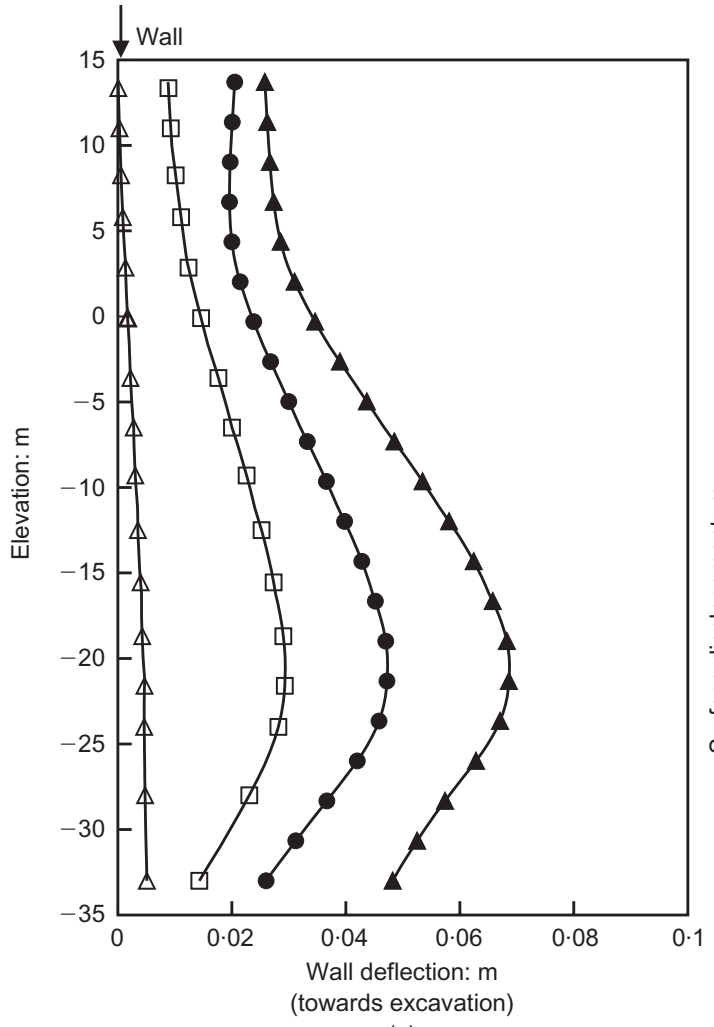

(a)

$$
\begin{aligned}
& \longrightarrow \text { Axisymmetric (soft out of plane) } \\
& \square \text { Plane strain } \\
& \triangle \text { Diaphragm wall } \\
& \square \text { Contiguous wall }
\end{aligned}
$$

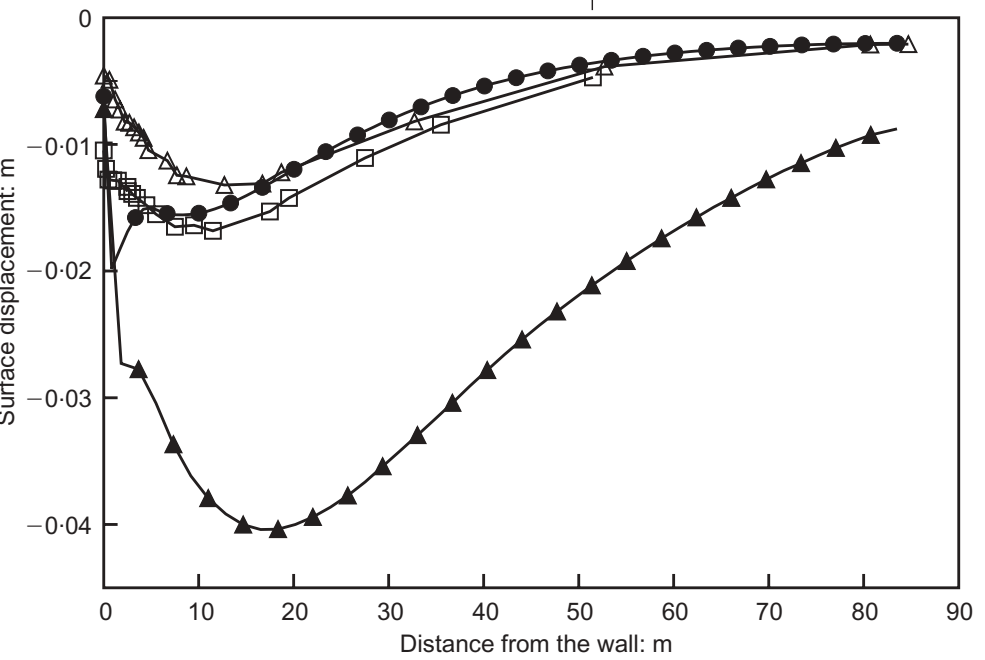

(b)

Fig. 42. Comparison of results from different geometries in the corner of the excavation: (a) wall deflections; (b) surface displacements of retained ground 
movements by a small margin compared with the threedimensional analysis, and this is consistent with the comparison of predictions and observations for the Westminster box presented in Fig. 35.

At the corner of the excavation (Fig. 42) the lateral wall movements for the diaphragm wall are very small and very different from those for the contiguous pile wall. However, the surface settlement troughs from the two analyses are very similar and are also similar to that obtained from the axisymmetric analysis.

These results clearly show that the type of wall can have a significant effect on wall movements. It can also affect the structural forces induced in it.

In summary, detailed three-dimensional analyses of real geotechnical problems are now possible, although they require considerable computing resources. Their use will increase in the future, as they can provide more detailed results, which should lead to optimised designs and cost savings.

From the above discussion it is clear that numerical analysis has many advantages over conventional methods of analysis.

Here ends the case for the motion.

\section{THE CASE AGAINST THE MOTION}

\section{Introduction}

The case against the motion is based on the following four points:

(a) There is no standard non-linear strategy.

(b) Some constitutive models cannot give sensible predictions.

(c) It is difficult to analyse some simple problems.

(d) Results can be user dependent.

This compares with the seven points used for the case for the motion. At this point some readers may be thinking that this imbalance might reflect the author's personal views and allegiances. This is not unreasonable, as the author has spent 25 years promoting numerical analysis. However, as will become evident, these four points are significant and more than adequate for the case against.

\section{(a) No standard non-linear strategy}

As noted at the beginning of this lecture, one of the main approximations involved in numerical analysis is related to the solution strategy adopted to solve the governing equations. The difficulty arises because the basic theory behind the numerical methods assumes material behaviour to be essentially linear-elastic. Application to problems in which material behaviour is non-linear then becomes problematic, because the material stiffness changes during the analysis, as illustrated in Fig. 4. As a first step to overcoming this problem the loading can be applied in a series of increments (or steps). However, because the increments are finite, the material stiffness will still change over the increment and should be accounted for. Unfortunately, there is no exact mathematically rigorous way of dealing with this, and consequently approximations must be introduced. These tend to be camouflaged in technical jargon.

The various finite element and finite difference programs deal with this problem in different ways, which results in inconsistencies. To illustrate this point three classes of nonlinear solution strategy used in finite element analysis will be considered. All of these can be found in software currently used to analyse geotechnical problems. It should be stressed that it is not necessary for the reader to understand the finer details of the strategies; however, it is important that the reader gets an overall grasp of the main assumptions made.

In all three cases the governing equations are reduced to the following incremental form:

$$
\left[\boldsymbol{K}_{\mathbf{G}}\right]^{i}\left\{\Delta \boldsymbol{d}_{\mathbf{n G}}\right\}^{i}=\left\{\Delta \boldsymbol{R}_{\mathbf{G}}\right\}^{i}
$$

where $\left[K_{\mathbf{G}}\right]^{i}$ is the incremental global stiffness matrix, $\left\{\Delta \boldsymbol{d}_{\mathbf{n G}}\right\}^{i}$ is the vector of incremental nodal displacements, $\left\{\Delta \boldsymbol{R}_{\mathbf{G}}\right\}^{i}$ is the vector of incremental nodal forces, and $i$ is the increment number. To obtain a solution to a boundary value problem, the change in boundary conditions is applied in a series of increments, and for each increment equation (8) must be solved. The final solution is obtained by summing the results from each increment. Because of the non-linear constitutive behaviour, the incremental global stiffness, $\left[\boldsymbol{K}_{\mathbf{G}}\right]^{i}$, is dependent on the current stress and strain levels and therefore is not constant but varies over an increment. Hence the solution of equation (8) is not straightforward.

Tangent stiffness algorithm. The tangent stiffness method, sometimes called the variable stiffness method, is the simplest solution strategy. In this approach, the incremental stiffness matrix $\left[\boldsymbol{K}_{\mathbf{G}}\right]^{i}$ in equation (8) is assumed to be constant over each increment and is calculated using the current stress state at the beginning of each increment. This is equivalent to making a piece-wise linear approximation to the non-linear constitutive behaviour. To illustrate the application of this approach, the simple problem of a uniaxially loaded bar of non-linear material is considered. If this bar is loaded, the true load-displacement response is as shown in Fig. 43. This might represent the behaviour of a strain-hardening plastic material that has a very small initial elastic domain.

In the tangent stiffness approach the applied load is split into a sequence of increments. In Fig. 43 three increments of load are shown, $\Delta \boldsymbol{R}_{1}, \Delta \boldsymbol{R}_{2}$ and $\Delta \boldsymbol{R}_{3}$. The analysis starts with the application of $\Delta \boldsymbol{R}_{1}$. The incremental global stiffness matrix $\left[\boldsymbol{K}_{\mathbf{G}}\right]^{1}$ for this increment is evaluated on the basis of the unstressed state of the bar corresponding to point a. For an elasto-plastic material $\left[\boldsymbol{K}_{\mathbf{G}}\right]^{1}$ might be constructed using the elastic material properties. Equation (8) is then solved to determine the nodal displacements $\left\{\Delta \boldsymbol{d}_{\mathbf{n G}}\right\}^{1}$. As the material stiffness is assumed to remain constant, the load-displacement curve follows the straight line $\mathrm{ab}^{\prime}$ in Fig. 43. In reality, the stiffness of the material does not remain constant during this loading increment, and the true solution is represented by the curved path ab. There is therefore an error in the

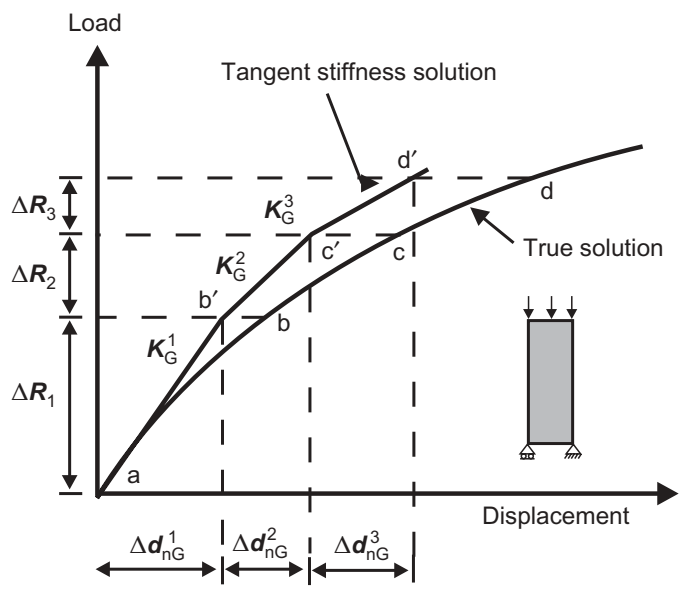

Fig. 43. Finite element application of the tangent stiffness algorithm 
predicted displacement equal to the distance $\mathrm{b}^{\prime} \mathrm{b}$; however, in the tangent stiffness approach this error is neglected. The second increment of load, $\Delta \boldsymbol{R}_{2}$, is then applied, with the incremental global stiffness matrix $\left[\boldsymbol{K}_{\mathbf{G}}\right]^{2}$ evaluated using the stresses and strains appropriate to the end of increment 1 - that is, point $b^{\prime}$ in Fig. 43. Solution of equation (8) then gives the nodal displacements $\left\{\Delta \boldsymbol{d}_{\mathbf{n G}}\right\}^{2}$. The load-displacement curve follows the straight path $b^{\prime} c^{\prime}$ in Fig. 43. This deviates further from the true solution, the error in the displacements now being equal to the distance $\mathrm{c}^{\prime} \mathrm{c}$. A similar procedure now occurs when $\Delta \boldsymbol{R}_{3}$ is applied. The stiffness matrix $\left[\boldsymbol{K}_{\mathbf{G}}\right]^{3}$ is evaluated using the stresses and strains appropriate to the end of increment 2-that is, point $\mathrm{c}^{\prime}$ in Fig. 43. The load-displacement curve moves to point $\mathrm{d}^{\prime}$ and again drifts further from the true solution. Clearly, the accuracy of the solution depends on the size of the load increments. For example, if the increment size was reduced so that more increments were needed to reach the same accumulated load, the tangent stiffness solution would be nearer to the true solution.

From the above simple example it may be concluded that, in order to obtain accurate solutions to strongly non-linear problems, many small solution increments are required. The results obtained using this method can drift from the true solution, and the stresses can fail to satisfy the constitutive model. Thus the basic solution requirements may not be fulfilled. Potts \& Zdravkovic (1999) have shown that the magnitude of the error is problem dependent and is affected by the degree of material non-linearity, the geometry of the problem, and the size of the solution increments used. Unfortunately, in general, it is impossible to predetermine the size of the solution increment required to achieve an acceptable error.

Visco-plastic algorithm. This method uses the equations of visco-plastic behaviour and time as an artifice to calculate the behaviour of non-linear, elasto-plastic, time-independent materials (Owen \& Hinton, 1980; Zienkiewicz \& Cormeau, 1974).

The method was originally developed for linear-elastic visco-plastic (that is, time-dependent) material behaviour. Such material can be represented by a network of the simple rheological units shown in Fig. 44. Each unit consists of an elastic and a visco-plastic component connected in series. The elastic component is represented by a spring, and the visco-plastic component by a slider and dashpot connected in parallel. If a load is applied to the network, then one of two situations occurs in each individual unit. If the load is such that the induced stress in the unit does not cause yielding, the slider remains rigid and all the deformation occurs in the spring. This represents elastic behaviour. Alternatively, if the induced stress causes yielding, the slider becomes free and the dashpot is activated. As the dashpot takes time to react, initially all deformation occurs in the spring. However, with time the dashpot moves. The rate of movement of the dashpot depends on the stress it supports and its fluidity. With time progressing, the dashpot moves at a decreasing rate, because some of the stress the unit is carrying is dissipated to adjacent units in the network, which as a result suffer further movements themselves. This represents visco-plastic behaviour. Eventually, a stationary condition is reached where all the dashpots in the network stop moving and are no longer sustaining stresses. This occurs when the stress in each unit drops below the yield surface and the slider becomes rigid. The external load is now supported purely by the springs within the network, but, importantly, straining of the system has occurred, not only due to compression or extension of the springs, but also due to movement of the dashpots. If the load was now removed,
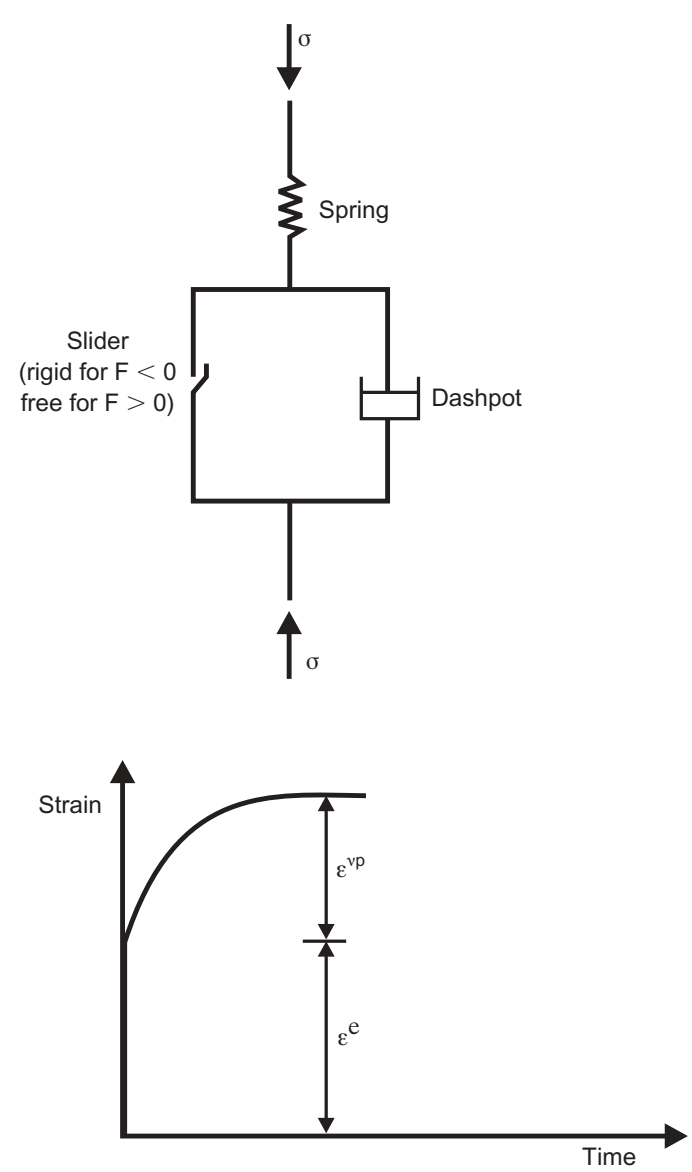

Fig. 44. Rheological model for visco-plastic algorithm

only the displacements (strains) occurring in the springs would be recoverable, the dashpot displacements (strains) being permanent.

Application to finite element analysis of elasto-plastic materials can be summarised as follows (see also Fig. 45). On application of a solution increment the system is assumed to instantaneously behave linear-elastically. If the resulting stress state lies within the yield surface, the incremental behaviour is elastic and the calculated displacements are correct. If the resulting stress state violates yield, the stress state can be sustained only momentarily, and viscoplastic straining occurs. The magnitude of the visco-plastic

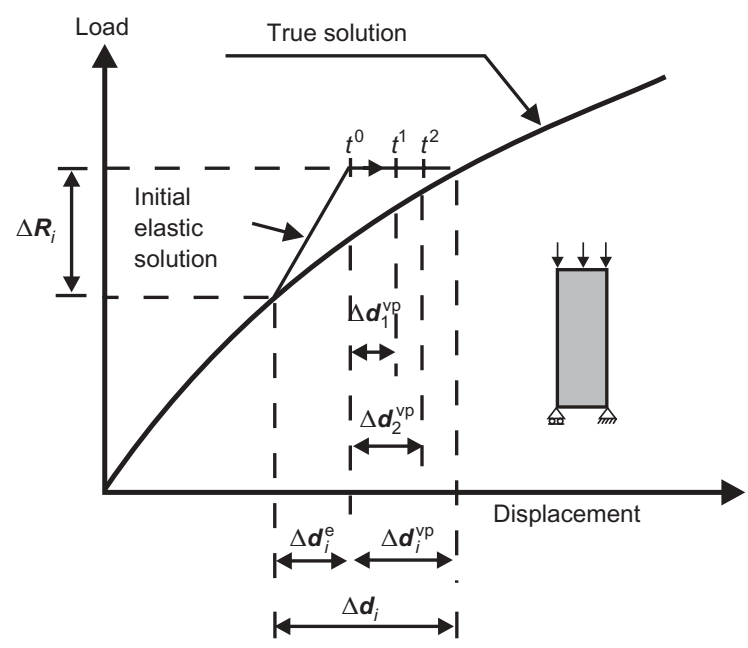

Fig. 45. Finite element application of the visco-plastic algorithm 
strain rate is determined by the value of the yield function, which is a measure of the degree by which the current stress state exceeds the yield condition. The visco-plastic strains increase with time, causing the material to relax, with a reduction in the yield function and hence in the visco-plastic strain rate. A marching technique is used to step forward in time until the visco-plastic strain rate is insignificant. At this point, the accumulated visco-plastic strain and the associated stress change are equal to the incremental plastic strain and stress change respectively. This process is illustrated for the simple problem of a uniaxially loaded bar of non-linear material in Fig. 45. For further details see Smith \& Griffiths (1988) or Potts \& Zdravkovic (1999).

Owing to its simplicity, the visco-plastic algorithm has been widely used. However, the method has its limitations for geotechnical analysis. First, the algorithm relies on the fact that for each increment the elastic parameters remain constant. The simple algorithm cannot accommodate elastic parameters that vary during the increment because, for such cases, it cannot determine the true elastic stress change associated with the incremental elastic strains. The best procedure is to use the elastic parameters associated with the accumulated stresses and strains at the beginning of the increment to calculate the elastic constitutive behaviour, and to assume that this remains constant for the increment. Such a procedure yields accurate results only if the increments are small and/or the elastic non-linearity is not great.

A more severe limitation of the method arises when the algorithm is used as an artifice to solve problems involving non-viscous material (that is, elasto-plastic materials). As can be seen from Fig. 45, the initial elastic solution predicts a stress state above the true solution. These stresses are then used in the algorithm to calculate the plastic strains. For an elasto-plastic material this implies that the differentials of the plastic potential that are used to evaluate the plastic strains are evaluated at an illegal stress state, which lies outside the yield surface. The process of using illegal stresses to determine the plastic behaviour continues for subsequent time steps. As previously noted, for the tangent stiffness algorithm, this is theoretically incorrect and results in failure to satisfy the constitutive equations. The magnitude of the error depends on the constitutive model and in particular on how sensitive the partial derivatives of the plastic potential are to the stress state.

Potts \& Zdravkovic (1999) show that, although the viscoplastic algorithm works well for simple elasto-plastic constitutive models such as Tresca and Mohr-Coulomb, it has severe limitations when used with critical-state type models. The accuracy of the algorithm is therefore dependent on the constitutive model used.

Modified Newton-Raphson algorithm. The previous discussion of both the tangent stiffness and visco-plastic algorithms has highlighted the fact that errors can arise when the constitutive behaviour is based on illegal stress states. The modified Newton-Raphson (MNR) algorithm attempts to rectify this problem by evaluating the constitutive behaviour only in, or very near to, legal stress space.

The MNR method uses an iterative technique to solve equation (8). The first iteration is essentially the same as that of the tangent stiffness method. However, it is recognised that the solution is likely to be in error, and the predicted incremental displacements are used to calculate the residual load, a measure of the error in the analysis. Equation (8) is then solved again with this residual load, $\{\psi\}$, forming the right-hand-side vector. Equation (8) can be rewritten as

$$
\left[\boldsymbol{K}_{\mathbf{G}}\right]^{i}\left(\left\{\Delta \boldsymbol{d}_{\mathbf{n G}}\right\}^{i}\right)^{j}=\{\psi\}^{j-1}
$$

The superscript $j$ refers to the iteration number, and $\{\psi\}^{\circ}=\left\{\Delta \boldsymbol{R}_{\mathbf{G}}\right\}^{i}$. This process is repeated until the residual load is small. The incremental displacements are equal to the sum of the iterative displacements $\left(\left\{\Delta \boldsymbol{d}_{\mathbf{n G}}\right\}^{i}\right)^{j}$. This approach is illustrated in Fig. 46 for the simple problem of a uniaxially loaded bar of non-linear material. In principle, the iterative scheme ensures that for each solution increment the analysis satisfies all solution requirements.

A key step in this calculation process is to determine the residual load vector. At the end of each iteration the current estimate of the incremental displacements is calculated and used to evaluate the incremental strains at each integration point. The constitutive model is then integrated along the incremental strain paths to obtain an estimate of the stress changes. These stress changes are added to the stresses at the beginning of the increment and used to evaluate consistent equivalent nodal forces. The difference between these forces and the externally applied loads (from the boundary conditions) gives the residual load vector. A difference exists initially because a constant incremental global stiffness matrix $\left[\boldsymbol{K}_{\mathbf{G}}\right]^{i}$ is assumed over the increment. Because of the non-linear material behaviour $\left[\boldsymbol{K}_{\mathbf{G}}\right]^{i}$ is not constant but varies with the incremental stress and strain changes.

As the constitutive behaviour changes over the increment, care must be taken when integrating the constitutive equations to obtain the stress change. Methods of performing this integration are termed stress point algorithms, and both explicit and implicit approaches have been proposed in the literature. There are many of these algorithms in use, and, as they control the accuracy of the final solution, users must verify the approach used in their software. In this respect note that all stress point algorithms contain additional assumptions: see Potts \& Zdravkovic (1999). Consequently, some algorithms are more accurate than others, and, in addition, no two computer programs will do exactly the same thing.

This process is called a Newton-Raphson scheme if the incremental global stiffness matrix $\left[\boldsymbol{K}_{\mathbf{G}}\right]^{i}$ is recalculated and inverted for each iteration on the basis of the latest estimate of the stresses and strains obtained from the previous iteration. To reduce the amount of computation, the modified Newton-Raphson (MNR) scheme calculates and inverts the stiffness matrix only at the beginning of the increment and uses it for all iterations within the increment. Sometimes the incremental global stiffness matrix is calculated using the elastic constitutive matrix, rather than the elasto-plastic matrix. Clearly, there are several options here, and many software packages allow the user to specify how the MNR

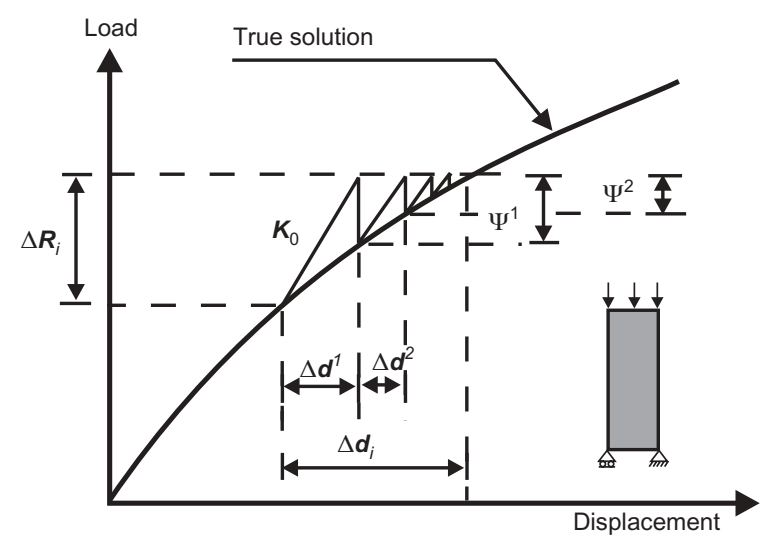

Fig. 46. Finite element application of the modified NewtonRaphson algorithm 
algorithm should work. In addition, some form of acceleration technique is often applied during the iteration process (Thomas, 1984; Crisfield, 1986). The various ways in which the MNR algorithm works can have an effect on the results of the analysis, but this is generally small compared with that of the stress point algorithm.

Idealised triaxial test. A comparison of the three solution strategies presented above suggests the following. The tangent stiffness method is the simplest, but its accuracy is influenced by increment size. The accuracy of the viscoplastic approach is also influenced by increment size, if complex constitutive models are used. The MNR method is potentially the most accurate, and is likely to be the least sensitive to increment size.

Potts \& Zdravkovic (1999) provide an extensive comparison of the three methods by considering a range of boundary value problems. Their results for an ideal drained triaxial compression test are presented here as an example. The test was deemed ideal, as the end effects at the top and bottom of the sample were considered negligible, and the stress and strain conditions were uniform throughout. Consequently, the sample can be represented by a single quadrilateral element. There are therefore no discretisation errors, and the analyses are only testing the ability of the different solution strategies to accurately integrate the constitutive equations.

The sample was assumed to be initially isotropically normally consolidated to a mean effective stress, $p^{\prime}$, of $200 \mathrm{kPa}$, with zero pore water pressure. The modified Cam clay model was used to represent the soil behaviour, and the soil parameters used for the analyses are shown in Table 4. Increments of compressive axial strain were applied to the sample until the axial strain reached $20 \%$, while maintaining a constant radial stress and zero pore water pressure. The results are presented as plots of volumetric strain and deviatoric stress $\left(\sigma_{1}^{\prime}-\sigma_{3}^{\prime}\right)$ against axial strain.

Results from three MNR analyses are presented in Fig. 47. The analyses differed in the size of the strain increment used, and the label associated with each line in the figure indicates the magnitude of the axial strain applied at each increment of that analysis. Also shown in Fig. 47 are results from the closed form analytical solution to this problem given by Potts \& Zdravkovic (1999).

It can be seen that there is some dependence of the results on the increment size, but that this is small. The results agree well with the analytical solution. Note that the stress point algorithm used to obtain these results is one of the most accurate that there is, and therefore the results presented give a good indication of the best that can be currently achieved.

The tangent stiffness results are presented in Fig. 48, where it can be seen that they are sensitive to increment size. Large errors occur for the larger increment sizes, but the accuracy improves as the increment size reduces. For the same increment size the results are much less accurate than those from the MNR analyses.

The results of the visco-plastic analyses are shown in Fig. 49 , where it can be seen that they are also very sensitive to

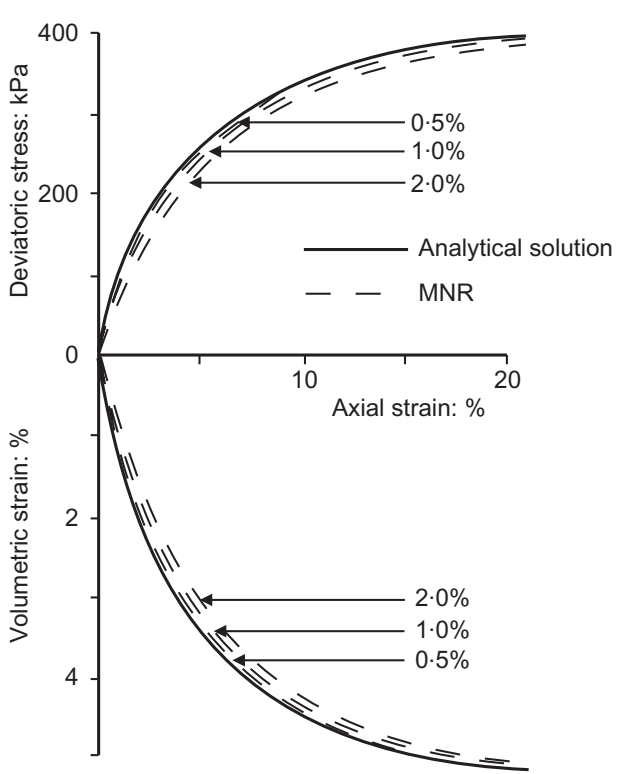

Fig. 47. Drained triaxial compression test prediction using the MNR algorithm

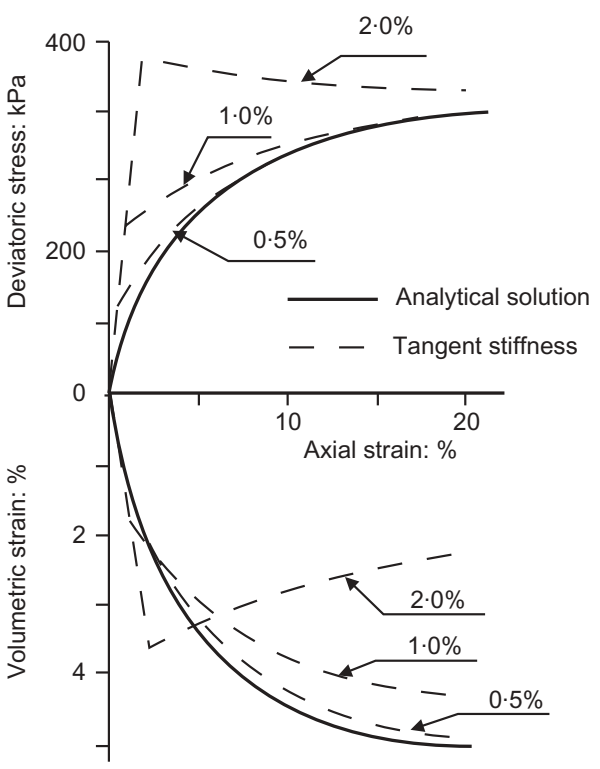

Fig. 48. Drained triaxial compression test prediction using the tangent stiffness algorithm

the increment size. Even the results from the analysis with the smallest increment size of $0 \cdot 1 \%$ are in considerable error. It is interesting to note that the visco-plastic algorithm is much more accurate when the soil behaves undrained and/ or when it is used with simpler constitutive models of the Tresca and Mohr-Coulomb types.

Table 4. Soil parameters for idealised triaxial test

\begin{tabular}{l|c}
\hline Description & Value \\
\hline Overconsolidation ratio & $1 \cdot 0$ \\
Specific volume at unit pressure on virgin consolidation line, $v_{1}$ & 1.788 \\
Slope of virgin consolidation line in $v-\ln p^{\prime}$ space, $\lambda$ & 0.066 \\
Slope of swelling line in $v-\ln p^{\prime}$ space, $\kappa$ & 0.0077 \\
Slope of critical-state line in $J-p^{\prime}$ plane, $M_{J}$ & 0.693 \\
Elastic shear modulus $G /$ Preconsolidation pressure, $p_{0}^{\prime}$ & 100 \\
\hline
\end{tabular}




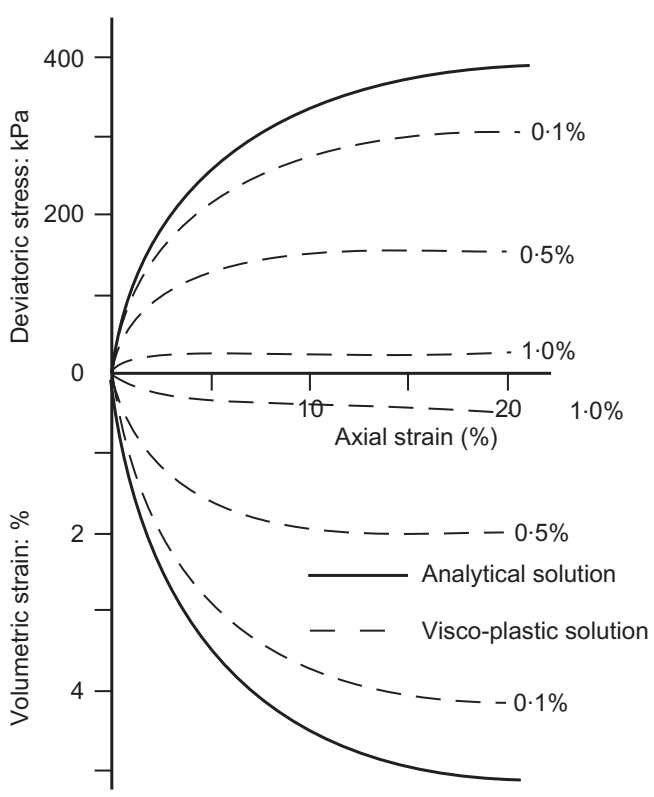

Fig. 49. Drained triaxial compression test prediction using the visco-plastic algorithm

It can be concluded from the above results, and from those presented by Potts \& Zdravkovic (1999), that for both the tangent stiffness and visco-plastic algorithms the increment size required for accurate predictions depends on the nature of the boundary value problem under investigation, the complexity of the constitutive model and whether the soil behaves drained or undrained. This is also true for some MNR approaches that use less accurate stress point algorithms than that used above.

Summary. There is no accepted non-linear solution strategy. Most of the finite element and finite difference computer programs currently available use different approaches. Consequently, they are likely to produce results of differing accuracy. It is a bit like having two calculators that, when asked to add 2 and 2 together, give different answers, for example 3 and 5 . As engineers we like our calculations to be accurate (or at least within a known small accuracy tolerance) and our assumptions and approximations to be confined to parameter selection and problem idealisation.

Although the solution schemes discussed above are applicable to the finite element method, similar alternatives arise with the other numerical methods.

\section{(b) Some constitutive models cannot give sensible predictions}

The fact that some of the most popular constitutive models can give non-sensible predictions is a serious problem and a pitfall that many users encounter, but are often unaware of. To illustrate the sorts of problem that can arise, we shall begin by considering the popular Mohr-Coulomb model. As noted previously in this lecture, this model can be used with an angle of dilation ranging from $v=0^{\circ}$ to $v=\phi^{\prime}$. This parameter controls the magnitude of the plastic dilation (plastic volume expansion), and remains constant once the state of stress in the soil is on the yield surface: see Fig. 7. This implies that the soil will continue to dilate indefinitely if shearing continues. Clearly, such behaviour is not realistic, as most soils will eventually reach a criticalstate condition, after which they will deform at constant volume if sheared any further. Such unrealistic behaviour does not have a great influence on boundary value problems that are kinematically unconfined. For example, it has already been shown that the dilation angle has only a relatively small effect on the bearing capacity of surface footings. However, it can have a major effect on problems that are kinematically confined (such as drained cavity expansion or drained axial pile loading), owing to the restrictions on volume change imposed by the boundary conditions. In particular, unrealistic results can be obtained in undrained analysis in which there is a severe constraint imposed by the zero total volume change restriction associated with undrained soil behaviour. This could arise in a coupled consolidation analysis when loading occurs relatively rapidly, or in an undrained stage of an analysis in which the soil is modelled in terms of an effective stress constitutive model, and a high bulk compressibility is assigned to the pore fluid. To illustrate these problems three examples are presented below.

The first example considers the problem of predicting the behaviour of a $1 \mathrm{~m}$ diameter, $20 \mathrm{~m}$ deep pile subjected to axial loading. The finite element mesh indicating the geometry and boundary conditions is shown in Fig. 50. Note the fine mesh around the pile, which meant that there was no need to complicate matters by adding interface elements between the pile and the soil. The pile was assumed to be wished in place (that is, installed without changing the insitu stress conditions in the soil) and then loaded vertically by displacing its top downwards. The soil was assumed to be dry (that is, no water present) and to behave in a drained manner using the Mohr-Coulomb constitutive model, with a Young's modulus, $E_{\mathrm{s}}=10^{5} \mathrm{kN} / \mathrm{m}^{2}$, a Poisson's ratio, $\mu_{\mathrm{s}}$ $=0 \cdot 3$, a cohesion, $c^{\prime}=0$ and angle of shearing resistance, $\phi^{\prime}=25^{\circ}$. Initial stresses in the soil were based on $\gamma_{\text {dry }}=18 \mathrm{kN} / \mathrm{m}^{3}$ and $K_{0}=1$. The pile was assumed to behave linear-elastically, with a Young's modulus, $E_{\mathrm{c}}=20 \times$ $10^{6} \mathrm{kN} / \mathrm{m}^{2}$ and a Poisson's ratio, $\mu_{\mathrm{c}}=0 \cdot 15$.

The results of two analyses are presented in Fig. 51. The only difference between these analyses was that in one analysis the angle of dilation, $v=\phi^{\prime}=25^{\circ}$, whereas in the other analysis $v=0^{\circ}$. For both analyses the load-displacement behaviour is presented in terms of the total load on the pile against pile head displacement and in terms of the shaft and base components of the total load.

Considering the analysis with $v=\phi^{\prime}=25^{\circ}$ it can be seen that no ultimate total load is indicated in Fig. 51(a). Both the shaft and base components of load continue to increase with pile head displacement. Although results are shown only for a pile head displacement of up to $0.02 \mathrm{~m}$ in Fig. 51(a), the analysis was continued to much greater displacements $(2.0 \mathrm{~m})$. Even at these larger displacements both the shaft and base loads continued to increase, and no ultimate capacity was predicted.

In contrast, the analysis with $v=0^{\circ}$ does predict an ultimate load at a pile head displacement of $2 \mathrm{~m}$. Results from this analysis are shown in Fig. 51(b) for displacements up to $0.09 \mathrm{~m}$ ( $9 \%$ of pile diameter). It can be seen that the shaft component of the pile capacity is fully mobilised at a pile head displacement of only $0.005 \mathrm{~m}$, whereas the base component is still increasing, and only reaches a maximum at a displacement of $2 \mathrm{~m}$.

Comparison of the results in Figs 51(a) and 51(b) indicates that not only does dilation affect the limit loads, but it also dominates the load-displacement behaviour. Further analyses with angles of dilation $0^{\circ}<v<25^{\circ}$ also indicate that no ultimate limit load is predicted (at least for a pile head displacement of $2 \mathrm{~m}$ ), and that the higher the dilation angle the stiffer the load-displacement curve. Consequently, the only analysis that predicts an ultimate pile load is that in which $v=0^{\circ}$. However, as most sands in the field exhibit 


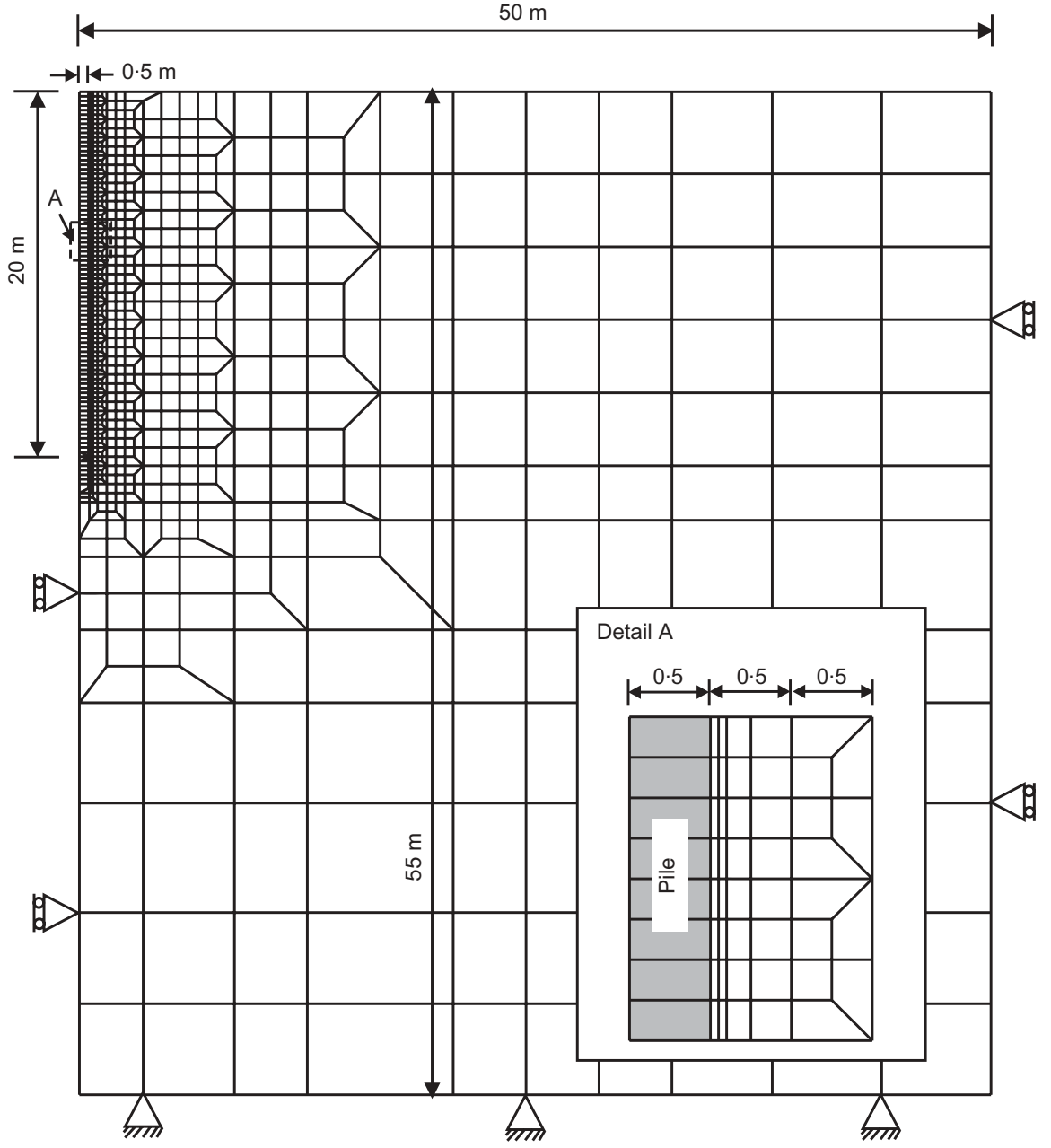

Fig. 50. Finite element mesh for single pile analysis

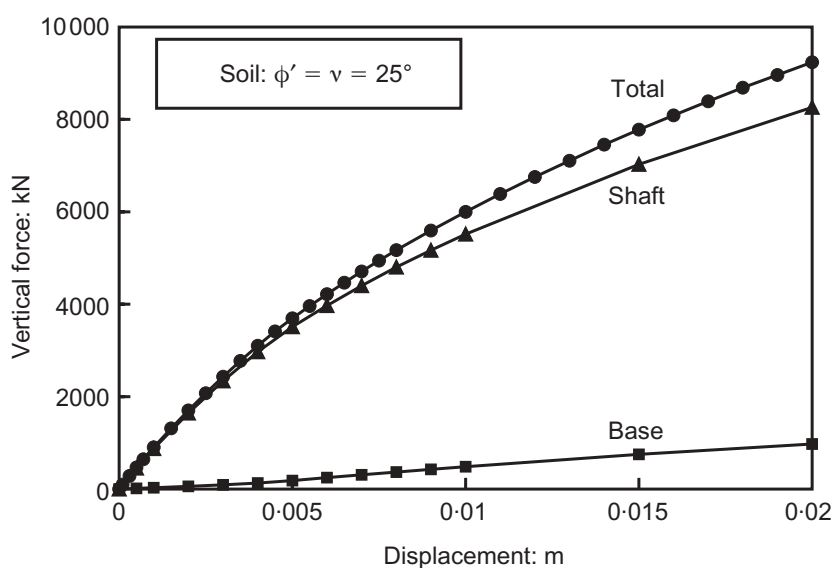

(a)

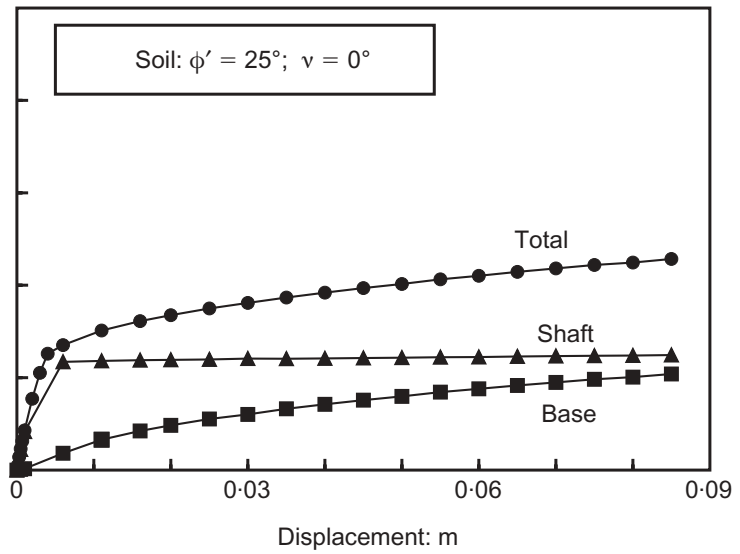

(b)

Fig. 51. Behaviour of a pile in drained soil: (a) soil with $v=\phi^{\prime}$; (b) soil with $v=0^{\circ}$

some fixed amount of dilation, predictions based on $v=0^{\circ}$ are likely to be too conservative.

The second example considers ideal (no end effects) undrained triaxial compression tests on a linear-elastic Mohr-Coulomb plastic soil, with parameters $E^{\prime}=10 \mathrm{MPa}$, $\mu=0 \cdot 3, c^{\prime}=0$ and $\phi^{\prime}=24^{\circ}$. As there are no end effects, a single quadrilateral finite element is used to model the triaxial sample with appropriate boundary conditions. The samples were assumed to be initially isotropically consolidated with $p^{\prime}=200 \mathrm{kPa}$ and zero pore water pressure. A series of finite element analyses were then performed, each with a different angle of dilation, $v$, in which the samples were sheared undrained. Undrained conditions were enforced by setting the bulk modulus of the pore water to be 1000 times larger than the effective elastic bulk modulus of the soil skeleton, $K_{\text {skel }}^{\prime}$. 
The results are shown in Figs 52(a) and 52(b) in the form of deviatoric stress $\left(\sigma_{1}^{\prime}-\sigma_{3}^{\prime}\right)$ against mean effective stress, $p^{\prime}$, and deviatoric stress against axial strain, $\varepsilon_{\mathrm{a}}$, respectively. It can be seen from Fig. 52(a) that all analyses follow the same stress path. However, the rate at which the stress state moves up the Mohr-Coulomb failure line differs for each analysis. This can be seen from Fig. 52(b). The analysis with zero plastic dilation, $v=0^{\circ}$, remains at a constant deviatoric and mean effective stress when it reaches the failure line. However, all other analyses move up the failure line, those with the larger dilation moving up more rapidly. They continue to move up the failure line indefinitely with continued shearing. Consequently, the only analysis that indicates failure (that is a limiting value of deviator stress) is the analysis performed with zero plastic dilation.

The third example considers the undrained loading of a smooth, rigid strip surface foundation. The soil was assumed to have the same parameters as those used for the triaxial tests above. The initial stresses in the soil were calculated on the basis of a saturated bulk unit weight of $20 \mathrm{kN} / \mathrm{m}^{3}$, a groundwater table at the soil surface, and a $K_{0}=1-\sin \phi^{\prime}$. The footing was loaded by applying increments of vertical displacement, and undrained conditions were again enforced by setting the bulk modulus of the pore water to be 1000 times $K_{\text {skel }}^{\prime}$. The results of two analyses, one with $v=0^{\circ}$ and the other with $v=\phi^{\prime}$, are shown in Fig. 53 in the form of load-displacement curves. The difference in the results is quite staggering: while the analysis with $v=0^{\circ}$ reaches a limit load, the analysis with $v=\phi^{\prime}$ shows a continuing increase in load with displacement. As with the undrained triaxial test, a limit load is obtained only if $v=0^{\circ}$.

It can be concluded from these examples that a limit load will be obtained only if $v=0^{\circ}$. Consequently, great care must be exercised when using the Mohr-Coulomb model in both confined and undrained analysis. It could be argued that the model should not be used with $v>0^{\circ}$ for such analysis. However, reality is not so simple, and often an analysis involves both an undrained and a drained phase (for example, undrained excavation followed by drained dissipation of excess pore water pressures).

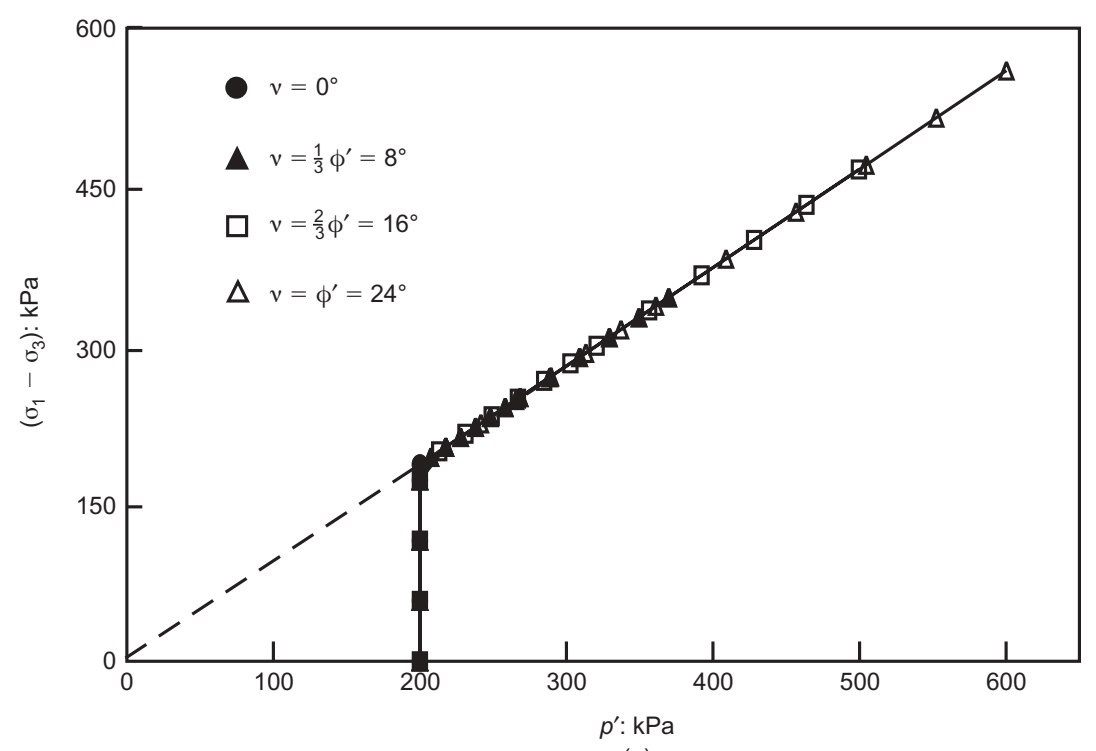

(a)

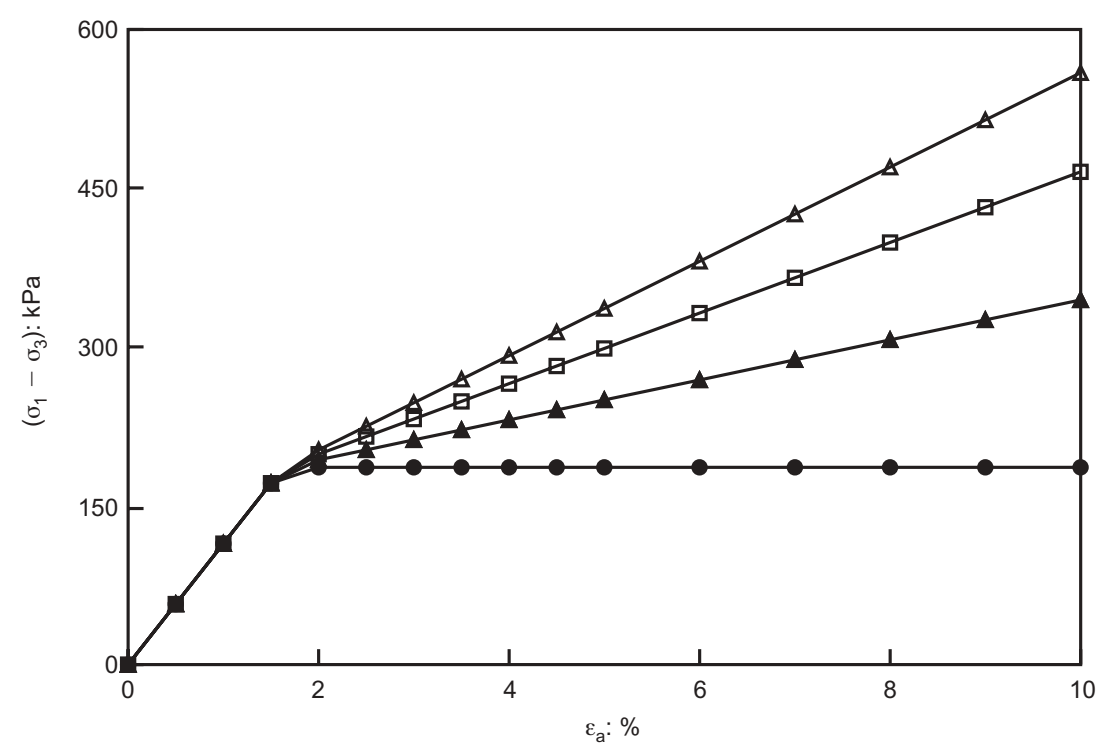

(b)

Fig. 52. Undrained triaxial compression with Mohr-Coulomb model: (a) stress paths; (b) stress-strain curves 


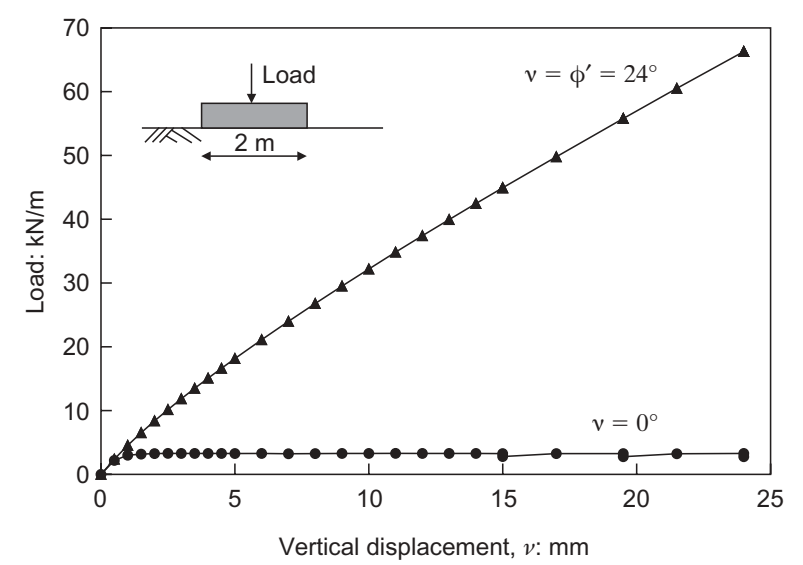

Fig. 53. Load-displacement curves for undrained loading of a strip footing, using the Mohr-Coulomb model with different angles of dilation

Although the examples described above have used the Mohr-Coulomb model, similar problems will occur with any constitutive model that predicts finite plastic volume changes at large strains. Consequently, some of the more advanced constitutive models that are currently available will suffer similar problems.

One way to avoid these problems is to use a model that reproduces critical-state conditions where, after a certain amount of shear strain, the model predicts no further change in volume. However, there can be other subtle problems that can arise with the use of these more sophisticated constitutive models. As an example, the use of the modified Cam clay model will be considered.

The original model combines compression and shear behaviour. However, the shear behaviour is formulated only in triaxial space, where two of the principal stresses have equal magnitude. For use in numerical analysis the model must therefore be extended to general stress space. This involves further assumptions. In this respect it is usual to assume soil behaviour to be isotropic. This enables the state of stress to be represented by three stress invariants, which in turn implies that the yield and plastic potential surfaces must also be expressed in terms of the three stress invariants. A logical choice for these invariants is the mean effective stress, $p^{\prime}$, the deviatoric stress, $J$, and the Lode's angle, $\theta$. These are defined in equations (9)-(11):

$$
\begin{aligned}
p^{\prime} & =\frac{1}{3}\left(\sigma_{1}^{\prime}+\sigma_{2}^{\prime}+\sigma_{3}^{\prime}\right) \\
J & =\frac{1}{\sqrt{6}} \sqrt{\left(\sigma_{1}^{\prime}-\sigma_{3}^{\prime}\right)^{2}+\left(\sigma_{1}^{\prime}-\sigma_{2}^{\prime}\right)^{2}+\left(\sigma_{2}^{\prime}-\sigma_{3}^{\prime}\right)^{2}} \\
\theta & =\tan ^{-1}\left[\frac{1}{\sqrt{3}}\left(2 \frac{\left(\sigma_{2}^{\prime}-\sigma_{3}^{\prime}\right)}{\left(\sigma_{1}^{\prime}-\sigma_{3}^{\prime}\right)}-1\right)\right]
\end{aligned}
$$

The choice of these invariants is not arbitrary, because the above quantities have geometric significance in principal effective stress space. For example, consider the stress state represented by point $\mathrm{S}\left(\sigma_{1}^{\prime} \mathrm{S}, \sigma_{2}^{\prime} \mathrm{S}, \sigma_{3}^{\prime} \mathrm{S}\right)$, which has invariants $p^{\prime \mathrm{S}}, J^{\mathrm{S}}$ and $\theta^{\mathrm{S}}$ in Fig. 54. The distance of the deviatoric plane in which $\mathrm{S}$ lies, from the origin, is $\sqrt{3} p^{\prime S}$ : see Fig. 54(a). The distance of $\mathrm{S}$ from the space diagonal in the deviatoric plane is given by $\sqrt{2} J^{\mathrm{S}}$, and the orientation of $\mathrm{S}$ within this plane by the value of $\theta^{\mathrm{S}}$ : see Fig. 54(b). In this figure, $\left(\sigma_{1}^{\prime}\right)^{\mathrm{pr}},\left(\sigma_{2}^{\prime}\right)^{\mathrm{pr}}$ and $\left(\sigma_{3}^{\prime}\right)^{\mathrm{pr}}$ refer to the projections of the principal stress axes onto the deviatoric plane. If $\sigma_{1}^{\prime} \mathrm{s}$ $\geqslant \sigma_{2}^{\prime} \mathrm{S} \geqslant \sigma_{3}^{\prime} \mathrm{S}, \mathrm{S}$ is constrained to lie between the lines marked as $\theta=-30^{\circ}$ and $\theta=+30^{\circ}$. These limiting values of $\theta$ correspond to triaxial compression $\left(\sigma_{1}^{\prime} \mathrm{S} \geqslant \sigma_{2}^{\prime} \mathrm{S}=\sigma_{3}^{\prime} \mathrm{S}\right)$ and triaxial extension $\left(\sigma_{1}^{\prime} \mathrm{S}=\sigma_{2}^{\prime} \mathrm{S} \geqslant \sigma_{3}^{\prime} \mathrm{S}\right)$ respectively.

The original modified Cam clay model uses two stress

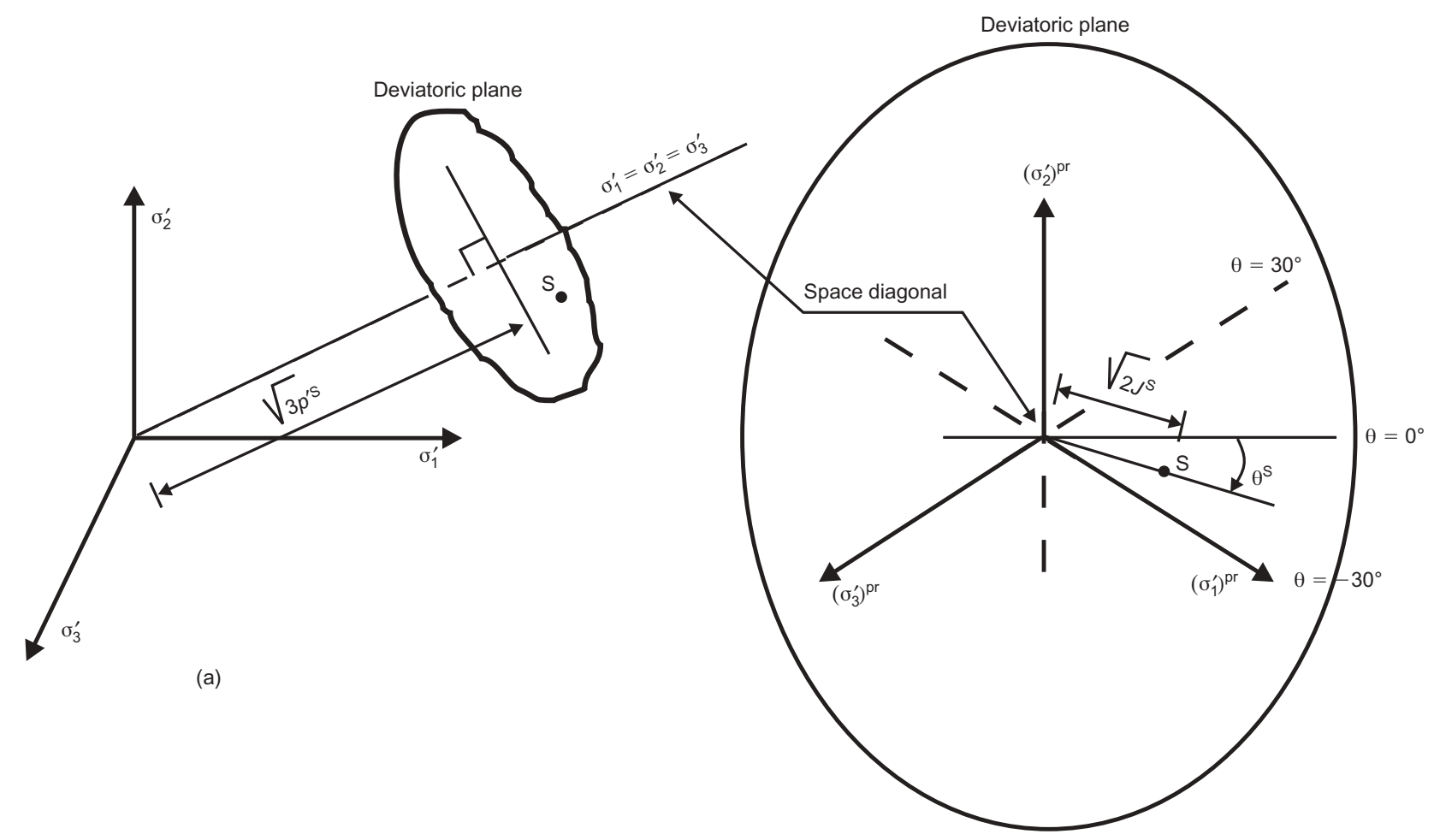

(b)

Fig. 54. Invariants in principal stress space 
values, the mean effective stress, $p^{\prime}$, and the shear stress, $q=\sigma_{1}^{\prime}-\sigma_{3}^{\prime}$. To generalise the model, $p^{\prime}$ is retained and $q$ is replaced by $J$. Although this is sufficient, it implies that the model is independent of the Lode's angle, $\theta$. In the deviatoric plane this means that the yield and failure (critical state) surfaces are circular.

An alternative approach is to allow the parameter $M_{J}$, the slope of the critical-state line in $J-p^{\prime}$ space, to vary with $\theta$. This will then control the shapes of the yield and failure surfaces in the deviatoric plane. Although there are various assumptions that could be made here, it will be assumed that the angle of shearing resistance, $\phi^{\prime}$, is a constant, an assumption consistent with conventional practice. This leads to the following definition of $M_{J}$ (Potts \& Zdravkovic, 1999):

$$
M_{J}=g(\theta)=\frac{\sin \phi^{\prime}}{\cos \theta+\frac{\sin \theta \sin \phi^{\prime}}{\sqrt{3}}}
$$

When plotted in the deviatoric plane the yield and failure surfaces plot as an irregular hexagon: see Fig. 55. Also plotted in this figure is the circle corresponding to the constant $M_{J}$ assumption. Both assumptions have been chosen to agree in triaxial compression. However, as the Lode's angle, $\theta$, changes, the constant $M_{J}$ assumption (circle in Fig. 55) implies higher $J$ values than if $M_{J}$ is based on equation (12) (Mohr-Coulomb hexagon in Fig. 55). This results in the angle of shearing resistance, $\phi^{\prime}$, varying with Lode's angle and having a magnitude higher than that for triaxial compression. This variation in $\phi^{\prime}$, for the constant $M_{J}$ assumption, can be expressed by

$$
\phi^{\prime}=\sin ^{-1}\left(\frac{M_{J} \cos \theta}{1-\frac{M_{J} \sin \theta}{\sqrt{3}}}\right)
$$

From this equation it is possible to express $M_{J}$ in terms of the angle of shearing resistance, $\phi_{\mathrm{TC}}^{\prime}$, in triaxial compression, that is, $\theta=-30^{\circ}$ :

$$
M_{J}\left(\phi_{\mathrm{TC}}^{\prime}\right)=\frac{2 \sqrt{3} \sin \phi_{\mathrm{TC}}^{\prime}}{3-\sin \phi_{\mathrm{TC}}^{\prime}}
$$

Figure 56 shows the variation of $\phi^{\prime}$ with $\theta$, given by equation (13), for three constant values of $M_{J}$. The values of $M_{J}$ have been determined from equation (14) using $\phi_{\mathrm{TC}}^{\prime}=20^{\circ}$, $25^{\circ}$ and $30^{\circ}$. If the plastic potential is circular in the

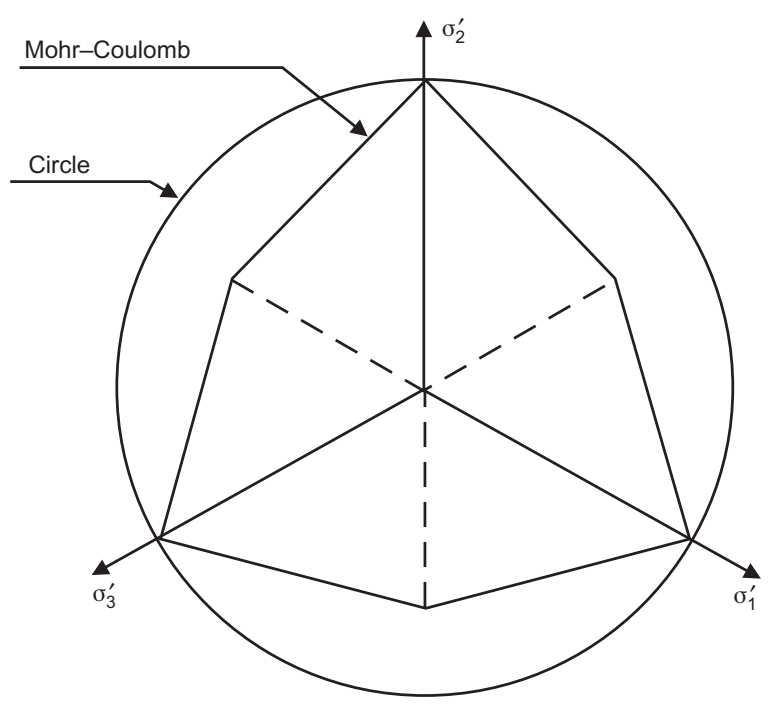

Fig. 55. Failure/yield surfaces in deviatoric plane

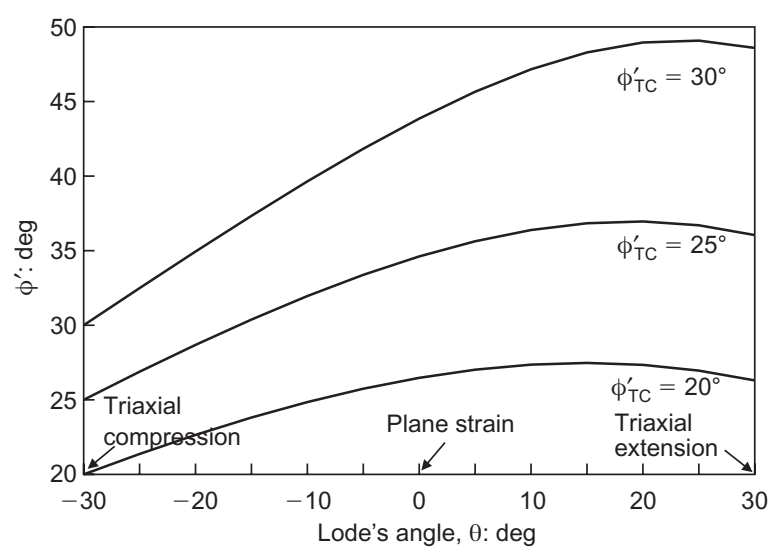

Fig. 56. Variation of $\phi^{\prime}$ with $\theta$ for constant $M_{J}$

deviatoric plane, Potts \& Zdravkovic (1999) show that plane-strain failure occurs when the Lode's angle, $\theta=0^{\circ}$. Fig. 56 indicates that for all values of $M_{J}$ there is a large change in $\phi^{\prime}$ with $\theta$. For example, if $M_{J}$ is set to give $\phi_{\mathrm{TC}}^{\prime}=25^{\circ}$, then under plane-strain conditions $\phi_{\mathrm{PS}}^{\prime}=34 \cdot 6^{\circ}$. This difference is considerable, and much larger than indicated by laboratory testing. The difference between $\phi_{\mathrm{TC}}^{\prime}$ and $\phi_{\mathrm{PS}}^{\prime}$ becomes greater the larger the value of $M_{J}$.

To investigate the effect of adopting the two options for $M_{J}$ in a boundary value problem, two analyses of a rough rigid strip footing, $2 \mathrm{~m}$ wide, have been performed. The modified Cam clay model was used to represent the soil, which had the following parameters: $\mathrm{OCR}=6, v_{1}=2 \cdot 848$, $\lambda=0 \cdot 161, \kappa=0 \cdot 0322, \mu=0 \cdot 2$. In one analysis the yield and plastic potential surfaces were assumed to be circular in the deviatoric plane. A constant value of $M_{J}=0.5187$ was used for this analysis, which is equivalent to $\phi_{\mathrm{TC}}^{\prime}=23^{\circ}$. In the second analysis a constant value of $\phi^{\prime}=23^{\circ}$ was used, giving a Mohr-Coulomb hexagon for the yield surface in the deviatoric plane. However, the plastic potential still gave a circle in the deviatoric plane, and therefore plane-strain failure occurred at $\theta=0^{\circ}$, as for the first analysis.

In both analyses the initial stress conditions in the soil were based on a saturated bulk unit weight of $18 \mathrm{kN} / \mathrm{m}^{3}$, a groundwater table at a depth of $2.5 \mathrm{~m}$, and a $K_{0}=1.227$. Above the groundwater table the soil was assumed to be saturated and able to sustain pore water suctions. Coupled consolidation analyses were performed, but the permeability and time steps were chosen such that undrained conditions existed. Loading of the footing was simulated by imposing increments of vertical displacement.

In summary, the input to both analyses is identical, except that in the first the strength parameter, $M_{J}$, is specified, whereas in the second $\phi^{\prime}$ is input. In both analyses $\phi_{\mathrm{TC}}^{\prime}=23^{\circ}$, and therefore any analysis in triaxial compression would give identical results. However, the strip footing problem is plane strain and therefore differences are expected. The resulting load-displacement curves are given in Fig. 57. The analysis with a constant $M_{J}$ gave a collapse load some $58 \%$ larger than the analysis with a constant $\phi^{\prime}$. The implications for practice are clear: if a user is not aware of this problem, or is not fully conversant with the constitutive model implemented in the software being used, they could easily base the input on $\phi_{\mathrm{TC}}^{\prime}=23^{\circ}$. If the model uses a constant $M_{J}$ formulation, this would then imply a $\phi_{\mathrm{PS}}^{\prime}=31 \cdot 2^{\circ}$, which in turn leads to a large error in the prediction of any collapse load.

There are limited experimental data on soil behaviour in the deviatoric plane, and consequently several alternatives for the shapes of the yield and plastic potential surfaces are 


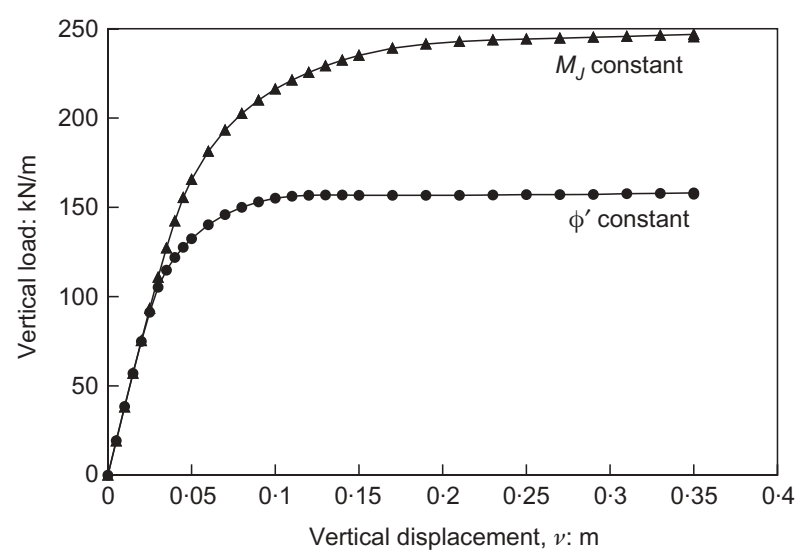

Fig. 57. Load-displacement curves for strip footing

available in the literature. Two of these have been discussed above, and they are shown along with those suggested by Matsuoka \& Nakai (1974) and Lade \& Duncan (1975) in Fig. 58. Clearly, more research is needed here, and in this respect laboratory tests using true triaxial and hollow cylinder apparatus are necessary.

The shapes of the yield, plastic potential and failure surfaces in the deviatoric plane can have a significant effect on predictions. This applies to all constitutive models, not just the modified Cam clay model considered in detail above. It is therefore essential that a software user understands these effects. At this point readers who use numerical analysis should ask themselves whether they actually know the assumptions made in the software they are using. In this respect the author's experience is that most software manuals do not supply such detailed information.

\section{(c) Difficult to analyse some simple problems}

This point for the case against appears to contradict the case for, which stated that numerical analysis could do everything that conventional analysis could do. However, as in all debates, there is room to be economical with the truth on both sides. Not everything in life is black and white, and differences in opinion lead to large grey areas.

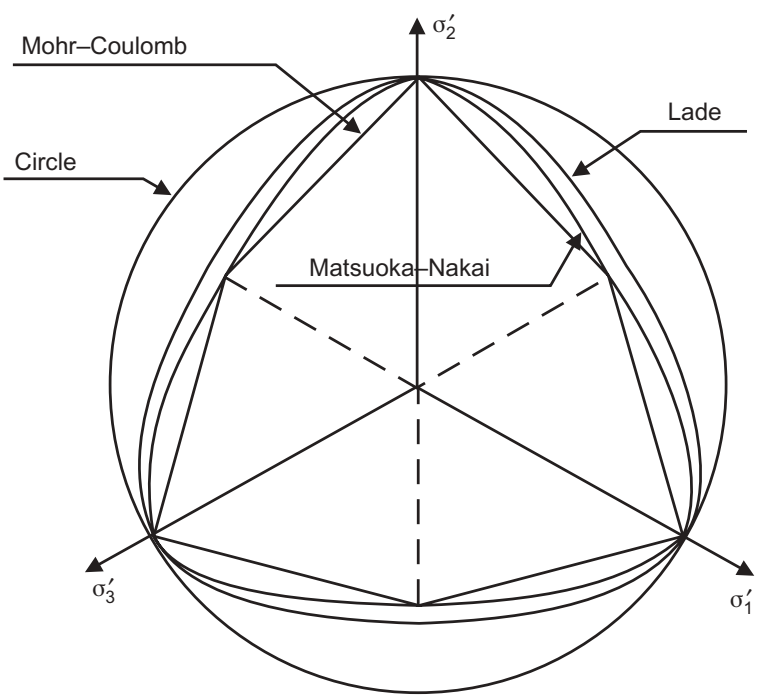

Fig. 58. Failure/yield surfaces in deviatoric plane
The problem to be considered here is concerned with excavation in front of an embedded cantilever wall retaining undrained clay: see Fig. 59. The wall is $1 \mathrm{~m}$ wide and $20 \mathrm{~m}$ deep, with $E=20 \times 10^{6} \mathrm{kPa}$ and $\mu=0 \cdot 15$. The clay has the following properties: $E_{\mathrm{u}}=60 \mathrm{MPa}, \mu_{\mathrm{u}}=0.499, s_{\mathrm{u}}$ $=60 \mathrm{kPa}, \gamma_{\mathrm{sat}}=20 \mathrm{kN} / \mathrm{m}^{3}$ and $K_{0}=1 \cdot 0$. The adhesion, $c_{\mathrm{w}}$, between the soil and the wall is assumed to be $0 \cdot 5 s_{\mathrm{u}}$. It is also assumed that, if tension cracks form, they will remain dry. This assumption is not essential, but it simplifies the presentation. The same conclusions apply if the cracks are filled with water. The problem is to determine the depth of excavation in front of the wall to initiate collapse.

A conventional limit equilibrium calculation indicates that the limiting depth of excavation is $11.6 \mathrm{~m}$, and at this level the depth of the tension crack at the back of the wall is $7 \cdot 35 \mathrm{~m}$.

As the soil behaves undrained, with a specified value of undrained strength $s_{\mathrm{u}}$, it can be represented by the Tresca constitutive model in any numerical analysis. In addition, interface elements are needed between the wall and the soil because the wall adhesion, $c_{\mathrm{w}}=0 \cdot 5 s_{\mathrm{u}}$. Feeding this information, the soil properties and the initial stress conditions into a finite element analysis (Run 1) results in a predicted limiting depth of excavation of $13.8 \mathrm{~m}$, considerably greater than that predicted by the simple limit equilibrium calculation $(11.6 \mathrm{~m})$.

The displaced shape of the wall at an excavation depth of $12 \mathrm{~m}$ and vectors of incremental displacement at the increment of the analysis just prior to collapse are shown in Fig. 60. Both plots indicate larger horizontal movements at and below excavation level than at the top of the wall. Clearly, this is unrealistic, as the wall is expected to behave as an embedded cantilever with greater movements at its top. The reason for this unrealistic prediction becomes clear when the stresses in the soil are investigated. The horizontal stresses acting on the retained side of the wall and the zone of soil in which tensile stresses occur are shown in Fig. 61, where it can be seen that tension extends to a depth of approximately $6.5 \mathrm{~m}$. These tensile stresses restrain the movement of the top of the wall. Clearly, this is unrealistic and occurs because the Tresca model allows the soil to sustain tensile stresses.

One possible way of overcoming this problem is to change the properties of the interface elements around the wall so that they cannot sustain tensile normal stresses. Once the normal stress is reduced to zero from its initial compressive value, the interface element simply opens without sustaining any further reduction in normal stresses. The interface element therefore simulates a crack forming between the soil

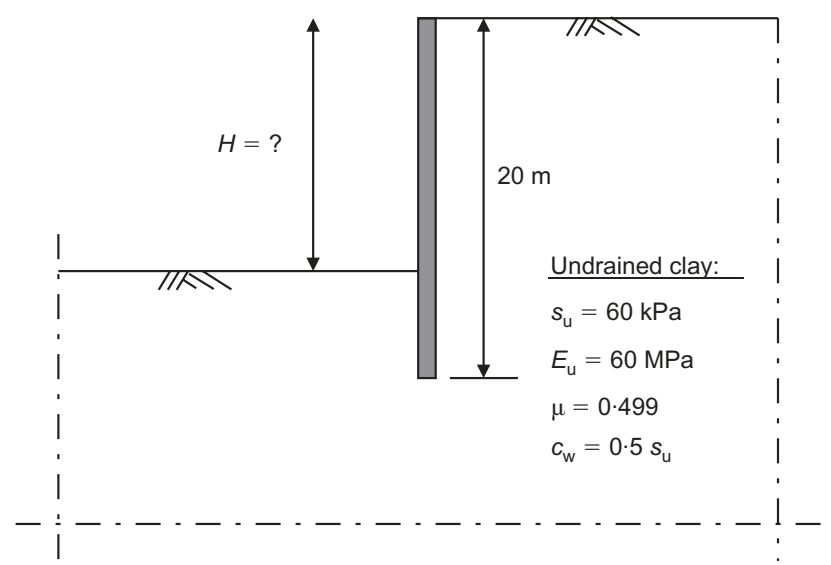

Fig. 59. Geometry of embedded cantilever wall problem and soil conditions 

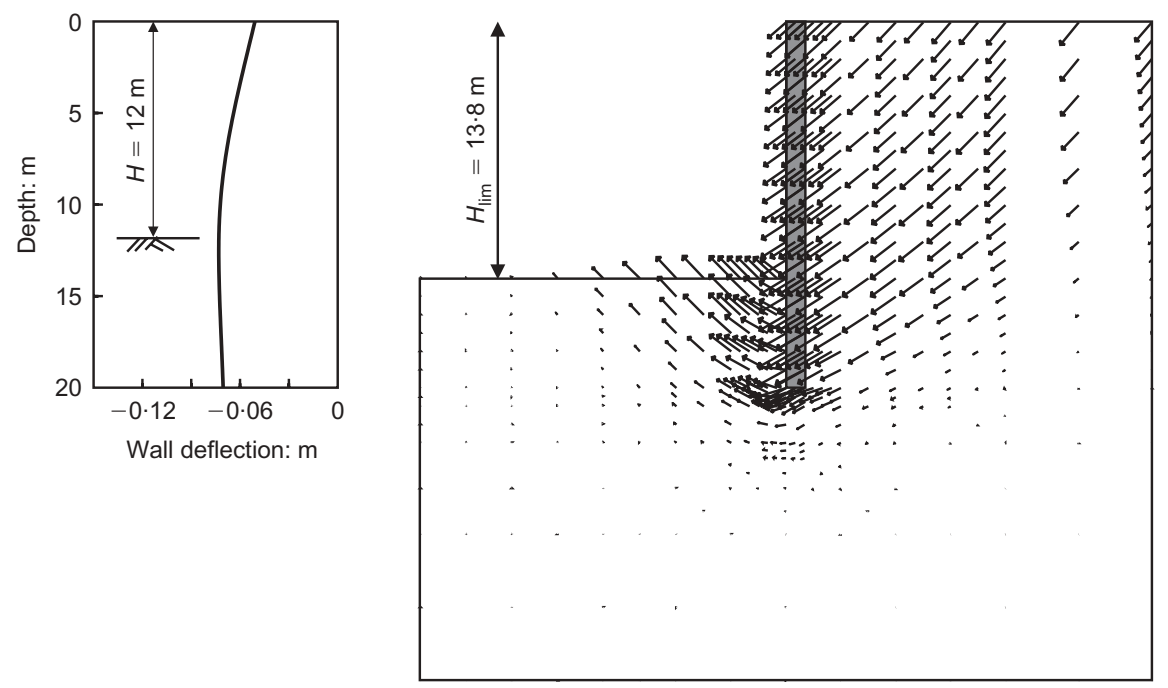

Fig. 60. FE analysis with Tresca model in both interface and soil elements (Run 1)
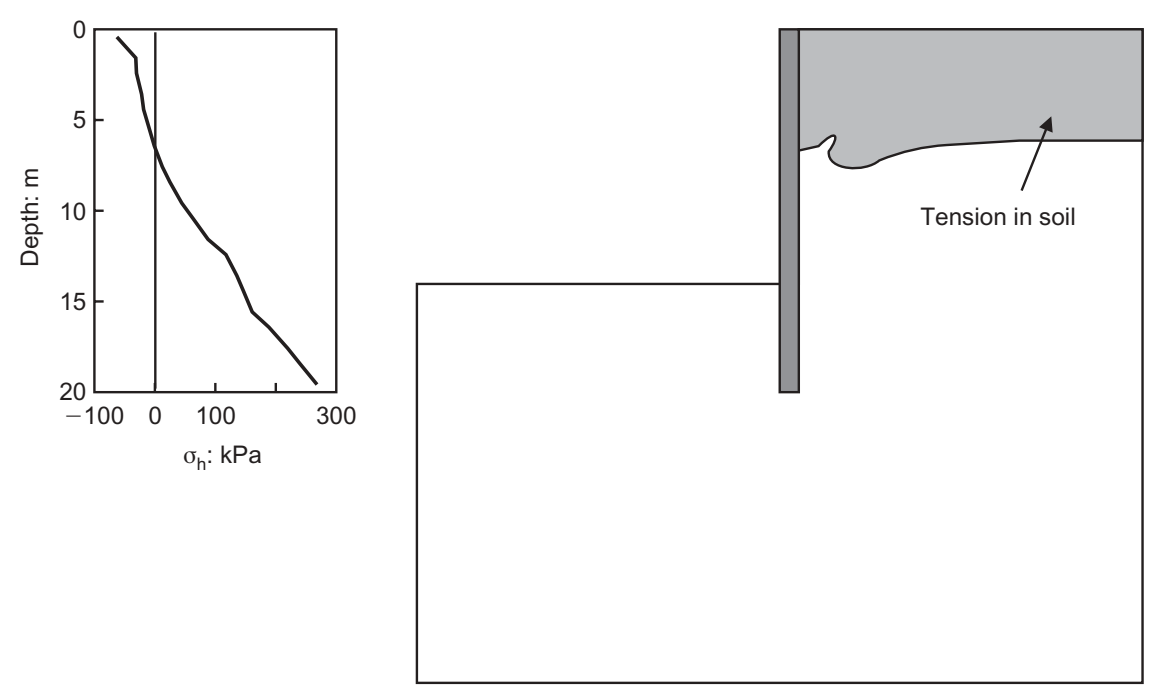

Fig. 61. Tension zone in soil for the conditions in Run 1

and the wall. In all other respects the analysis (Run 2) is the same as the previous one.

Lateral wall displacements at an excavation depth of $12 \mathrm{~m}$ and vectors of incremental displacement just prior to failure from this analysis are presented in Fig. 62. These are now more realistic, indicating that the largest movements occur at the top of the wall, and that failure involves active and passive shear zones behind and in front of the wall respectively. The analysis indicates a limiting depth of excavation of $12.9 \mathrm{~m}$, which, although less than the first analysis, is still $1.3 \mathrm{~m}$ greater than the limit equilibrium value.

The zone of soil sustaining tensile stresses and the horizontal stress distribution acting on the back of the wall are shown in Fig. 63. It can be seen that there are no horizontal stresses acting on the back of the wall down to a depth of approximately $10 \mathrm{~m}$, but there is still a large zone of tension in the retained clay. At first this might seem contradictory, but it arises because the interface elements limit only the horizontal stress between the soil and the wall. There is no restriction imposed on the stresses within the soil mass, and consequently tensile stresses, not necessarily in the horizontal direction, have occurred. These stresses will affect the results. Using interface elements that cannot sustain tension has therefore not solved the problem.

An alternative way of overcoming this problem is not to allow tension to occur in the soil. This requires modification of the Tresca constitutive model. There are several ways of dealing with this, some being better than others (see Nyaoro, 1989). The most accurate and theoretically correct way is to introduce a tension cut-off, in the form of a second yield surface, and its associated plastic potential. This means that the software has to deal with both this and the Tresca model simultaneously. Clearly, this is computationally more difficult than dealing with a single yield surface. Note also that such modelling is still an approximation to real soil behaviour, in which tension first occurs in directions not consistent with the orientations of the final tension cracks. Clearly, rotation of the direction of tensile stress must occur, and although this is accounted for by a double yield surface model of the type described above, the variation in stiffness and plastic strains is probably a gross approximation.

Results from an analysis (Run 3) using a double yield surface model for the soil indicate a limiting depth of 


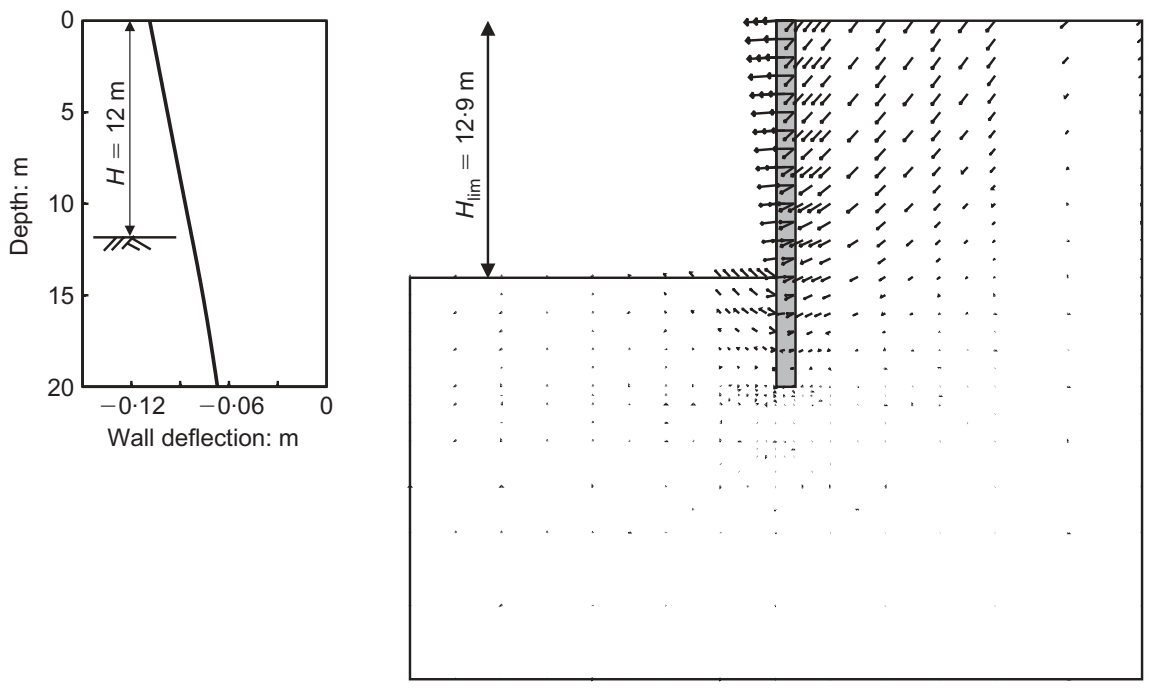

Fig. 62. FE analysis with no tension permitted in interface elements (Run 2)

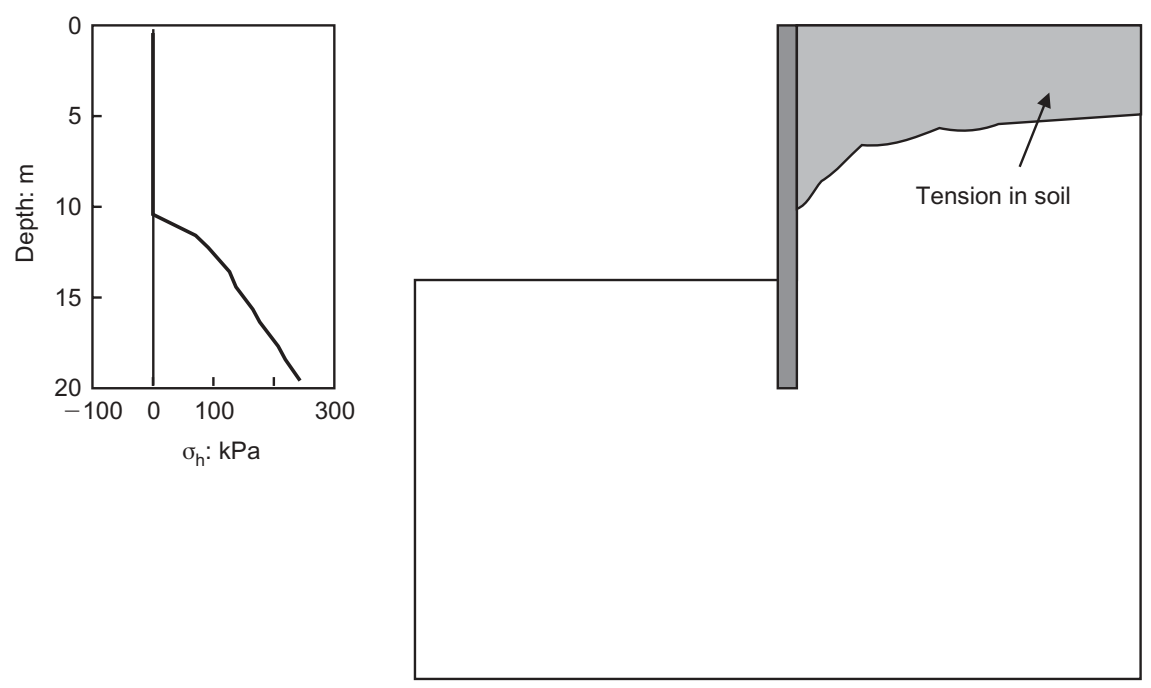

Fig. 63. Tension zone in soil for the conditions in Run 2

excavation of $12.1 \mathrm{~m}$. In this analysis no restriction was imposed on the normal stresses in the interface elements. However, no tensile stresses were predicted in the soil nor between the soil and the back of the wall. The lateral wall displacements at an excavation depth of $12 \mathrm{~m}$ and vectors of incremental displacement just prior to failure from such an analysis are presented in Fig. 64.

The limiting depth of excavation and maximum wall bending moment for all three analyses, along with those from the limit equilibrium calculation, are compared in Table 5. It can be seen that, although the numerical predictions become closer to those from the limit equilibrium calculation as the numerical analysis improves on its ability to simulate tension cracks, there are still considerable differences.

It can be concluded that it is not straightforward to model this simple problem using numerical analysis. The results obtained depend on how the no-tension requirement is modelled. Numerical analysis produces results that are less conservative (that is, deeper excavation depths and smaller bending moments) than conventional methods, which themselves are already viewed cautiously. (d) Results can be user dependent

This is the most powerful argument for the case against the motion. It is also the most worrying and, from a computational analyst's point of view, extremely depressing. To illustrate this point, results from two benchmarking exercises will be considered. Benchmarking is involved in the process of testing, validating, verifying or checking the performance or operation of computer software. One approach involves devising a problem, asking a group of people to produce independent analysis, and then correlating the results. The two examples to be considered here involve a tunnel and an excavation.

Undrained analysis of a shield tunnel. This benchmarking exercise was organised by the Co-Operation in Science and Technology (COST) Action C7 for soil-structure interaction in urban civil engineering. The problem consists of excavating a circular hole, under plane-strain conditions, in either an elastic or an elasto-plastic soil. For the latter situation, the soil is assumed to have an undrained strength constant with depth.

Undrained conditions were stipulated, and a set of 

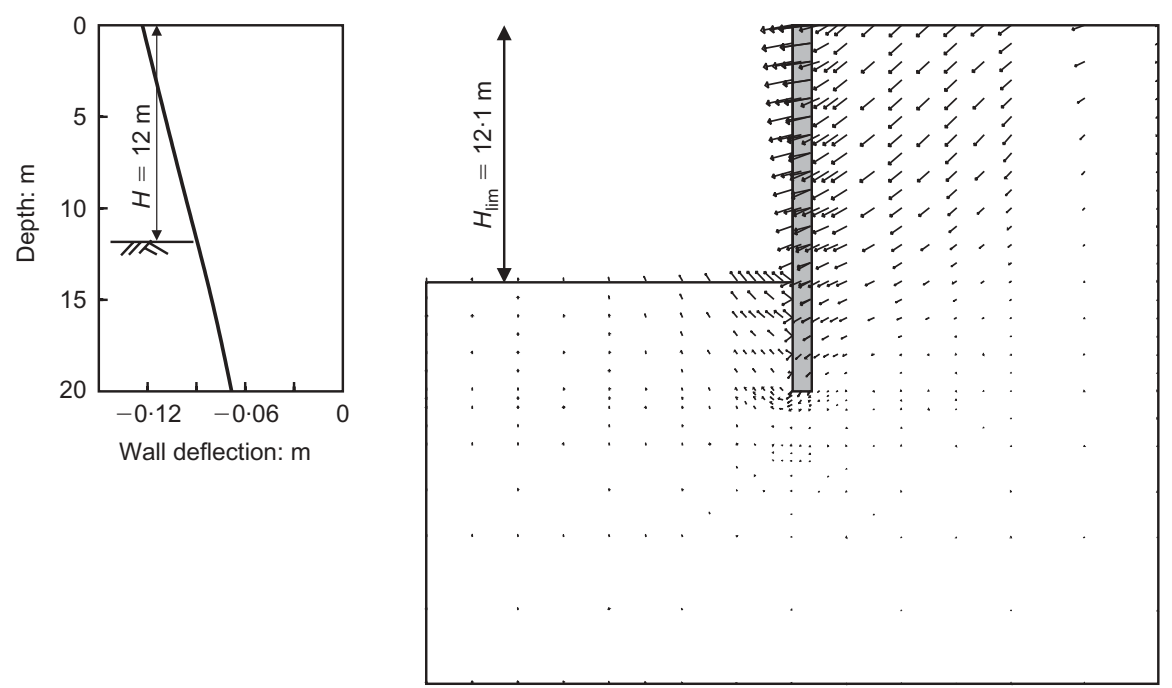

Fig. 64. FE analysis with no tension permitted in soil (Run 3)

Table 5. Summary of maximum excavation depths and bending moments

\begin{tabular}{l|c|c}
\hline Method of analysis & $\begin{array}{c}\text { Maximum excavation } \\
\text { depth: } \mathrm{m}\end{array}$ & $\begin{array}{c}\text { Maximum bending } \\
\text { moment: } \mathrm{kNm} / \mathrm{m}\end{array}$ \\
\hline Limit equilibrium & $11 \cdot 6$ & 498 \\
FE, Run 1 & $13 \cdot 8$ & 1491 \\
FE, Run 2 & $12 \cdot 9$ & 194 \\
FE, Run 3 & $12 \cdot 1$ & 244 \\
\hline
\end{tabular}

analyses was required from each participant, all performed in terms of total stresses under plane-strain conditions. The detailed results from this benchmarking exercise can be found in Potts et al. (2002). Only some of the results from two of the analyses will be presented here.

The tunnel diameter is $10 \mathrm{~m}$ and the depth of cover above the tunnel crown is $15 \mathrm{~m}$. At a depth of $45 \mathrm{~m}$ below ground surface bedrock occurs: see Fig. 65. Consequently, the only geometric dimension not prescribed is related to the position of the lateral boundaries.

In the first analysis to be considered here the participants were asked to excavate and construct the tunnel with a prescribed volume loss in an elasto-plastic soil with a constant value of $s_{\mathrm{u}}=60 \mathrm{kPa}$. They were told that the soil had a saturated bulk unit weight of $20 \mathrm{kN} / \mathrm{m}^{3}$ and a $K_{0}$ (in terms of total stress) of 0.75 . They were also given the elastic properties of the soil and the lining, but here we shall concentrate only on the initial stress conditions.

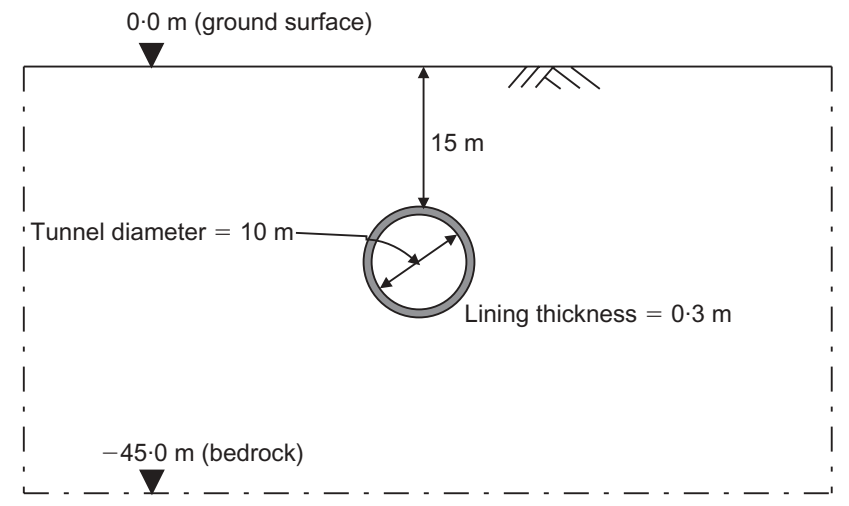

Fig. 65. Geometry for the analysis of a shield tunnel
The distributions of the initial vertical and horizontal total stresses with depth in the ground, prior to tunnel construction, are shown in Fig. 66. As $K_{0}=0.75$, the difference between the vertical and horizontal total stresses increases in magnitude with depth. As the undrained strength remains constant (that is, $s_{\mathrm{u}}=60 \mathrm{kPa}$ ), then below a certain depth the deviator stress $\left[=0 \cdot 5\left(\sigma_{\mathrm{v}}-\sigma_{\mathrm{h}}\right)\right]$ will exceed $s_{\mathrm{u}}$. As can be seen from Fig. 66, this occurs at a depth of $26 \mathrm{~m}$, just below the position of the tunnel invert. Clearly this is not possible, and there is an inconsistency between the initial stresses and the undrained strength. However, most of the software programs used by the participants accepted these initial conditions and produced results without flagging this inconsistency as an error or issuing a warning message. Some of these programs were commercial software regularly used in geotechnical practice. In the author's opinion this state of affairs is totally unacceptable.

In the second analysis to be reported here, the participants were asked to repeat the above analysis but with $K_{0}=1 \cdot 0$, which of course avoids the inconsistency between initial stresses and undrained strength. They were provided with all the soil and lining properties: $G_{\mathrm{s}}=12 \mathrm{MPa}, \mu_{\mathrm{s}}=0 \cdot 495$, $s_{\mathrm{u}}=60 \mathrm{kPa}, \quad \gamma_{s}=20 \mathrm{kN} / \mathrm{m}^{3}, \quad K_{0}=1, \quad E_{1}=21 \mathrm{GPa}, \quad \mu_{1}=$ $0 \cdot 18, \gamma_{1}=24 \mathrm{kN} / \mathrm{m}^{3}$. They were also instructed to perform a full tunnel excavation, inserting the lining at an appropriate stage of the analysis so that after construction the volume loss was $2 \%$. Consequently, the participants had only to decide on the lateral extent of their finite element mesh or finite difference grid, generate the mesh or grid, input the material properties and boundary conditions and run the analysis.

The results from the 11 participants are shown in Fig. 67 in the form of ground surface settlements at the end of the analysis. Note that the participants were from a wide range of European countries, and were experienced analysts. Nevertheless, the scatter in the results is very large. Perhaps even more worrying are the unrealistic shapes of many of the settlement troughs and the fact that many of these do not correlate with a volume loss of $2 \%$. In this respect only two of the participants stated that they had checked the achieved volume loss, and therefore it can be concluded that most of the other participants did not.

A review of the results revealed that the large settlements obtained in one of the analyses could be explained by a misinterpretation of volume loss (4\% had been applied), and that in another analysis a vertical restraint had been imposed 

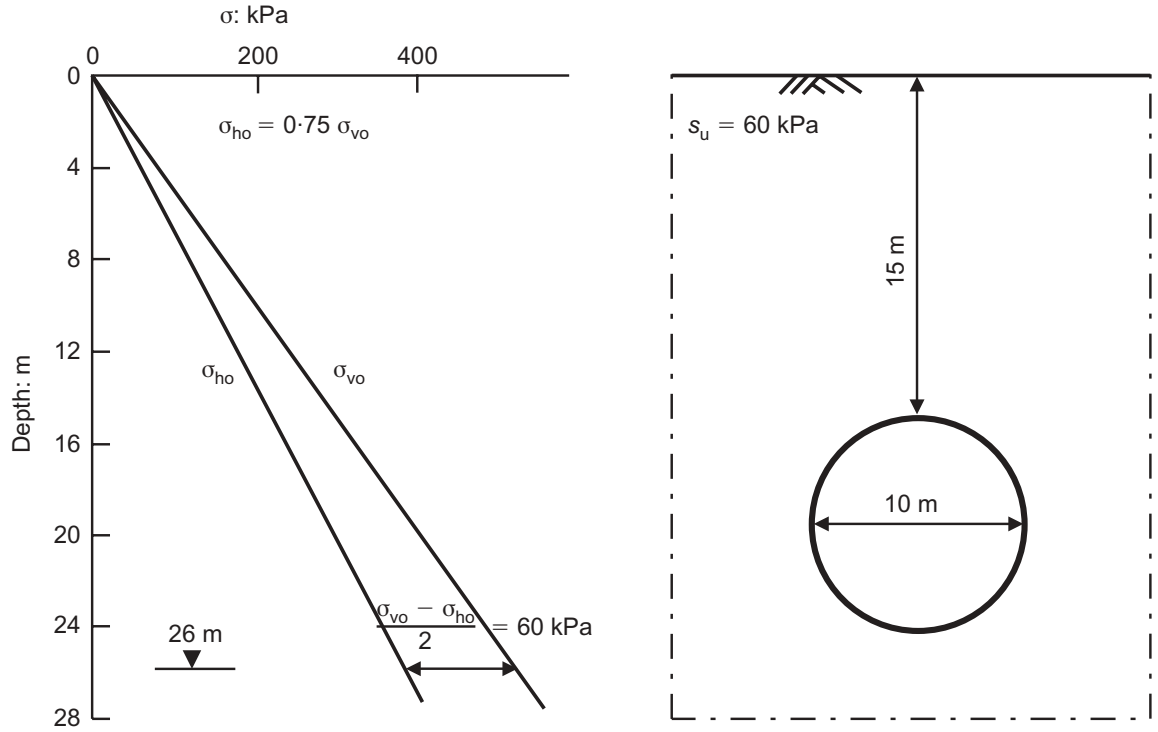

Fig. 66. Initial stress conditions for the original analysis of a shield tunnel

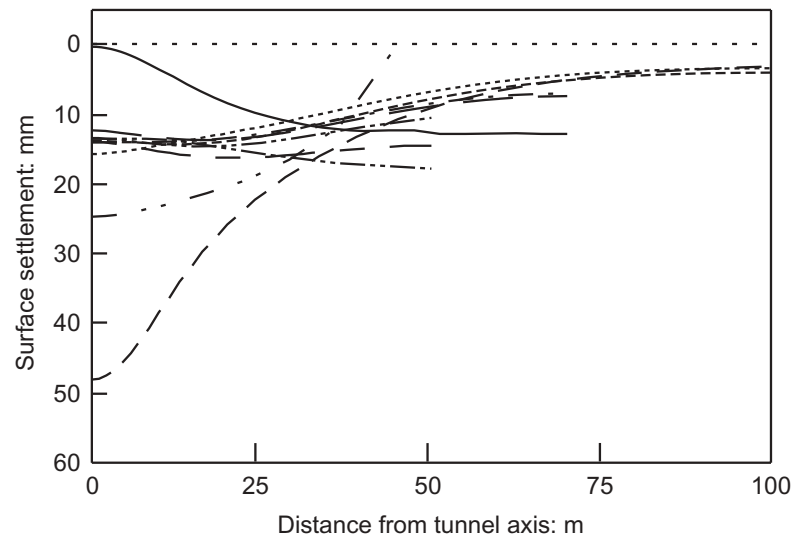

Fig. 67. Surface settlement troughs obtained from different participants (first attempt; after Potts et al., 2002)

on the far field vertical boundary, which influenced the result. However, in the other solutions no obvious cause for the differences could be found, except that the far field vertical boundary had been placed at different distances from the symmetry axis of the tunnel. Consequently, after some discussion the participants were asked to repeat their analyses, but with the distance from the axis of symmetry to the far field vertical boundary set at $100 \mathrm{~m}$. It was also specified that only a lateral restraint was to be applied on this far field vertical boundary. The results from these analyses are presented in Fig. 68, again in the form of the predicted surface settlement troughs. The scatter in results is less than for the initial analyses, but it is still significant, especially above the tunnel crown. Again, many of the analyses did not achieve the specified volume loss.

Deep excavation. This second benchmarking example was organised by Working Group 1.6 'Numerical methods in geotechnics' of the German Society for Geotechnics. In fact, it is one of a series of three that the Society has organised to date. The other two involve a shotcrete tunnel and a tied-back excavation.

The problem geometry is shown in Fig. 69, and Table 6 lists the relevant material properties and construction stages.

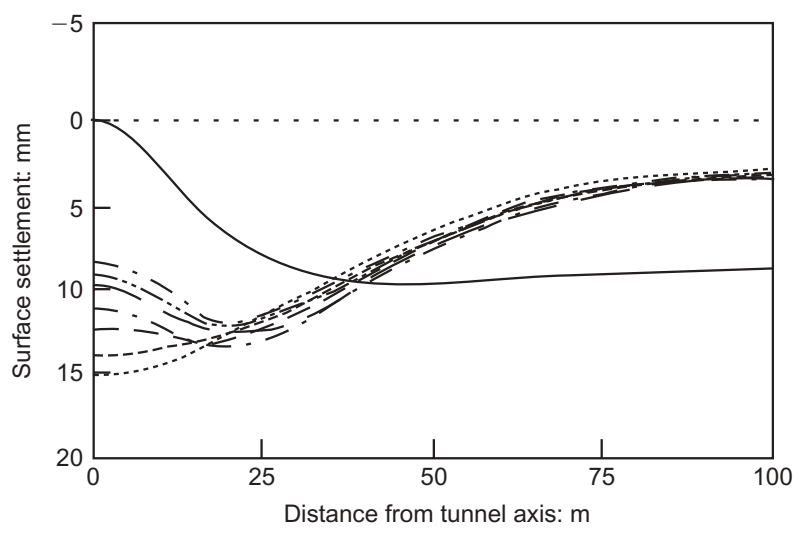

Fig. 68. Surface settlement troughs obtained from different participants (second attempt; after Potts et al., 2002)

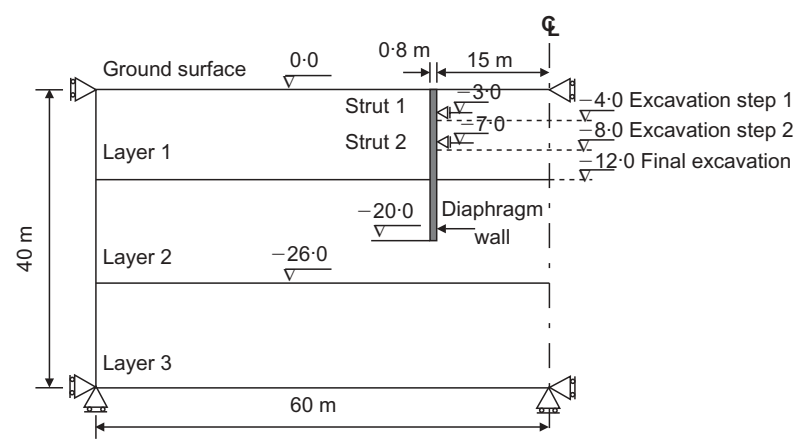

Fig. 69. Geometry for the analysis of a deep excavation

Note that the soil is assumed to be dry. The participants were also instructed to assume plane-strain conditions, use a linear-elastic perfectly plastic Mohr-Coulomb model to represent the soil, assume perfect bonding between the diaphragm wall and adjacent soil, model the struts as rigid, neglect the influence of wall construction (that is, assume it was 'wished in place'), and to model the wall with either beam or continuum elements. Consequently, the participants had only to generate a mesh, input the material properties and boundary conditions and run the analysis. 
Table 6. Material properties for deep excavation benchmark problem

\begin{tabular}{l|c|c|c|c|c|c}
\hline Material & $E: \mathrm{kPa}$ & $\mu$ & $\phi^{\prime}:$ degrees & $c^{\prime}: \mathrm{kPa}$ & $K_{0}$ & $\gamma: \mathrm{kN} / \mathrm{m}^{3}$ \\
\hline Layer 1 & 20000 & $0 \cdot 3$ & 35 & 2 & $0 \cdot 5$ & 21 \\
Layer 2 & 12000 & $0 \cdot 4$ & 26 & 10 & $0 \cdot 65$ & 19 \\
Layer 3 & 80000 & $0 \cdot 4$ & 26 & 10 & $0 \cdot 65$ & 19 \\
Wall $(t=0 \cdot 8 \mathrm{~m})$ & $21 \times 10^{6}$ & $0 \cdot 15$ & - & - & - & 22 \\
\hline
\end{tabular}

Construction sequence:

Step 1: Excavation to level $-4 \cdot 0 \mathrm{~m}$.

Step 2: Excavation to level $-8.0 \mathrm{~m}$ with strut 1 (at $-3.0 \mathrm{~m}$ ) active.

Step 3: Full excavation to level $-12.0 \mathrm{~m}$ with struts 1 and 2 (at $-3.0 \mathrm{~m}$ and $-7.0 \mathrm{~m}$ respectively) active.

There were 12 participants, and five of these used the same commercially available computer program. Predicted horizontal displacements of the top of the wall after construction stage 1, excavation to $-4 \mathrm{~m}$, are presented in Fig. 70. Each of the vertical bars in this figure represents the prediction from a single participant. Not only are the magnitudes of the movements all different, but there is also no consensus as to the direction of movement, with $50 \%$ of the participants predicting movements towards the excavation and $50 \%$ predicting movements into the retained ground. As the wall is acting as an embedded cantilever during this stage of the analysis, the latter predictions are somewhat unrealistic.

Vertical displacements of the retained ground surface after the final excavation stage are shown in Fig. 71. The results are almost evenly distributed between the limiting values, showing a very large scatter. Further information on this example and the other benchmark problems organised by the

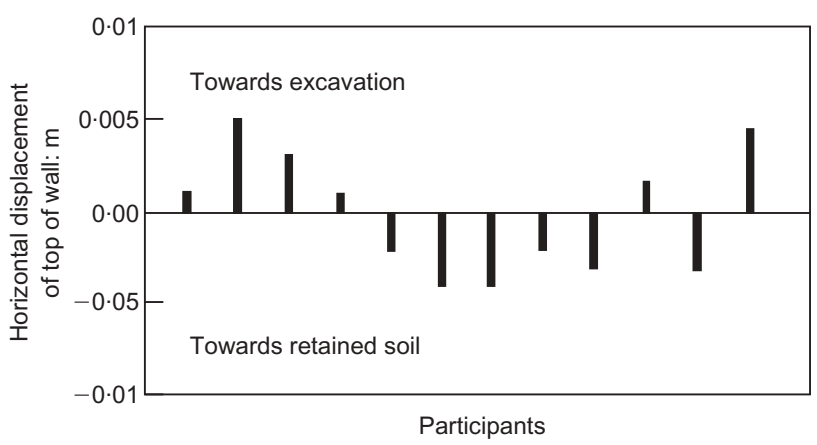

Fig. 70. Horizontal displacement of the top of the wall, stage 1 (after Schweiger, 1998)

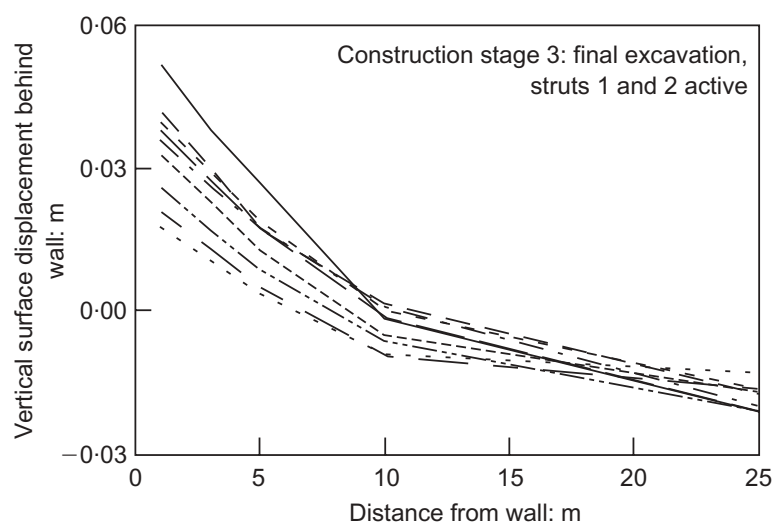

Fig. 71. Surface displacements of the retained ground behind the wall, stage 3 (after Schweiger, 1998)
German Society for Geotechnics can be found in Schweiger (1997, 1998, 2000) and Potts et al. (2002)

Comments. It should be stressed that the results of the two examples presented above are typical of other benchmarking exercises. In addition, both examples are relatively simple. They did not involve the participants in the selection of constitutive models, nor in assigning parameter values. There have been benchmarking exercises where this has been the case, and these have resulted in considerably greater scatter in the results: see Schweiger (2000) or Potts et al. (2002).

In summary, benchmarking exercises have shown that it is not possible for different users to obtain consistent results, even for problems that are essentially completely defined. As some of the participants used the same software package, this cannot be the fault of the software alone. A significant amount of human error is involved, and this implies that the users have insufficient training and/or experience in the use of advanced numerical analysis.

Here ends the case against the motion.

\section{DISCUSSION}

The motion under debate is 'Numerical methods of analysis have reached the stage where they are superior to conventional approaches and can replace them in the geotechnical design process'. The cases for and against have been presented and can be briefly summarised as follows:

Case for

(a) Numerical analyses can do everything conventional analysis can do, plus much more.

(b) Their ability to predict mechanisms of behaviour is a major advantage.

(c) Numerical analysis can deal with both simple and complex problems.

Case against

(a) There are uncertainties in the numerical algorithms.

(b) There are limitations with current constitutive models.

(c) Results from numerical analysis are user dependent.

As in all debates, it is up to you, the reader, to decide whether or not the motion is carried.

Irrespective of your decision, the author hopes that he has demonstrated the enormous power and potential of numerical analysis. It is by far the best analysis tool that geotechnical engineers have at their disposal, and its use in the design process will increase in the future. However, like all tools, it needs a skilled operator. In this respect the author believes that to perform useful numerical analyses (and the emphasis is on 'useful') requires:

(a) an in-depth understanding of soil mechanics and the theory behind numerical analysis

(b) an appreciation of the limitations of constitutive models 
(c) familiarisation with the software used to perform the analysis.

At this point those readers who undertake numerical analysis might wish to reflect on how well their own experience satisfies these requirements. The benchmarking exercises imply that many users are not proficient enough. This is perhaps not surprising, as our undergraduate and postgraduate courses do not cover all of these requirements in sufficient depth. This position must clearly change if numerical analysis is to fulfil its enormous potential. This has implications for education, the profession and software suppliers.

Ideally, the education system should include more numerical analysis and constitutive modelling in the teaching syllabus. However, this implies a potential increase in the teaching load on the students. As both undergraduate and postgraduate courses are currently full, this then raises the question as to what material can be omitted. Perhaps there is room to teach less of peripheral subjects, such as management, or teach less on conventional analysis. Clearly, some difficult decisions will have to be made, and in this respect academia will need help from both the profession and industry.

The profession and industry should provide guidance on best practice for the use of numerical analysis and provide appropriate training. This must be based on fair and impartial advice. It is worth noting that although several advice documents exist relating to laboratory and field testing (AGS, 1998, 2000; BSI, 1999; Head, 1992, 1994, 1998; Mair \& Wood, 1987; Meigh, 1987), few exist covering best practice for numerical analysis. Earlier, while presenting the benchmark examples, the author referred to the work of COST Action C7. Working group A of this Action has produced a document entitled Guidelines for the use of advanced numerical analysis, which has recently been published by Thomas Telford Ltd (Potts et al., 2002). This document does not address all of the problems associated with numerical analysis, but it is a start. It was the intention that Technical Committee 12 (TC12) of the International Society of Soil Mechanics and Geotechnical Engineering (ISSMGE) should take this document and improve on it. However, regretably a decision has been made by ISSMGE to disband TC12.

The only other advice documents, apart from textbooks, related to the use of numerical analysis in geotechnical engineering that the author is aware of are those produced by the German Society for Geotechnics. There are three of these, all of which are based on the results of benchmarking exercises. They cover general recommendations (Meissner, 1991), recommendations for numerical simulations in tunnelling (Meissner, 1996), and recommendations for deep excavations (Meissner, 2002).

It is also imperative that software suppliers provide a full description of how their software works, especially their non-linear solution strategy. They should also disclose all approximations and limitations. It would also be useful if they could implement some standard constitutive models. This would, at least in theory, allow users of two different software programs to analyse the same problem. At present the only constitutive models that appear in most geotechnical software are Tresca and Mohr-Coulomb, although, even here, the formulations are not always standard. As already noted, these models are relatively simple and do not fully test the accuracy of a non-linear solution strategy. These models also have restrictions and shortcomings, as demonstrated in this lecture. The specification of standard models should ideally be made by some independent body, and as a minimum should include Tresca, Mohr-Coulomb and a simple critical-state model such as modified Cam clay. These models should be fully prescribed so that there are no ambiguities. The author is not recommending that only these standard models be used to analyse geotechnical problems. The reason for including them is so that users of different software can, in principle, analyse the same problem and consequently determine where differences, not associated with the constitutive model, arise. As more complex models become accepted, then these too could be included as standard.

\section{CONCLUSIONS}

As noted at the beginning of this lecture, analysis is only part of the design process. However, it is an important part. The author is in no doubt that, in the future, numerical analysis will play a pivotal role in this process. With the rapid advances in both computer hardware and software this is likely to be sooner rather than later. The pitfalls discussed in this lecture are not insurmountable. However, more work is needed, and each of us has a role to play. Benchmarking must continue and the lessons learnt used to produce guidelines for best practice. Collection and publication of case histories are essential to aid the validation process. Academia must adapt its teaching. Site investigation practice and the form of investigations will have to change so that relevant soil parameters can be collected. All too often routine investigations are undertaken with no regard to how the results may be used in analysis. Even those engineers not directly involved in performing or checking numerical analysis have a role in recognising where numerical analysis may bring benefits and cost savings. The end result will be safer, more appropriate and more economical geotechnical structures.

\section{ACKNOWLEDGEMENTS}

The author wishes to acknowledge the staff and research students of the Soil Mechanics Section at Imperial College for their support during the preparation of this lecture. In particular he would like to thank Dr Lidija Zdravkovic, who performed some of the analysis, produced the figures and provided academic support. $\mathrm{He}$ is also grateful to $\mathrm{Dr} \mathrm{H}$. Schweiger for permission to use some of the benchmarking results, and to Crossrail and the Moor House Partnership for permission to use the results from the three-dimensional analyses of the Moor House site.

\section{REFERENCES}

AGI (1991). The Leaning Tower of Pisa: present situation. Proc. 10th Eur. Conf. Soil Mech. Found. Engng, Florence, 4, A. A. Balkema, pp. 1437-1444.

AGS (1998). The selection of geotechnical soil laboratory testing. Association of Geotechnical and Geoenvironmental Specialists, London.

AGS (2000). Guidelines for combined geoenvironmental and geotechnical investigations. Association of Geotechnical and Geoenvironmental Specialists, London.

Bromhead, E. N. (1992). The stability of slopes. London: Blackie.

British Standards Institution (1996). Eurocode 7: Geotechnical design, DD ENV 1997-1. Milton Keynes: BSI.

British Standards Institution (1999). Code of practice for site investigation, BS 5930. Milton Keynes: BSI.

Burland, J. B. \& Potts, D. M. (1994). Development and application of a numerical model for the leaning tower of Pisa. In Prefailure deformation of geomaterials (eds S. Shibuya, T. Mitachi and S. Miure), pp. 715-737. Rotterdam: Balkema.

Caquot, A. \& Kerisel, J. (1948). Tables for the calculation of passive pressure, active pressure and bearing capacity of 
foundations (translated by Ministry of Works, Chief Scientific Advisors Division, London). Paris: Gauthier-Villars.

Chen, W. F. (1975). Developments in geotechnical engineering, 7, Limit analysis and soil plasticity. Amsterdam, Elsevier.

Coulomb, C. A. (1776). Essai sur une application des règles de minimis à quelques problèmes de statique, relatifs à l'árchitecture. Mem. Math. Phys. Acad. R. Sci. 7, 343-382.

Crisfield, M. A. (1986). Finite elements and solution procedures for structural analysis. Swansea: Pineridge Press.

Gaba, A. R., Simpson, B., Powrie, W. \& Beadman, D. R. (2002). Embedded retaining walls: guidance for economic design, RP 629. London: Construction Industry Information and Research Association

Hansen, J. B. (1970). A revised and extended formula for bearing capacity, Bulletin No. 28. Danish Geotechnical Institute.

Head, K. H. (1992). Manual of soil laboratory testing, 2nd edn, vol. 1, Soil classification and compaction tests. Copenhagen, Pentech Press.

Head, K. H. (1994). Manual of soil laboratory testing, 2nd edn, vol. 2, Permeability, shear strength and compressibility tests. London, Pentech Press.

Head, K. H. (1998). Manual of soil laboratory testing, 2nd edn, vol. 3, Effective stress tests. London, Pentech Press.

Higgins, K. G., Mair, R. J. \& Potts, D. M. (1996). Numerical modelling of the influence of the Westminster Station excavation and tunnelling on the Big Ben clock tower. In Geotechnical aspects of underground construction in soft clay (eds R. J. Mair and R. N. Taylor), pp. 525-530. Rotterdam: Balkema.

Lade, P. V. \& Duncan, J. M. (1975). Elasto-plastic stress-strain theory for cohesionless soil. J. Geotech. Engng Div., ASCE 101, $1037-1053$.

Lambe, T. W. (1973). Predictions in soil engineering. Géotechnique 23, No. 2, 149-202.

Mair, R. J., Hight, D. W. \& Potts, D. M. (1992). Finite element analyses of settlements above a tunnel in soft ground, Contractor Report 265. Crowthorne: Transport and Road Research Laboratory.

Mair, R. J. \& Wood, D. M. (1987). Pressuremeter testing; London: CIRIA-Butterworths.

Matsuoka, H. \& Nakai, T. (1974). Stress-deformation and strength characteristics of soil under three different principal stresses. Proc. Jpn Soc. Civ. Engrs 232, 59-70.

Meigh, A. C. (1987). Cone penetration testing. London: CIRIAButterworths.

Meissner, H. (1991). Empfehlungen des Arbeitskreises 1·6, 'Numerik in der Geotechnik', Abschnitt 1, 'Allgemeine Empfehlungen'. Geotechnik 14, 1-10.

Meissner, H. (1996). Tunnelbau unter Tage-Empfehlungen des Arbeitskreises 1.6, 'Numerik in der Geotechnik', Abschnitt 2. Geotechnik 19, 99-108.

Meissner, H. (2002). Baugruben-Empfehlungen des Arbeitskreises 1.6, 'Numerik in der Geotechnik', Abschnitt 3. Geotechnik 25, $45-56$.

Meyerhof, G. G. (1963). Some recent research on the bearing capacity of foundations. Can. Geotech. J. 1, No. 1, 16-26.

Nyaoro, D. L. (1989). Analysis of soil-structure interaction by finite elements. $\mathrm{PhD}$ thesis, Imperial College, University of London.

Owen, D. R. J. \& Hinton, E. (1980). Finite elements in plasticity: theory and practice. Swansea: Pineridge Press.

Potts, D. M. \& Burland, J. B. (2000). Development and application of a numerical model for simulating the stabilisation of the Leaning Tower of Pisa. In Developments in theoretical geomechanics (eds D. W. Smith and J. P. Carter), pp. 737-758. Rotterdam: Balkema.

Potts, D. M. \& Zdravkovic, L. (1999). Finite element analysis in geotechnical engineering: Theory. London: Thomas Telford.

Potts, D. M. \& Zdravkovic, L. (2001). Finite element analysis in geotechnical engineering: Application. London: Thomas Telford.

Potts, D. M., Axelsson, K., Grande, L., Schweiger, H. \& Long, M. (2002). Guidelines for the use of advanced numerical analysis. London: Thomas Telford.

Prandtl, L. (1920). Uber die Harte Platischer Korper. Nach. Gesell. Wiss. Gottingen, Math-Phys. KL, pp.74ff.

Rankine, W. J. M. (1857). On the stability of loose earth. Phil. Trans. R. Soc. London 147, No. 2, 9-27.
Ravaska, O. (2002). A sheet pile wall design according to Eurocode 7 and Plaxis. In Numerical methods in geotechnical engineering (ed. P. Mestat), pp. 649-654. Paris: Presses de 1'ENPC/LCPC.

Roscoe, K. H. \& Burland, J. B. (1968). On the generalised stressstrain behaviour of 'wet' clay. In Engineering plasticity, pp. 535-609. Cambridge: Cambridge University Press.

Roscoe, K. H. \& Schofield, A. N. (1963). Mechanical behaviour of an idealised 'wet' clay. Proc. 2nd Eur. Conf. Soil Mech. Found. Engng, Wiesbaden 1, 47-54.

Schweiger, H. F. (1997). Berechnungsbeispiele des AK 1.6 der DGGT-Vergleich der Ergebnisse fur Beispiel 1 (Tunnel) und 2 (Baugrube). Tagungsband Workshop 'Numerik in der Geotech$n i k$ ', DGGT/AK 1·6, pp. 1-29.

Schweiger, H. F. (1998). Results from two geotechnical benchmark problems. Proc. 4th Eur. Conf. Numer. Methods Geotech. Engng, (A. Civi dini (ed.)), Springer Udine, Stuttgart, 645-654.

Schweiger, H. F. (2000). Ergebnisse des Berechnungsbeispieles Nr.3 '3-fach verankerte Baugrube'. Tagungsband Workshop 'Verformungsprognose für tiefe Baugruben', DGGT/AK 1·6, pp. 7-67.

Sieffert, J. G. \& Bay-Gress, Ch. (2000). Comparison of European bearing capacity calculation methods for shallow foundations. Proc. Inst. Civ. Engrs Geotech. Engng 143, 65-74.

Sokolovskii, V. V. (1960). Statics of soil media. London: Butterworth Scientific.

Sokolovskii, V. V. (1965). Statics of granular media. Oxford: Pergamon Press.

Smith, I. M. \& Griffiths, D. V. (1988). Programming the finite element method. New York: John Wiley \& Sons.

Thomas, J. N. (1984). An improved accelerated initial stress procedure for elasto-plastic finite element analysis. Int. J. Numer. Methods Geomech. 8, 359-379.

Vesic, A. S. (1973). Analysis of ultimate loads of shallow foundations. J. Soil Mech. Found. Engng Div., ASCE 99, No. SM1, $45-73$.

Zienkiewicz, O. C. \& Cormeau, I. C. (1974). Visco-plasticity, plasticity and creep in elastic solids: a unified numerical solution approach. Int. J. Numer. Methods Engng 8, 821-845.

\section{VOTE OF THANKS}

PROFESSOR P. R. VAUGHAN, Imperial College of Science, Technology and Medicine

It gives me great personal pleasure to propose this vote of thanks.

Not very long ago I asked Skem what he thought was the most significant development in our subject over his career. Without significant pause for thought he said, 'numerical analysis'. When you think about it, this is self-evident. Our ability to synthesise our knowledge of material properties and to compare the results with observations of reality has changed beyond measure.

David Potts came to Imperial College in 1979 and lived just down the corridor. I watched with fascination his attachment to a succession of computers that he purchased at knock-down prices from his own consulting income. One at least was reputed to have fallen off the back of a lorry.

David brings rare attributes to this new world: a highly focused competence in numerical methods themselves, a wide knowledge of the mathematical models on which these methods feed, and a great interest in finding out how to apply them to real engineering problems. He has shown us these interests tonight. And I do not forget that he did part of his $\mathrm{PhD}$ at Cambridge in the laboratory (or at least in the centrifuge pit).

This is the 42nd Rankine Lecture. The use of computers in geotechnics started at about the same time as this lecture series. Finite element analyses started not long after, yet this is only the second time that we have had a Rankine Lecture largely or wholly about numerical analysis. Does this tell us that we are not confident or proficient in our use of these new techniques? David has asked us to consider whether we 
get the best out of them. They can turn our calculations into analyses, which are so much more powerful and informative. They can tell us what we do not expect. Used intelligently, they will even save us money. However, it has not made analysis easier or cheaper or accessible to staff of lower skill.

I am reliably informed that, when David was interviewed for his chair, the Rector asked, 'If your program is so impressive, why don't you market it?' David replied, 'Come with me to Heathrow.' 'What?' said the Rector. 'Come with me to Heathrow,' said David, 'I want you to walk across the tarmac, climb into a Jumbo, and sit in the pilot's seat. The plane's yours. Now fly it.' Maybe one day planes will fly automatically, but what price someone entering 'Paris' in the computer, instead of 'New York'?

The new methods are at least as easy to abuse as the old ones. What do we sometimes do? Go down to the DIY shop and buy a program? Give it to the newest recruit at the back of the drawing office, genuflect towards it once a month, and make our reports look much more expensive by sticking a hundred pages of computer printout in the back, offering up a prayer the while that no-one will ask us what it means?
Leave the engineering science and the decision-making to the people at the software house who wrote the program, because we have more important things to do?

The questions David has addressed will not go away. Neither could we make them do so if we wanted. Burning books had little effect; neither would burning programs. Numerical analysis is here to stay. Currently we do not do as well as we should. We have an obligation to use the best state-of-the-art tools to solve our problems, and an obligation to use them effectively. If we do not, the courts may draw our omission to our attention.

David has shown us that, to use this technique effectively, we need to understand the approximations involved in the method itself, and how to simulate the behaviour of our multiplicity of engineering materials. How do we effectively integrate this technique into our procedures? How do we staff it? How do we educate people to be able to do it? How do we pay for it?

So, what are we going to do? David has challenged us to think about it. There is much to think about. Thank you David, for a most stimulating and thought-provoking lecture. 